\title{
Recommendations for the quantitative analysis of landslide risk
}

\author{
J. Corominas - C. van Westen - P. Frattini $\cdot$ L. Cascini - J.-P. Malet $\cdot$ \\ S. Fotopoulou $\cdot$ F. Catani $\cdot$ M. Van Den Eeckhaut $\cdot$ O. Mavrouli $\cdot$ \\ F. Agliardi - K. Pitilakis $\cdot$ M. G. Winter $\cdot$ M. Pastor $\cdot$ S. Ferlisi $\cdot$ V. Tofani $\cdot$ \\ J. Hervás · J. T. Smith
}

Received: 4 June 2013/Accepted: 11 October 2013/Published online: 24 November 2013

(C) The Author(s) 2013. This article is published with open access at Springerlink.com

\begin{abstract}
This paper presents recommended methodologies for the quantitative analysis of landslide hazard, vulnerability and risk at different spatial scales (site-specific, local, regional and national), as well as for the verification and validation of the results. The methodologies described focus on the evaluation of the probabilities of occurrence of different landslide types with certain characteristics. Methods used to determine the spatial distribution of landslide intensity, the characterisation of the elements at risk, the assessment of the potential degree of damage and the quantification of the vulnerability of the elements at risk, and those used to perform the quantitative risk analysis are also described. The paper is intended for use by
\end{abstract}

J. Corominas ( $₫) \cdot$ O. Mavrouli

Department of Geotechnical Engineering and Geosciences, Technical University of Catalonia, 08034 Barcelona, Spain e-mail: jordi.corominas@upc.edu

\section{C. van Westen}

Faculty of Geo-information Sciences and Earth Observation, University of Twente, 7500 AE Enschede, The Netherlands

\section{P. Frattini - F. Agliardi}

Department of Earth and Environmental Science, Università degli Studi di Milano-Bicocca, 20126 Milan, Italy

L. Cascini $\cdot$ S. Ferlisi

Department of Civil Engineering, University of Salerno, 84084 Salerno, Italy

\section{J.-P. Malet}

Centre National de la Recherche Scientifique, Institut de Physique du Globe de Strasbourg, 67084 Strasbourg, France

\section{S. Fotopoulou $\cdot$ K. Pitilakis}

Research Unit of Geotechnical Earthquake Engineering and Soil

Dynamics, Department of Civil Engineering, Aristotle

University of Thessaloniki, 54124 Thessaloniki, Greece scientists and practising engineers, geologists and other landslide experts.

Keywords Landslides · Risk · Hazard · Vulnerability · Susceptibility · Methodology for quantitative analysis - Rockfalls - Debris flow . Slow-moving landslides

\section{Introduction}

Despite considerable improvements in our understanding of instability mechanisms and the availability of a wide

\footnotetext{
F. Catani $\cdot$ V. Tofani

Department of Earth Sciences, University of Firenze,

50121 Florence, Italy
}

M. Van Den Eeckhaut · J. Hervás

Institute for Environment and Sustainability, Joint Research

Centre, European Commission, 21027 Ispra, Italy

M. G. Winter

Transport Research Laboratory (TRL), 13 Swanston Steading, 109 Swanston Road, Edinburgh EH10 7DS, UK

M. Pastor

ETS Ingenieros de Caminos, Universidad Politécnica de Madrid, 28071 Madrid, Spain

J. T. Smith

Golder Associates (formerly TRL), Cavendish House, Bourne

End Business Park, Cores End Road, Bourne End SL8 8AS, UK 
range of mitigation techniques, landslides still cause a significant death toll and significant economic losses all over the world. Recent studies (Petley 2012) have shown that loss of life is concentrated in less developed countries, where there is relatively little investment in understanding the hazards and risks associated with landslides, due largely to a lack of appropriate resources. Cooperative research and greater capacity-building efforts are required to support the local and regional administrations which are in charge of landslide risk management in most of the countries.

Authorities and decision makers need maps depicting the areas that may be affected by landslides so that they are considered in development plans and/or that appropriate risk mitigation measures are implemented. A wide variety of methods for assessing landslide susceptibility, hazard and risk are available and, to assist in risk management decisions, several institutions and scientific societies have proposed guidelines for the preparation of landslide hazard maps (i.e. OFAT, OFEE, OFEFP 1997; GEO 2006; AGS 2007; Fell et al. 2008a, b), with the common goal being to use a unified terminology and highlight the fundamental data needed to prepare the maps and guide practitioners in their analyses. Some of them are intended to be introduced into legislated standards (OFAT, OFEE, OFEFP 1997; AGS 2007). However, the methodologies implemented diverge significantly from country to country, and even within the same country (Corominas et al. 2010).

To manage risk, it must be first analysed and evaluated. The landslide risk for an object or an area must be calculated with reference to a given time frame for which the expected frequency or probability of occurrence of an event of intensity higher than a minimum established value is evaluated. In that respect, there is an increasing need to perform quantitative risk analysis (QRA). QRA is distinguished from qualitative risk analysis by the input data, the procedures used in the analysis and the final risk output. In contrast with qualitative risk analysis, which yields results in terms of weighted indices, relative ranks (e.g. low, moderate and high) or numerical classification, QRA quantifies the probability of a given level of loss and the associated uncertainties.

QRA is important for scientists and engineers because it allows risk to be quantified in an objective and reproducible manner, and the results can be compared from one location (site, region, etc.) to another. Furthermore, it helps with the identification of gaps in the input data and the understanding of the weaknesses of the analyses used. For landslide risk managers, it is also useful because it allows a cost-benefit analysis to be performed, and it provides the basis for the prioritisation of management and mitigation actions and the associated allocation of resources. For society in general, QRA helps to increase the awareness of existing risk levels and the appreciation of the efficacy of the actions undertaken.

For QRA, more accurate geological and geomechanical input data and a high-quality DEM are usually necessary to evaluate a range of possible scenarios, design events and return periods. Lee and Jones (2004) warned that the probability of landsliding and the value of adverse consequences are only estimates. Due to limitations in the available information, the use of numbers may conceal the fact that the potential for error is great. In that respect, QRA is not necessarily more objective than the qualitative estimations, as, for example, probability may be estimated based on personal judgment. It does, however, facilitate communication between geoscience professionals, land owners and decision makers.

Risk for a single landslide scenario may be expressed analytically as follows:

$R=P\left(M_{i}\right) P\left(X_{j} \mid M_{i}\right) P\left(T \mid X_{j}\right) V_{i j} C$,

where $R$ is the risk due to the occurrence of a landslide of magnitude $M_{i}$ on an element at risk located at a distance $X$ from the landslide source, $P\left(M_{i}\right)$ is the probability of occurrence of a landslide of magnitude $M_{i}, P\left(X_{j} \mid M_{i}\right)$ is the probability of the landslide reaching a point located at a distance $X$ from the landslide source with an intensity $j$, $P\left(T \mid X_{j}\right)$ is the probability of the element being at the point $X$ at the time of occurrence of the landslide, $V_{i j}$ is the vulnerability of the element to a landslide of magnitude $i$ and intensity $j$, and $C$ is the value of the element at risk.

Three basic components appear in Eq. 1 that must be specifically considered in the assessment: the hazard, the exposure of the elements at risk, and their vulnerability. They are characterised by both spatial and nonspatial attributes. Landslide hazard is characterised by its probability of occurrence and intensity (see the "Landslide hazard assessment" section); the latter expresses the severity of the hazard. The elements at risk are the population, property, economic activities, including public services, or any other defined entities exposed to hazards in a given area (UN-ISDR 2004). The elements at risk also have spatial and nonspatial characteristics. The interaction of hazard and the elements at risk involves the exposure and the vulnerability of the latter. Exposure indicates the extent to which the elements at risk are actually located in the path of a particular landslide. Vulnerability refers to the conditions, as determined by physical, social, economic and environmental factors or processes, which make a community susceptible to the impact of hazards (UN-ISDR 2004). Physical vulnerability is evaluated as the interaction between the intensity of the hazard and the type of elements at risk, making use of so-called vulnerability curves (see "Vulnerability assessment" section). For further explanations of hazard and risk analysis, the reader is 
referred to textbooks such as Lee and Jones (2004), Glade et al. (2005) and Smith and Petley (2008).

Probably the most critical issue is the determination of the temporal occurrence of landslides. In many regions, a lack of data prevents the performance of a quantitative determination of the probability of slope failure or landslide reactivation within a defined time span. Despite this limitation, landslide risk management decisions are sometimes taken considering the spatial distribution of existing or potential landslides. This is carried out by means of the analysis of the landslide predisposing factors or susceptibility analysis (see the "Suggested methods for landslide susceptibility assessment" section).

The goal of these recommendations is to present an overview of the existing methodologies for the quantitative analysis and zoning of landslide susceptibility, hazard and risk at different scales, and to provide guidance on how to implement them. They are not intended to become standards. The aim is to provide a selection of quantitative tools to researchers and practitioners involved in landslide hazard and risk analysis, and mapping procedures. Users must be aware of the information and tasks required to characterise the landslide areas, to assess the hazard level, and to evaluate the potential risks as well as the associated uncertainties.

The paper is structured similarly to the JTC-1 Guidelines (Fell et al. 2008a, b); indeed, some of the authors were deeply involved in the preparation of those Guidelines. However, all of the sections have been updated. The sections "QRA framework", "Landslide zoning at different scales", and "Input data for landslide risk analysis" describe the framework of the QRA and its main components; the requirements associated with the scale of work as well as the hazard and risk descriptors; and the input data and their sources. The sections "Suggested methods for landslide susceptibility assessment", "Landslide hazard assessment", and "Suggested methods for quantitative landslide risk analysis" discuss, respectively, the available methods for quantifying and mapping landslide susceptibility, hazard and risk. Finally, the "Evaluation of the performance of landslide zonation maps" section presents procedures to check the reliability of the maps and validate the results. At the end of the document, an "Appendix" section is included with basic definitions of the terms used.

These recommendations focus on quantitative approaches only. Significant efforts have been made to expound on topics that were only marginally treated in previously published guidelines, and this sometimes required novel developments: (a) the procedures for preparing landslide hazard maps from susceptibility maps; (b) the analysis of hazards from multiple landslide types; (c) the assessment of the exposure of the elements at risk; (d) the assessment of the vulnerability, particularly the physical vulnerability and the construction of vulnerability curves; and (e) the verification of the models and the validation of the landslide maps.

\section{QRA framework}

The general framework involves the complete process of risk assessment and risk control (or risk treatment). Risk assessment includes the process of risk analysis and risk evaluation. Risk analysis uses available information to estimate the risk to individuals, population, property or the environment from hazards. Risk analysis generally contains the following steps: hazard identification, hazard assessment, inventory of elements at risk and exposure, vulnerability assessment and risk estimation. Since all of these steps have an important spatial component, risk analysis often requires the management of a set of spatial data and the use of geographic information systems. Risk evaluation is the stage at which values and judgments enter the decision process, explicitly or implicitly, including considerations of the importance of the estimated risks and the associated social, environmental, and economic consequences, in order to identify a range of alternatives for managing the risks.

Landslide hazard assessment requires a multi-hazard approach, as different types of landslides may occur, each with different characteristics and causal factors, and with different spatial, temporal and size probabilities. Also, landslide hazards often occur in conjunction with other types of hazards (e.g. flooding or earthquakes). Figure 1, based on Van Westen et al. (2005), gives the framework of multi-hazard landslide risk assessment, with an indication of the various steps (A-H). The first step (A) deals with the input data required for a multi-hazard risk assessment, focussing on the data needed to generate susceptibility maps for initiation and runout, triggering factors, multitemporal inventories and elements at risk.

The second step (B) focuses on susceptibility assessment, and is divided into two components. The first, which is the most frequently used, deals with the modelling of potential initiation areas (initiation susceptibility), which can make use of a variety of different methods (inventorybased, heuristic, statistical, deterministic), which will be discussed later in this document. The resulting maps will display the source areas for the modelling of potential runout areas (reach probability).

The third step (C) deals with landslide hazard assessment, which heavily depends on the availability of so-called event-based landslide inventories, which are inventories of landslides caused by the same triggering event. By linking landslide distributions to the temporal probability of the triggering event, it is possible to carry 
Fig. 1 Framework of multihazard landslide risk assessment (based on Van Westen et al. 2005)
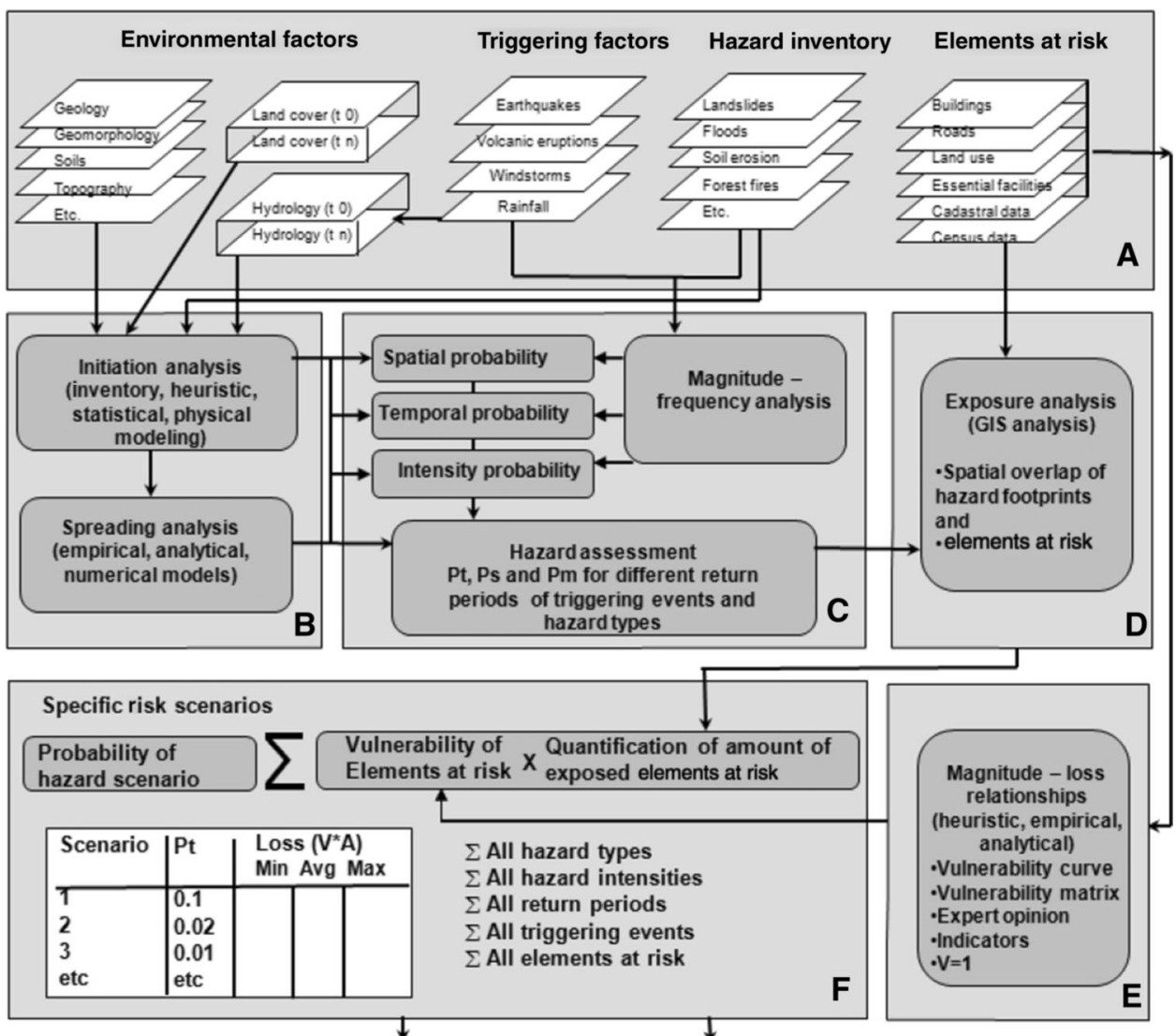

\section{Quantitative risk assessment}

Combining specific risk curves
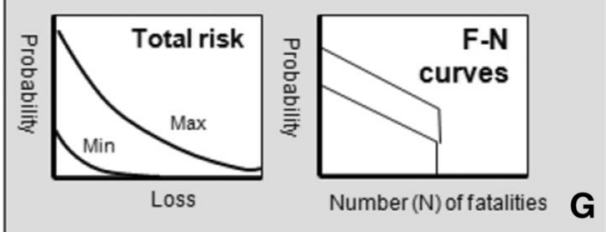

Number (N) of fatalities $\mathbf{G}$
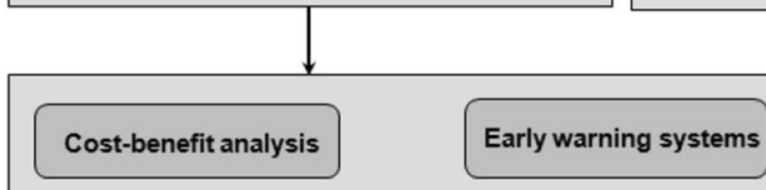

Preparedness planning

\section{Qualitative risk assessment}

If risk cannot be quantified

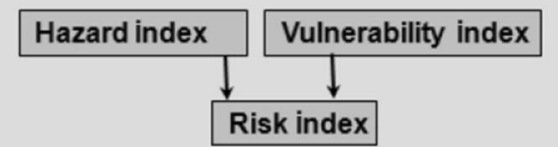

Spatial multi-criteria evaluation

H
Spatial planning

Environmental impact assessment I out a magnitude frequency analysis. Event-based landslide inventories, in addition to other factors, are also used to determine the spatial probability of landslide initiation and runout, and to determine the size probability of potential landslides for a given return period. The fourth step (D) is the exposure analysis, which involves overlaying hazard maps and elements-at-risk maps in a GIS environment.

Step (E) focuses on vulnerability assessment, and indicates the various types of vulnerability and approaches that can be used. The focus is on the use of expert opinion, empirical data and physically based analytical or numerical models in defining vulnerability classes, and the application of available vulnerability curves or vulnerability matrices. Most of the focus is on determining the physical vulnerability of the elements at risk. Other types of vulnerability (e.g. social, environmental, and economic) are mostly analysed using a spatial multi-criteria evaluation as part of a qualitative risk assessment (step H), and are not discussed here. 
Step (F) integrates the hazard, vulnerability and the nature and quantity of the elements at risk (either as the number of people, number of buildings, or economic value). The risk for each specific element (specific risk) is calculated for many different situations, and related to landslide type, volume, return period of the triggering event, and type of element at risk.

The integration of step $(\mathrm{G})$ presents the quantitative risk assessment approach, in which the results are shown in risk curves plotting the expected losses against the probability of occurrence for each landslide type individually, and expressing the uncertainty based on the uncertainties of the inputs in the risk analysis.

This can be illustrated by generating two loss curves expressing the minimum and maximum losses for each triggering event return period, or the associated annual probability. The individual risk curves can be integrated into total risk curves for a particular area, and the population loss can be expressed as F-N curves (IUGS 1997). The risk curves can be constructed for different basic units such as individual slopes, road sections, settlements, municipalities, regions or provinces.

Step $(\mathrm{H})$ deals with methods for qualitative risk assessment, which are mostly based on integrating a hazard index and a vulnerability index using spatial multi-criteria evaluation. The last step (I) deals with the use of risk information in various stages of disaster risk management. Only steps (A)-(G) are discussed in this paper.

\section{Landslide zoning at different scales}

Landslide zoning is the division of land into homogeneous areas or domains, and their ranking according to degrees of actual or potential landslide susceptibility, hazard or risk. The first formal applications of landslide zoning, based on qualitative approaches, date back to the 1970s (e.g. Brabb et al. 1972; Humbert 1972; Kienholz 1978), while quantitative methods were developed in the late 1980s (Brand 1988), and particularly in the 1990s for the risk management of individual slopes (Wong et al. 1997a; Hardingham et al. 1998) or a large number of slopes (OFAT, OFEE, OFEFP 1997; Wong and Ho 1998). These developments are described by Ho et al. (2000) and Wong (2005). Further significant developments of landslide zoning have been recorded during the last decade, as highlighted by

- The guidelines developed by the Australian Geomechanics Society (AGS 2000, 2007),

- The analysis of questions related to the scale of work (Cascini et al. 2005; Cascini 2008),

- The approaches adopted and the development trends in risk analysis practice from site-specific (Wong 2005) to the global (Nadim et al. 2006; Nadim and Kjeksta 2009; Hong et al. 2007) scale, and

- The JTC-1 Guidelines (Fell et al. 2008a).

Starting from these developments, this section introduces the different maps and goals as well as the zoning scales, considering that both the type and purpose of zoning should be determined by the end users. The end users also need (Fell et al. 2008a) to

(i) Understand the availability of potential input data,

(ii) Assess the implications (e.g. in terms of effort and/or costs) for the acquisition of new data, and

(iii) Define realistic goals for the zoning study, taking into account time frames, budgets and resource limitations.

Types and purposes of landslide zoning maps

Landslide zoning may be performed by preparing different maps that, according to the type of zoning, can be classified into:

- Landslide inventory maps

- Landslide susceptibility zoning maps

- Landslide hazard zoning maps

- Landslide risk zoning maps

Within the framework of landslide risk management (Fig. 1), landslide zoning maps may be intended for different purposes (Fell et al. 2008a): information, advisory, statutory, design (see also the "Landslide zoning map scales" section).

Considering the number of stakeholders involved in landslide risk management-owners, occupiers, affected public, regulatory authorities, geotechnical professionals and risk analysts (Fell et al. 2005) - as well as the different extents of the areas to be zoned, the landslide zoning map must be prepared at an appropriate scale. Suggestions and recommendations on these topics are provided in the following sections.

Landslide zoning map scales

The current practice in Europe (Corominas et al. 2010) shows that the scale of the landslide zoning maps required by state or local authorities varies significantly from country to country, depending on the coverage, input data and methods that are used as well as the information provided (qualitative or quantitative).

On the basis of current practice, and considering that landslide zoning may also be requested by land developers or those developing major infrastructure (such as highways and railways), the most common zoning map scales are 
described hereafter, together with some considerations regarding the outputs and pursued purposes.

The scale of work constrains the type of approach to be followed to achieve the purposes of the zoning purposes. For instance, maps at national $(<1: 250,000)$ and regional $(1: 250,000-1: 25,000)$ scales do not allow the mapping of individual small slope failures (i.e. landslide-affected areas not exceeding a few thousands of square metres). Thus, landslides have to be treated collectively, and neither runout nor intensity-frequency analyses can be performed at these scales. Similarly (see also Sect. 5.6), elements at risk must be identified and quantified for well-defined spatial units (administrative units or grid cells) or homogeneous units with similar characteristics (e.g. in terms of type and density of the elements at risk). As a consequence, susceptibility, hazard and risk approaches for national and regional zoning map scales are based on the following assumptions:

- Geological conditions in the study area are homogeneous

- All slopes have similar probabilities of failure

- The exact location of the slope failure (landslide) is not required

- All landslides are of a similar size

- Runout distance is not calculated; nor are the spatial distribution and the intensity

- Elements-at-risk data are collected for given spatial/ homogeneous units

On the contrary, at local $(1: 25,000-1: 5,000)$ and sitespecific $(>1: 5,000)$ scales, single landslides and single elements at risk must be taken into account in zoningrelated activities.

According to Soeters and van Westen (1996), zoning maps at a national scale are created to give a general overview of problem areas for an entire country. This can be used to inform national policy makers and the general public; furthermore, they may be also used to specify and plan warning systems controlled by central authorities. The areas to be investigated are larger than tens of thousands of square kilometres.

Regional scale work is typically suited to the activities of planners in the early phases of regional development projects or for engineers evaluating possible constraints due to instability in the development of large engineering projects and regional development plans. Such work may also be used to specify and plan warning systems and urban emergency plans at a regional level. Typical areas to be investigated exceed $1,000 \mathrm{~km}^{2}$ and reach up to tens of thousands of square kilometres.

Local scale maps have enough resolution to support slope stability analyses over large areas and combine the outputs with runout analyses; these, in turn, are very
Table 1 Examples of hazard descriptors for dealing with potential landslides at different scales of work

\begin{tabular}{|c|c|c|c|}
\hline Scale of work & Runout & $\mathrm{I}(\mathrm{M}) / \mathrm{F}^{\mathrm{a}}$ & Hazard descriptor \\
\hline $\begin{array}{l}\text { National } \\
<1: 250,000\end{array}$ & $\begin{array}{l}\text { Not } \\
\text { included }\end{array}$ & $\begin{array}{l}\text { Not } \\
\text { considered }\end{array}$ & $\begin{array}{l}\text { No. of landslides/ } \\
\text { administrative } \\
\text { unit/year }\end{array}$ \\
\hline $\begin{array}{l}\text { Regional } \\
1: 250,000-1: 25,000\end{array}$ & $\begin{array}{l}\text { Usually } \\
\text { not } \\
\text { included }\end{array}$ & $\begin{array}{l}\text { Often a fixed } \\
\text { (constant) } \\
\text { magnitude } \\
\text { value }\end{array}$ & $\begin{array}{l}\text { No. of landslides/ } \\
\mathrm{km}^{2} / \text { year }\end{array}$ \\
\hline $\begin{array}{l}\text { Local } \\
1: 25,000-1: 5,000\end{array}$ & Included & $\begin{array}{l}\text { Spatially } \\
\text { distributed } \\
\text { magnitude } \\
\text { (intensity) }\end{array}$ & $\begin{array}{l}\text { Annual } \\
\text { probability of } \\
\text { occurrence (or } \\
\text { return period) of } \\
\text { a given } \\
\text { magnitude or } \\
\text { intensity }\end{array}$ \\
\hline $\begin{array}{l}\text { Site-specific } \\
>1: 5,000\end{array}$ & Included & $\begin{array}{l}\text { Spatially } \\
\text { distributed } \\
\text { intensity }\end{array}$ & $\begin{array}{l}\text { Annual } \\
\text { probability of } \\
\text { occurrence (or } \\
\text { return period) of } \\
\text { a given intensity }\end{array}$ \\
\hline
\end{tabular}

${ }^{\text {a }}$ Intensity (magnitude)/frequency

sensitive to the resolution of the DEM and to the quality of the input data. The local scale is typically used for statutory purposes (the zoning maps may be legally binding for public administrators and land users), and it is the reference scale used when planning and implementing urban developments, warning systems and emergency planes at the local level. Moreover, this scale is required to rank the areas most at risk and to prioritise those requiring mitigation works aimed at reducing the risk to properties. Areas of zoning usually range from 10 to $1,000 \mathrm{~km}^{2}$.

The site-specific zoning map scale may be used for statutory purposes, and it is the only one that can be adopted at the level of the site investigation before the design phase of control works (Soeters and van Westen 1996). The sizes of study areas may range up to tens of square kilometres.

Regardless of the zoning methods and the scale adopted, the use of common descriptors to differentiate landslide magnitude and intensity as well as to quantify landslide susceptibility, hazard and risk is strongly encouraged in order to allow comparisons between different geo-environmental contexts (Fell et al. 2008a).

\section{Descriptors for landslide hazard and risk}

Descriptors consist of parameters or combinations of parameters that are chosen according to the type of landslide zoning; well-established ranges of quantitative values for these parameters can be associated with nominal scales (very high, high,...., very low). Different descriptors are required depending on 
- The scale of analysis (the mapping units adopted for the national scale may be different to those adopted at the site-specific scale) and the related zoning purposes (information, advisory, statutory and design)

- The landslide type (potential or existing) and the characteristics of the landslides (e.g. magnitude)

- The characteristics of the exposed elements (e.g. linear infrastructures, urbanised areas, other)

- The adopted risk acceptability/tolerability criteria, which may vary from country to country (Leroi et al. 2005).

Table 1 provides examples of landslide hazard descriptors that should be considered in zoning activity.

\section{Input data for landslide risk analysis}

This section reviews the input data required for assessing landslide susceptibility, hazard and risk. Taking into account the huge amount of literature on this topic, a summary will be given of the parameters that are most suitable for analysing the occurrence of, and the potential for, different landslide mechanisms (rockfalls, shallow landslides and debris flows, and slow-moving large landslides). The main data layers required for landslide susceptibility, hazard and risk analysis can be subdivided into four groups: landslide inventory data, environmental factors, triggering factors and elements at risk (Soeters and van Westen 1996; Van Westen et al. 2008). Of these, the landslide inventory is the most important, as it gives insight in the location of past landslide occurrences, as well as their failure mechanisms, causal factors, frequency of occurrence, volumes and the damage that has been caused.

\section{Parameters controlling the occurrence of landslides}

The occurence and frequency-magnitude of mass movements are controlled by a large number of factors, which can be subdivided into intrinsic, or predisposing, factors that contribute to the instability of the slope and the factors that actually trigger the event. The type and weighting of each factor depends on the environmental setting (e.g. climatic conditions, internal relief, geological setting, geomorphological evolution and processes) and may also differ substantially within a given area due to subtle differences in terrain conditions (e.g. soil properties and depth, subsurface hydrology, density and orientation of discontinuities, local relief). Different combinations of factors may control different types of landslides within the same area. A recent overview of landslide mechanisms and triggers is presented by Crosta et al. (2012). They provide a detailed description of the different landslide triggers, such as rainfall and changes in slope hydrology, changes in slope geometry due to excavation or erosion, earthquakes and related dynamic actions, snowmelt and permafrost degradation, deglaciation and related processes in the paraglacial environment, rock/soil weathering and related degradation, volcanic processes, and human activity.

The large diversity in predisposing and triggering factors complicates the analysis of landslide susceptibility and hazard, for which the methods and approaches, and the data required, differ from case to case. Also, the scale at which the analysis takes place plays an important role. Glade and Crozier (2005) present a discussion of the relation between data availability, model complexity and predictive capacity. It is not possible to provide strict guidelines on the type of data required for a landslide hazard and risk analysis in the form of a prescribed uniform list of predisposing and triggering factors. The selection of causal factors differs depending on the scale of analysis, the characteristics of the study area, the landslide type, and the failure mechanisms. A list of the possible factors controlling the occurrence of landslides is given in Table 2, differentiated for various landslide mechanisms. The list of factors is not exhaustive, and it is important to select the specific factors that are related to the landslide types and failure mechanisms in each particular environment. However, it does give an idea of the type of factors related to topography, geology, soil types, hydrology, geomorphology, land use, earthquakes, volcanoes, weather and climatic conditions.

\section{Sources of input data}

To consider the factors indicated in Table 2 in landslide hazard and risk analysis at any of the spatial scales described in the "Landslide zoning at different scales" section, they need to be presented as maps. Table 3 gives an overview of the sources of input data, together with an indication of the main types of data, their characteristics, the method used, and the importances of the four types of landslide mechanisms considered. The sources of input data for landslide hazard and risk analysis can be subdivided into the following components: laboratory analysis, field measurements, monitoring networks, field mapping, archive studies and ancillary data, and remote sensing. There are relatively few publications that provide an overview of the sources of input data and data requirements for quantitative landslide hazard and risk analysis (e.g. Van Westen et al. 2008). Most textbooks on landslide hazard and risk analysis (e.g. Lee and Jones 2004; Glade et al. 2005) do not treat this topic separately. An overview of laboratory experiments, field mapping procedures, and monitoring techniques as input for quantitative landslide hazard assessment can be found in textbooks (e.g. Turner and Schuster 1996) and in more recent overviews such as 
Table 2 Overview of factors controlling the occurrence of landslides, and their relevance in landslide susceptibility and hazard assessment for different landslide mechanisms $(\mathrm{R}=$ rockfalls, $\mathrm{S}=$ shallow landslides and debris flows, $\mathrm{L}=$ large, slow-moving landslides)

\begin{tabular}{|c|c|c|c|c|c|c|c|}
\hline \multirow[t]{2}{*}{ Group } & \multirow[t]{2}{*}{ Parameters } & \multirow[t]{2}{*}{ Relevance for landslide susceptibility and hazard assessment } & \multicolumn{2}{|c|}{$\begin{array}{l}\text { Type } \\
\text { of } \\
\text { factor }\end{array}$} & \multicolumn{3}{|c|}{$\begin{array}{l}\text { Landslide } \\
\text { mechanisms }\end{array}$} \\
\hline & & & $\mathrm{C}$ & $\mathrm{T}$ & $\mathrm{R}$ & $\mathrm{S}$ & $\mathrm{L}$ \\
\hline \multirow[t]{5}{*}{ Topography } & $\begin{array}{l}\text { Elevation, internal } \\
\text { relief }\end{array}$ & Elevation differences result in potential energy for slope movements & $\bullet$ & & $\mathrm{H}$ & $\mathrm{C}$ & $\mathrm{H}$ \\
\hline & Slope gradient & Slope gradient is the predominant factor in landslides & $\bullet$ & $\bullet$ & $\mathrm{C}$ & $\mathrm{C}$ & $\mathrm{C}$ \\
\hline & Slope direction & $\begin{array}{l}\text { Might reflect differences in soil moisture and vegetation, and plays an } \\
\text { important role in relation to discontinuities }\end{array}$ & 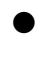 & & $\mathrm{C}$ & M & M \\
\hline & $\begin{array}{l}\text { Slope length, shape, } \\
\text { curvature, } \\
\text { roughness }\end{array}$ & Indicator of slope hydrology, important for runout trajectory modelling & ○ & & $\mathrm{C}$ & $\mathrm{H}$ & $\mathrm{H}$ \\
\hline & $\begin{array}{l}\text { Flow direction and } \\
\text { accumulation }\end{array}$ & Used in slope hydrological modelling, e.g. for the wetness index & • & & M & $\mathrm{C}$ & $\mathrm{H}$ \\
\hline \multirow[t]{5}{*}{ Geology } & Rock types & Determine the engineering properties of rock types & $\bullet$ & & $\mathrm{C}$ & $\mathrm{H}$ & $\mathrm{C}$ \\
\hline & Weathering & $\begin{array}{l}\text { Types of weathering (physical/chemical), depth of weathering, } \\
\text { individual weathering zones and age of cuts are important factors }\end{array}$ & ○ & & $\mathrm{C}$ & $\mathrm{H}$ & $\mathrm{H}$ \\
\hline & Discontinuities & $\begin{array}{l}\text { Discontinuity sets and characteristics, relation with slope directions and } \\
\text { inclination }\end{array}$ & $\bullet$ & & $\mathrm{C}$ & M & $\mathrm{H}$ \\
\hline & Structural aspects & Geological structure in relation to the slope angle/direction & 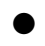 & & $\mathrm{H}$ & $\mathrm{H}$ & $\mathrm{H}$ \\
\hline & Faults & Distance from active faults or widths of fault zones & $\bullet$ & & $\mathrm{H}$ & $\mathrm{H}$ & $\mathrm{H}$ \\
\hline \multirow[t]{4}{*}{ Soils } & Soil types & Origin of the soil determines its properties and geometry & 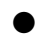 & & $\mathrm{L}$ & $\mathrm{C}$ & $\mathrm{H}$ \\
\hline & Soil depth & $\begin{array}{l}\text { In superficial formations, depth determines the potential movable } \\
\text { volume }\end{array}$ & $\bullet$ & & $\mathrm{L}$ & $\mathrm{C}$ & $\mathrm{H}$ \\
\hline & $\begin{array}{l}\text { Geotechnical } \\
\text { properties }\end{array}$ & Grain size, cohesion, friction angle, bulk density & ○ & & $\mathrm{L}$ & $\mathrm{C}$ & $\mathrm{H}$ \\
\hline & $\begin{array}{l}\text { Hydrological } \\
\text { properties }\end{array}$ & Pore volume, saturated conductivity, PF curve & ○ & & $\mathrm{L}$ & $\mathrm{H}$ & $\mathrm{H}$ \\
\hline \multirow[t]{4}{*}{ Hydrology } & Groundwater & $\begin{array}{l}\text { Spatial and temporal variations in depth to groundwater table, perched } \\
\text { groundwater tables, wetting fronts, pore water pressure, soil suction }\end{array}$ & $\bullet$ & & $\mathrm{L}$ & $\mathrm{H}$ & $\mathrm{H}$ \\
\hline & Soil moisture & Spatial and temporal variations in soil moisture content & 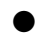 & 0 & $\mathrm{~L}$ & $\mathrm{H}$ & $\mathrm{H}$ \\
\hline & $\begin{array}{l}\text { Hydrological } \\
\text { components }\end{array}$ & $\begin{array}{l}\text { Interception, evapotranspiration, throughfall, overland flow, infiltration, } \\
\text { percolation, etc. }\end{array}$ & • & & M & $\mathrm{H}$ & $\mathrm{H}$ \\
\hline & $\begin{array}{l}\text { Stream network and } \\
\text { drainage density }\end{array}$ & $\begin{array}{l}\text { Buffer zones around streams; in small scale assessment, drainage } \\
\text { density may be used as an indicator for type of terrain }\end{array}$ & $\bullet$ & & $\mathrm{L}$ & $\mathrm{H}$ & $\mathrm{H}$ \\
\hline \multirow[t]{3}{*}{ Geomorphology } & $\begin{array}{l}\text { Geomorphological } \\
\text { environment }\end{array}$ & Alpine, glacial, periglacial, denudational, coastal, tropical, etc. & $\bullet$ & & $\mathrm{H}$ & $\mathrm{H}$ & $\mathrm{H}$ \\
\hline & Old landslides & $\begin{array}{l}\text { Material and terrain characteristics have changed, making these } \\
\text { locations more prone to reactivations }\end{array}$ & ○ & & M & $\mathrm{H}$ & $\mathrm{C}$ \\
\hline & $\begin{array}{l}\text { Past landslide } \\
\text { activity }\end{array}$ & $\begin{array}{l}\text { Historical information on landslide activity is often crucial for } \\
\text { determining landslide hazards and risk }\end{array}$ & $\bullet$ & & $\mathrm{C}$ & $\mathrm{C}$ & $\mathrm{C}$ \\
\hline \multirow{7}{*}{$\begin{array}{l}\text { Land use and } \\
\text { anthropogenic } \\
\text { factors }\end{array}$} & Current land use & $\begin{array}{l}\text { Type of land use/land cover, vegetation type, canopy cover, rooting } \\
\text { depth, root cohesion, weight }\end{array}$ & 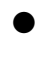 & & $\mathrm{H}$ & $\mathrm{H}$ & $\mathrm{H}$ \\
\hline & Land-use changes & Temporal variations in land use/land cover & 0 & 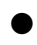 & M & $\mathrm{C}$ & $\mathrm{H}$ \\
\hline & $\begin{array}{c}\text { Transportation } \\
\text { infrastructure }\end{array}$ & Buffers around roads in sloping areas with road cuts & $\bullet$ & & M & $\mathrm{H}$ & $\mathrm{H}$ \\
\hline & Buildings & Slope cuts made for building construction & ○ & & M & $\mathrm{H}$ & $\mathrm{H}$ \\
\hline & $\begin{array}{l}\text { Drainage and } \\
\text { irrigation networks }\end{array}$ & Leakages from such networks may be an important cause of landslides & ○ & ○ & $\mathrm{L}$ & $\mathrm{H}$ & $\mathrm{H}$ \\
\hline & $\begin{array}{l}\text { Quarrying and } \\
\text { mining }\end{array}$ & $\begin{array}{l}\text { These activities alter the slope geometry and stress distribution. } \\
\text { Vibrations due to blasting can trigger landslides }\end{array}$ & ○ & D & $\mathrm{H}$ & $\mathrm{H}$ & $\mathrm{H}$ \\
\hline & Dams and reservoirs & Reservoirs change the hydrological conditions. Tailing dams may fail & ○ & & $\mathrm{L}$ & $\mathrm{H}$ & $\mathrm{H}$ \\
\hline
\end{tabular}


Table 2 continued

\begin{tabular}{|c|c|c|c|c|c|c|c|}
\hline \multirow[t]{2}{*}{ Group } & \multirow[t]{2}{*}{ Parameters } & \multirow[t]{2}{*}{ Relevance for landslide susceptibility and hazard assessment } & \multicolumn{2}{|c|}{$\begin{array}{l}\text { Type } \\
\text { of } \\
\text { factor }\end{array}$} & \multicolumn{3}{|c|}{$\begin{array}{l}\text { Landslide } \\
\text { mechanisms }\end{array}$} \\
\hline & & & $\mathrm{C}$ & $\mathrm{T}$ & $\mathrm{R}$ & $\mathrm{S}$ & $\mathrm{L}$ \\
\hline \multirow[t]{4}{*}{$\begin{array}{l}\text { Earthquakes and } \\
\text { volcanoes }\end{array}$} & Seismicity & $\begin{array}{l}\text { Earthquake magnitude/frequency relations, historical intensity maps } \\
\text { linked with co-seismic landslide inventories }\end{array}$ & & $\bullet$ & $\mathrm{C}$ & $\mathrm{C}$ & $\mathrm{C}$ \\
\hline & Fault mechanism & $\begin{array}{l}\text { Fault locations, fault type, length of fault rupture, buried or exposed, } \\
\text { distance from fault, hanging wall/footwalls }\end{array}$ & ○ & ) & $\mathrm{H}$ & $\mathrm{H}$ & $\mathrm{H}$ \\
\hline & Volcano type & Height and composition of volcanic edifice, magma chamber stability & ○ & 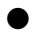 & M & $\mathrm{H}$ & $\mathrm{H}$ \\
\hline & $\begin{array}{l}\text { Volcanic eruption } \\
\text { types }\end{array}$ & $\begin{array}{l}\text { Lateral explosions, collapse of magma chambers, pyroclastic flows, } \\
\text { lahars }\end{array}$ & 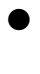 & ○ & M & $\mathrm{H}$ & $\mathrm{H}$ \\
\hline \multirow[t]{2}{*}{$\begin{array}{l}\text { Weather and } \\
\text { climate }\end{array}$} & Precipitation & $\begin{array}{l}\text { Daily or continuous data, weather patterns, magnitude/frequency } \\
\text { relations, IDF curves, rainfall thresholds, antecedent rain, PADF } \\
\text { curves }\end{array}$ & & 0 & $\mathrm{C}$ & $\mathrm{C}$ & $\mathrm{C}$ \\
\hline & Temperature & $\begin{array}{l}\text { Important influence on hydrology and the condition of vegetation. Rapid } \\
\text { temperature changes, snowmelt, frost-thaw cycles, permafrost }\end{array}$ & 0 & 0 & $\mathrm{H}$ & $\mathrm{H}$ & $\mathrm{H}$ \\
\hline
\end{tabular}

The relevance is indicated as $C$ (crucial), $H$ (highly important), $M$ (moderately important), and $L$ (less important). The type of factor is indicated as either $C$ (conditioning factor) or $T$ (triggering factor)

Springman et al. (2011). Reviews on data collection related to individual components are more common. For example, Jongmans and Garambois (2007) provide a review of geophysical methods for landslide investigations, Corominas and Moya (2008) present an overview of dating methods used in landslide studies, and Cepeda et al. (2012) give a review of the methods for using meteorological data to analyse rainfall thresholds for quantitative landslide hazard assessment. Pitilakis et al. (2011) provide a comprehensive review of the data that need to be collected for the characterisation and physical vulnerability assessment of elements at risk, such as buildings, roads, pipelines, etc. Good overviews of the use of remote sensing data for landslide hazard and risk analysis can be found in Soeters and van Westen (1996), Metternicht et al. (2005), Singhroy (2005), Kääb (2010), Michoud et al. (2010) and Stumpf et al. (2011). Remote sensing is a field that has experienced very important developments over the last two decades, with the introduction of Earth-orbiting satellites that have different characteristics with respect to their spatial, temporal and spectral resolution. For a recent overview, see the comprehensive database hosted at http://gdsc.nlr.nl/ FlexCatalog/catalog.html.

Table 3 indicates the method used to collect spatial data of each type. Many of the crucial input data are obtained as point information. These are either linked to specific features (e.g. landslides, buildings) or they are sample points that are used to characterise spatial units (e.g. soil types, vegetation types). In the latter case, they need to be converted into maps through spatial interpolation using environmental correlation with landscape attributes (e.g. geostatistical interpolation methods such as co-kriging).
There are also points that provide information on regional variables (e.g. precipitation) that need to be interpolated as well. Many types of data are in the form of area-based features (e.g. landslide polygons, buildings) or cover the whole study area (e.g. digital elevation models, vegetation, geology). As can be seen from the examples of data types listed in Table 3, a large amount of data is needed to carry out a quantitative landslide hazard and risk study. The availability of ancillary data, the size of the study area, the homogeneity of the terrain and the availability of resources will determine the type and quantity of the data needed, which will eventually also govern the type of susceptibility method used and the possibility of converting a susceptibility map into a quantitative hazard and risk map (Van Westen et al. 2008; Fell et al. 2008a, b).

In the following sections, some of the main types of input data are explained in more depth.

Landslide inventories

Landslide inventory databases should display information on landslide activity (preferably with the state, style and distribution of activity, as defined by Cruden and Varnes 1996 and by WP/WLI 1993), and therefore require multitemporal landslide information over larger regions. For detailed mapping scales, activity analysis is often restricted to a single landslide, and requires more landslide monitoring. In order to produce a reliable map that predicts the landslide hazard and risk in a certain area, it is crucial to have insight into the spatial and temporal frequencies of landslides, and therefore each landslide hazard or risk study should begin with a landslide inventory that is as complete 
Table 3 Overview of sources of input data and their relevance to quantitative landslide hazard and risk analysis for different landslide mechanisms $(\mathrm{R}=$ rockfalls, $\mathrm{S}=$ shallow landslides and debris flows, $\mathrm{L}=$ large, slow-moving landslides

\begin{tabular}{|c|c|c|c|c|c|c|c|c|c|c|}
\hline \multirow[t]{2}{*}{ Main source } & \multirow[t]{2}{*}{ Group of data } & \multirow[t]{2}{*}{ Examples } & \multirow[t]{2}{*}{$\mathrm{M}$} & \multicolumn{4}{|c|}{ Scale } & \multicolumn{3}{|c|}{ Relevance } \\
\hline & & & & $\mathrm{N}$ & $\mathrm{R}$ & $\mathrm{L}$ & $\mathrm{S}$ & $\mathrm{R}$ & $\mathrm{S}$ & $\mathrm{L}$ \\
\hline \multirow[t]{4}{*}{$\begin{array}{l}\text { Laboratory } \\
\text { analysis }\end{array}$} & Soil properties & $\begin{array}{l}\text { Grain size distribution, saturated and unsaturated shear } \\
\text { strength, soil water retention curves, saturated hydraulic } \\
\text { conductivity, clay minerals, sensitivity, viscosity, bulk } \\
\text { density }\end{array}$ & Ps & $\times$ & $\times$ & $\bigcirc$ & O & $\mathrm{L}$ & $\mathrm{C}$ & $\mathrm{H}$ \\
\hline & Rock properties & $\begin{array}{l}\text { Unconfined compressive strength, shear strength, } \\
\text { mineralogy }\end{array}$ & Ps & $\times$ & $x$ & $\bigcirc$ & 0 & $\mathrm{C}$ & $\mathrm{L}$ & $\mathrm{C}$ \\
\hline & Vegetation prop & $\begin{array}{l}\text { Root tensile strength, root pullout strength, } \\
\text { evapotranspiration }\end{array}$ & Ps & $\times$ & $\times$ & $\bigcirc$ & ○ & $\mathrm{L}$ & $\mathrm{H}$ & M \\
\hline & Age dating & Radiocarbon C-14, pollen analysis & $\mathrm{Pf}$ & $\bigcirc$ & $\bigcirc$ & $\bigcirc$ & ○ & $\mathrm{L}$ & $\mathrm{L}$ & $\mathrm{H}$ \\
\hline \multirow[t]{7}{*}{$\begin{array}{l}\text { Field } \\
\text { measurements }\end{array}$} & Landslide age & $\begin{array}{l}\text { Dendrochronology, lichenometry, varves, } \\
\text { tephrochronology, archaeological artifacts }\end{array}$ & Pf & $\bigcirc$ & $\bigcirc$ & $\bigcirc$ & ○ & M & M & $\mathrm{H}$ \\
\hline & Soil depth & Drillholes, trenches, pits, outcrops, auguring & Ps & $\times$ & $\times$ & $\bigcirc$ & ○ & $\mathrm{L}$ & $\mathrm{C}$ & M \\
\hline & Geophysics & $\begin{array}{l}\text { Seismic refraction, microseismic monitoring, electrical } \\
\text { resistivity, electromagnetic method, magnetic method, } \\
\text { ground-penetrating radar, borehole geophysical } \\
\text { methods }\end{array}$ & Ps & $x$ & $x$ & O & ○ & $\mathrm{L}$ & M & $\mathrm{H}$ \\
\hline & Soil characteristics & Standard penetration tests, field vane test & Ps & $\times$ & $\times$ & $\bigcirc$ & 0 & $\mathrm{~L}$ & $\mathrm{C}$ & M \\
\hline & Rock characteristics & $\begin{array}{l}\text { Lithology, discontinuities (types, spacing, orientation, } \\
\text { aperture, infilling), rock mass rating }\end{array}$ & Ps & $\times$ & $\times$ & $\bigcirc$ & O & $\mathrm{C}$ & $\mathrm{L}$ & $\mathrm{H}$ \\
\hline & $\begin{array}{l}\text { Hydrological } \\
\text { characteristics }\end{array}$ & $\begin{array}{l}\text { Infiltration capacity, water table fluctuation, soil suction, } \\
\text { pore water pressure }\end{array}$ & Ps & $x$ & $\times$ & $\bigcirc$ & 0 & $\mathrm{H}$ & $\mathrm{C}$ & $\mathrm{C}$ \\
\hline & $\begin{array}{l}\text { Vegetation } \\
\text { characteristics }\end{array}$ & $\begin{array}{l}\text { Root depth, root density, vegetation species, crop factor, } \\
\text { canopy storage, throughfall ratio }\end{array}$ & Ps & $\times$ & $\times$ & $\bigcirc$ & 0 & M & $\mathrm{H}$ & $\mathrm{L}$ \\
\hline \multirow[t]{4}{*}{$\begin{array}{c}\text { Monitoring } \\
\text { networks }\end{array}$} & $\begin{array}{l}\text { Landslide } \\
\text { displacement }\end{array}$ & $\begin{array}{l}\text { Electronic distance meters, global positing systems, } \\
\text { theodolite, terrestrial laser scanner, ground-based } \\
\text { interferometry, etc. }\end{array}$ & Pf & $x$ & $\times$ & $\bigcirc$ & 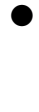 & $\mathrm{H}$ & $\mathrm{H}$ & $\mathrm{H}$ \\
\hline & Groundwater & Piezometers, tensiometers, discharge stations & $\mathrm{P}$ & $\times$ & $\times$ & $\bigcirc$ & ○ & $\mathrm{H}$ & $\mathrm{C}$ & $\mathrm{C}$ \\
\hline & Meteorological data & Precipitation, temperature, humidity, windspeed & Pn & ○ & ○ & ○ & ○ & $\mathrm{H}$ & $\mathrm{H}$ & $\mathrm{H}$ \\
\hline & Seismic data & $\begin{array}{l}\text { Seismic stations, strong motion stations, microseismic } \\
\text { studies }\end{array}$ & $\mathrm{Pn}$ & ○ & ○ & ○ & $\bullet$ & $\mathrm{H}$ & $\mathrm{H}$ & $\mathrm{H}$ \\
\hline \multirow[t]{8}{*}{ Field mapping } & Landslides & $\begin{array}{l}\text { Type, (relative) age, speed of movement, state of activity, } \\
\text { initiation, transport, runout zone, area, depth, volume, } \\
\text { causes, development }\end{array}$ & Af & O & ? & ○ & ○ & $\mathrm{C}$ & $\mathrm{C}$ & $\mathrm{C}$ \\
\hline & Geomorphology & $\begin{array}{l}\text { Characterisation of landforms, processes, and surface } \\
\text { materials }\end{array}$ & Ac & O & O & ○ & 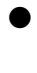 & $\mathrm{L}$ & $\mathrm{H}$ & $\mathrm{H}$ \\
\hline & Soil types & $\begin{array}{l}\text { Texture, soil classification, boundary mapping, } \\
\text { conversion into engineering soil types }\end{array}$ & Ac & $\bigcirc$ & $\bigcirc$ & ○ & ○ & $\mathrm{L}$ & $\mathrm{C}$ & $\mathrm{H}$ \\
\hline & Lithology & $\begin{array}{l}\text { Lithological mapping, weathering zones, boundary } \\
\text { mapping, formations, members, conversion into } \\
\text { engineering rock types }\end{array}$ & Ac & ○ & $\bigcirc$ & ○ & ○ & $\mathrm{C}$ & $\mathrm{H}$ & $\mathrm{H}$ \\
\hline & Structural geology & $\begin{array}{l}\text { Strike and dip measurements of bedding planes, and } \\
\text { discontinuities, stratigraphic reconstruction, fault } \\
\text { mapping, structural reconstruction }\end{array}$ & Ac & O & O & ○ & 0 & $\mathrm{H}$ & $\mathrm{L}$ & $\mathrm{H}$ \\
\hline & Vegetation & Vegetation type, density, leaf area index & Ac & $\bigcirc$ & $\bigcirc$ & ○ & - & $\mathrm{L}$ & $\mathrm{H}$ & M \\
\hline & Land use & $\begin{array}{l}\text { Land-use types, characterisation of vegetation per land } \\
\text { use }\end{array}$ & Ac & O & ○ & ○ & 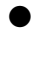 & $\mathrm{H}$ & $\mathrm{H}$ & $\mathrm{H}$ \\
\hline & Elements at risk & $\begin{array}{l}\text { Building typology, structural system, building height, } \\
\text { foundation system, road classification, pipeline } \\
\text { classification }\end{array}$ & $\begin{array}{l}\text { Af } \\
\mathrm{L}\end{array}$ & O & O & 0 & $\mathbf{0}$ & $\mathrm{H}$ & $\mathrm{H}$ & $\mathrm{H}$ \\
\hline
\end{tabular}


Table 3 continued

\begin{tabular}{|c|c|c|c|c|c|c|c|c|c|c|}
\hline \multirow[t]{2}{*}{ Main source } & \multirow[t]{2}{*}{ Group of data } & \multirow[t]{2}{*}{ Examples } & \multirow[t]{2}{*}{ M } & \multicolumn{4}{|c|}{ Scale } & \multicolumn{3}{|c|}{ Relevance } \\
\hline & & & & $\mathrm{N}$ & $\mathrm{R}$ & $\mathrm{L}$ & $\mathrm{S}$ & $\mathrm{R}$ & $\mathrm{S}$ & $\mathrm{L}$ \\
\hline \multirow{7}{*}{$\begin{array}{l}\text { Archive studies } \\
\text { and ancillary } \\
\text { data }\end{array}$} & Past landslide events & $\begin{array}{l}\text { Historical information on location, date of occurrence, } \\
\text { triggering mechanism, size, volume, runout length }\end{array}$ & $\begin{array}{l}\text { Af } \\
\text { Pf }\end{array}$ & $\bigcirc$ & O & 0 & ○ & $\mathrm{H}$ & $\mathrm{H}$ & $\mathrm{C}$ \\
\hline & Damage data & $\begin{array}{l}\text { Historical information on economic losses and } \\
\text { population affected with dates, location and } \\
\text { characterisation }\end{array}$ & Pf & O & O & $\bigcirc$ & $\bigcirc$ & $\mathrm{H}$ & $\mathrm{H}$ & $\mathrm{H}$ \\
\hline & Meteorological data & $\begin{array}{l}\text { Precipitation (continuous or daily), temperature, } \\
\text { windspeed, humidity }\end{array}$ & Pn & ○ & - & ○ & ○ & $\mathrm{H}$ & $\mathrm{H}$ & $\mathrm{H}$ \\
\hline & Changes in land use & $\begin{array}{l}\text { Historical maps of land use/land cover for different } \\
\text { periods }\end{array}$ & Ac & ○ & - & ○ & ○ & M & $\mathrm{H}$ & $\mathrm{H}$ \\
\hline & Elements at risk & $\begin{array}{l}\text { Historical maps of buildings, transportation } \\
\text { infrastructure, economic activities and population } \\
\text { characteristics }\end{array}$ & $\begin{array}{l}\text { Af } \\
\mathrm{L}\end{array}$ & $\bullet$ & ○ & 0 & ○ & $\mathrm{H}$ & $\mathrm{H}$ & $\mathrm{H}$ \\
\hline & Digital elevation & $\begin{array}{l}\text { Topographic maps with contour lines, digital elevation } \\
\text { models from existing catalogues }\end{array}$ & Ac & ○ & - & ○ & ○ & $\mathrm{H}$ & $\mathrm{H}$ & $\mathrm{H}$ \\
\hline & Thematic maps & $\begin{array}{l}\text { Geological, geomorphological, drainage network and } \\
\text { other existing thematic maps }\end{array}$ & Ac & ○ & - & O & ○ & $\mathrm{H}$ & $\mathrm{H}$ & $\mathrm{H}$ \\
\hline \multirow[t]{3}{*}{ Remote sensing } & $\begin{array}{l}\text { Aerial photographs } \\
\text { and high-resolution } \\
\text { satellite images }\end{array}$ & $\begin{array}{l}\text { Image interpretation for mapping and characterising } \\
\text { landslide locations, geomorphology, faults and } \\
\text { lineaments, land use/land cover, elements-at-risk } \\
\text { mapping }\end{array}$ & $\begin{array}{l}\text { Af } \\
\text { Ac }\end{array}$ & O & ○ & ○ & 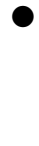 & $\mathrm{C}$ & $\mathrm{C}$ & $\mathrm{C}$ \\
\hline & $\begin{array}{l}\text { Multi-spectral } \\
\text { imagery }\end{array}$ & $\begin{array}{l}\text { Image classification methods for mapping of landslides, } \\
\text { land use/land cover, normalised difference vegetation } \\
\text { index, leaf area index }\end{array}$ & $\begin{array}{l}\text { Af } \\
\text { Ac }\end{array}$ & ○ & - & ○ & ○ & M & $\mathrm{H}$ & M \\
\hline & Digital elevation data & $\begin{array}{l}\text { Airborne stereophotogrammetry, spaceborne stereo- } \\
\text { photogrammetry, LiDAR, InSAR }\end{array}$ & Ac & 0 & - & 0 & 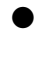 & $\mathrm{C}$ & $\mathrm{C}$ & $\mathrm{C}$ \\
\hline
\end{tabular}

The relevance is indicated as $C$ (crucial), $H$ (highly important), $M$ (moderately important), and $L$ (less important). The potential for this information to be collected at different scales is also indicated by: $\mathbf{0}=$ possible, $\bigcirc=$ difficult, $\times=$ not possible. The scales are $N$ (national scale), $R$ (regional scale), $L$ (local scale), and $S$ (site-specific scale). $M$ indicates the method used for spatial data collection, with $P f=$ point data linked to specific features (e.g. landslides), $P s=$ sample points characterising spatial units (e.g. soil types, vegetation types), $P n=$ points in a network which need to be interpolated, $A f=$ area-based feature data (e.g. landslide polygons, buildings), $A c=$ complete area coverage, $L=$ line data

as possible in both space and time, and which follows international nomenclature (IAEG Commission on Landslides 1990).

Landslide inventories can be carried out using a variety of techniques. A recent overview of the methods used for landslide inventory mapping is given by Guzzetti et al. (2012). Visual interpretation of stereoscopic imagery (either aerial photographs or very high resolution optical satellite images) remains the most widely used method, and results in inventories of high resolution (Cardinali 2002) when specific local conditions (such as vegetation limitations) are met and when it is carried out by expert interpreters. Nowadays, the use of Google Earth data is a good alternative for many areas, and many parts of the world are covered by high-resolution imagery which can be downloaded and combined in GIS with a digital elevation model to generate stereoscopic images, which are essential in landslide interpretation. One of the most important developments is the use of shaded relief images produced from
LiDAR DEMs, from which the objects (e.g. vegetation) on the Earth's surface have been removed, for the visual interpretation of landslide phenomena (Haugerud et al. 2003; Ardizzone et al. 2007; Van Den Eeckhaut et al. 2009; Razak et al. 2011).

Landslide inventory mapping using visual stereo image interpretation is a time-consuming task, and requires extensive skills, training and perseverance. In many cases, such skilled interpreters are not available, or landslide inventories have to be produced within a short period of time after the occurrence of a triggering event, requiring the application of automated detection methods based on remote sensing. Michoud et al. (2010) and Stumpf et al. (2011) provide complete overviews of the various remote sensing methods and tools that can be used for (semi-) automated landslide mapping and monitoring. A large number of methods make use of passive optical remote sensing tools, such as pixel-based classification of or change detection from spaceborne images (Hervás et al. 
2003; Borghuis et al. 2007; Mondini et al. 2011), or objectoriented classification of or change detection from spaceborne images (Martha et al. 2010a; Lu et al. 2011).

Many methods used for landslide mapping and monitoring make use of digital elevation measurements that may be derived from a wide range of tools, such as terrestrial photographs (Travelletti et al. 2010), terrestrial videos, UAV-based aerial photographs (Niethammer et al. 2011), airborne stereophotogrammetry and spaceborne stereophotogrammetry (Martha et al. 2010b). Also, the application of LiDAR data from both airborne laser scanning (ALS) and terrestrial laser scanning (TLS) has proven very successful (Jaboyedoff et al. 2012). Apart from LiDAR, the most useful tool for landslide inventory mapping and monitoring using remote sensing is in the InSAR domain. Interferometric synthetic aperture radar (InSAR) has been used extensively for measuring surface displacements. Multi-temporal InSAR analyses using techniques such as persistent scatterer (PS) InSAR (Ferretti et al. 2001) and small baseline (SB) InSAR (Berardino et al. 2002) can be used to measure the displacements of permanent scatterers such as buildings with millimetre accuracy, and allow the deformation history to be reconstructed (Farina et al. 2006).

\section{Predisposing factors}

Since topographic information and its various derivatives play an important role in landslide hazard analysis, the use of high-resolution digital elevation models (DEMs) is crucial. DEMs can be derived through a large variety of techniques, such as by digitising contours from existing topographic maps, topographic levelling, electronic distance measurement (EDM), differential GPS measurements, (digital) photogrammetry using imagery taken from the ground or a wide range of platforms, InSAR, and LiDAR. Global DEMs are now available from several sources, such as the SRTM (Shuttle Radar Topography Mission: Farr et al. 2007) and the ASTER (Advanced Spaceborne Thermal Emission and Reflection Radiometer: METI/NASA 2009). In the near future, a more accurate global DEM is expected from TanDEM-X (TerraSAR-X Add-On for Digital Elevation Measurements), which will provide a DEM for the entire Earth's surface to a vertical accuracy of $<2 \mathrm{~m}$ and a spatial accuracy of $12 \mathrm{~m}$ (Nelson et al. 2009; Smith and Pain 2009). Many types of maps (such as those of slope steepness, orientation, length, curvature, upslope contributing area) can be derived from DEMs using GIS operations.

Traditionally, geological maps represent a standard component in heuristic and statistical landslide hazard assessment methods (Aleotti and Chowdhury 1999; Dai et al. 2002; Chacón et al. 2006). It is recommended that the traditional legend of a geological map, which focuses on the litho-stratigraphical subdivision into formations, should be converted into an engineering geological classification with more emphasis on Quaternary sediments and more information on the rock composition and rock mass strength. In detailed hazard studies, specific engineering geological maps are generated and rock types are characterised using field tests and laboratory measurements (Dobbs et al. 2012). 3-D geological maps have been used for detailed analyses, although the amount of outcrop and borehole information collected limits this method to scales of 1:5,000 or larger. Its use is generally restricted to the site investigation level (e.g. Xie et al. 2003) at present, although this may be expected to change in the future when more detailed information becomes available from boreholes and geophysical studies, as computer technology and data availability has transformed our ability to construct 3D digital models of the shallow subsurface (e.g. Culshaw 2005).

Aside from lithological information, structural information is very important for landslide hazard assessments. At the medium and large scales, attempts have been made to generate maps indicating dip direction and dip angle that are based on field measurements, but the success of this depends very strongly upon the number of structural measurements and the complexity of the geological structure (Ghosh et al. 2010).

Representation of soil properties is a key problem in the use of physically based slope stability models for landslide hazard assessments, particularly for shallow failures such as debris avalanches and debris slides, as well as deepseated slumps in soil (Guimaraes et al. 2003). Regolith depth, often referred to by geomorphologists and engineers as soil depth, is defined as the depth from the surface to more-or-less consolidated material. Despite being a major factor in landslide modelling, most studies have ignored its spatial variability by using constant values over generalised land units in their analyses (Bakker et al. 2005; Bathurst et al. 2007; Talebi et al. 2008; Montgomery and Dietrich 1994; Santacana et al. 2003). Soil thickness can be modelled using physically based methods that model rates of weathering, denudation and accumulation (Dietrich et al. 1995; D'Odorico 2000) or empirical methods that determine correlations with topographical factors such as slope, or it can be predicted using geostatistical methods (Tsai et al. 2001; Van Beek 2002; Penížek and Borůvka 2006; Catani et al. 2007). Such methods have also been used to model the distributions of relevant geotechnical and hydrological properties of soils (Hengl et al. 2004). However, the accurate modeling of soil thickness and parameters over large areas remains difficult due to high spatial variability. This implies that the final prediction of slope hydrology and stability will still have a large component of 
randomness. In addition to the limitations on accurately determining the spatial variability, the measurement accuracy and the temporal variability of the parameters are two other significant sources of error which will propagate into the final simulation of slope hydrology and stability (Kuriakose et al. 2009).

Soil samples collected at different depths with the drilling of boreholes and analysis of the grain-size distribution curves provide additional information about soil depth and bedrock topography, which is also important for determining subsurface hydrology.

Geomorphological maps are generated at various scales to show land units based on their shapes, materials, processes and genesis. Although some countries, such as Germany, the Netherlands, Poland and Belgium, have established legend systems to this end (Gustavsson et al. 2006), there is no generally accepted legend for geomorphological maps, and there may be large variations in content based on the experience of the geomorphologist. An important field within geomorphology is the quantitative analysis of terrain forms from DEMs-called geomorphometry or digital terrain analysis. This combines elements from the earth sciences, engineering, mathematics, statistics and computer science (Pike 2000). Part of the work focuses on the automatic classification of geomorphological land units based on morphometric characteristics at small scales (Asselen and Seijmonsbergen 2006), or on the extraction of slope facets at medium scales which can be used as the basic mapping units in statistical analysis (Cardinali 2002).

Land use is often considered a static factor in landslide hazard studies, and relatively few studies have considered changing land use as a factor in the analysis (Matthews et al. 1997; Van Beek and Van Asch 2004). However, there are an increasing number of studies that have analysed the effect of land-use changes in landslide susceptibility assessment (Glade 2003). For physically based modelling, it is very important to have temporal land-use/land-cover maps and to find the changes in the mechanical and hydrological effects of vegetation. Land-use maps are made on a routine basis from medium-resolution satellite imagery. Although change detection techniques such as post-classification comparison, temporal image differencing, temporal image ratioing, or Bayesian probabilistic methods have been widely applied in land-use applications, only fairly limited work has been done on the inclusion of multi-temporal land-use change maps in landslide hazard studies (Kuriakose 2010).

\section{Triggering factors}

Data relating to triggering factors represent another important set of input data for landslide hazard assessment.
Data on precipitation, seismicity and anthropogenic activities have very important temporal components, knowledge of which is required in the conversion of landslide susceptibility maps to hazard maps. The magnitude-frequency relation for the triggering event is used to determine the probability of landslide occurrences caused by that particular trigger. Magnitude-frequency relations of triggering events can be linked to landslide occurrence in several ways, as will be discussed in the "Derivation of $\mathrm{M}-\mathrm{F}$ relations" section. Rainfall and temperature data are collected at meteorological stations, and values throughout the study area are then derived through interpolation of the station data. After that, correlations between precipitation indicators and dates of historical landslide occurrences are elucidated in order to establish rainfall thresholds (Cepeda et al. 2012). A good example in Europe is the European Climate Assessment \& Dataset project (http://eca.knmi.nl/). The use of weather radar for rainfall prediction in landslide studies is a promising approach, as it allows storm cells to be tracked with high spatial resolution, which in turn permits short-term forecasts or warnings (e.g. Crosta and Frattini 2003).

Physically based models for landslide susceptibility can incorporate rainfall as a dynamic input of the model, which allows susceptibility maps for future scenarios with climatic change to be prepared (Collison et al. 2000; Melchiorre and Frattini 2012; Comegna et al. 2012). Analysis of earthquake-triggered landslide susceptibility and hazard is still not very well developed due to the difficulty involved in determining possible earthquake scenarios, for example with respect to the antecedent moisture conditions and their associated co-seismic landslide distributions (Keefer 2002; Meunier et al. 2007; Gorum et al. 2011). In order to establish better relationships between seismic, geological and terrain factors for the prediction of coseismic landslide distributions, more digital event-based co-seismic landslide inventories need to be produced for different environments, earthquake magnitudes and faulting mechanisms. Another approach to earthquake-induced landslide susceptibility mapping uses a heuristic rule-based approach in GIS with factor maps related to shaking intensity (using the USGS ShakeMap data), slope angle, material type, moisture, slope height and terrain roughness (Miles and Keefer 2009).

\section{Elements at risk}

Elements at risk are all of the elements that may be affected by the occurrence of hazardous phenomena, such as population, property or the environment. The consequences of a landslide and subsequently the risk depend on the type of elements that are present in an area. Inventories of elements at risk can be carried out at various levels, depending 
on the objectives of the study (Alexander 2005). Elementsat-risk data should be collected for certain basic spatial units, which may be grid cells, administrative units or homogeneous units with similar characteristics in terms of type and density of elements at risk. Risk can also be analysed for linear features (e.g. transportation lines) and specific sites (e.g. a dam site).

Building information can be obtained in several ways. Ideally, it is available as building footprint maps, with associated attribute information on building typology, structural system, building height, foundation type, as well as the value of the building and its contents (Pitilakis et al. 2011). It can also be derived from existing cadastral databases and (urban) planning maps, or it may be available in an aggregated form as the number and types of buildings per administrative unit. If such data are not available, building footprint maps can be generated using screen digitisation from high-resolution images, or through automated building mapping using high-resolution multispectral satellite images and LiDAR (Brenner 2005).

Population data sets have static and dynamic components. The static component relates to the number of inhabitants per mapping unit and their characteristics, whereas the dynamic component refers to their activity patterns and their distribution in space and time. Population distributions can be expressed in terms of either the absolute number of people per mapping unit or the population density. Census data are the obvious source of demographic data. However, for many areas, census data are unavailable, outdated or unreliable. Therefore, other approaches may also be used to model the population distribution along with remote sensing and GIS, in order to refine the spatial resolution of population data from available population information (so-called dasymetric mapping, Chen et al. 2004).

\section{Data quality}

The occurrence of landslides is governed by complex interrelationships between factors, some of which cannot be determined in detail, and others only with a large degree of uncertainty. Some important aspects in this respect are the error, accuracy, uncertainty and precision of the input data, and the objectivity and reproducibility of the input maps (see the "Evaluation of the performance of landslide zonation maps" section). The accuracy of input data refers to the degree of closeness of the measured or mapped values or classes of a map to its actual (true) value or class in the field. An error is defined as the difference between the mapped value or class and the true one. The precision of a measurement is the degree to which repeated measurements under unchanged conditions show the same results. Uncertainty refers to the degree to which the actual characteristics of the terrain can be represented spatially in a map.

The error in a map can only be assessed if another map or other field information is available that is error-free and can be used for verification (e.g. elevation). DEM error sources have been described by Heuvelink (1998) and Pike (2000); these can be related to the age of data, incomplete density of observations or spatial sampling, processing errors such as numerical errors in the computer, interpolation errors or classification and generalisation problems and measurement errors such as positional inaccuracy (in the $x$ - and $y$-directions), data entry faults, or observer bias. Reviews of the uncertainties associated with digital elevation models are provided by Fisher and Tate (2006), Wechsler (2007) and Smith and Pain (2009). The quality of the input data used for landslide hazard and risk analysis is related to many factors, such as the scale of the analysis, the time and money allocated for data collection, the size of the study area, the experience of the researchers, and the availability and reliability of existing maps. Also, existing landslide databases often present several drawbacks (Ardizzone et al. 2002; Van Den Eeckhaut and Hervás 2012) related to their spatial and (especially) temporal completeness (or incompleteness), and the fact that they are biased toward landslides that have affected infrastructure such as roads.

\section{Suggested methods for landslide susceptibility assessment}

A landslide susceptibility map subdivides the terrain into zones with differing likelihoods that landslides of a certain type may occur. Landslide susceptibility assessment can be considered the initial step towards a landslide hazard and risk assessment, but it can also be an end product in itself that can be used in land-use planning and environmental impact assessment. This is especially the case in smallscale analyses or in situations where insufficient information is available on past landslide occurrence to allow the spatial and temporal probabilities of events to be assessed.

Landslide susceptibility maps contain information on the type of landslides that might occur and on their spatial likelihood of occurrence in terms of identifying the most probable initiation areas (based on a combination of geological, topographical and land-cover conditions) and the possibility of extension (upslope through retrogression and/ or downslope through runout). The likelihood may be indicated quantitatively through indicators (such as the density as the number per square kilometre, or the area affected per square kilometre).

The methods used for landslide susceptibility analysis are usually based on two assumptions. The first is that past 
Fig. 2 Methods for landslide susceptibility assessment

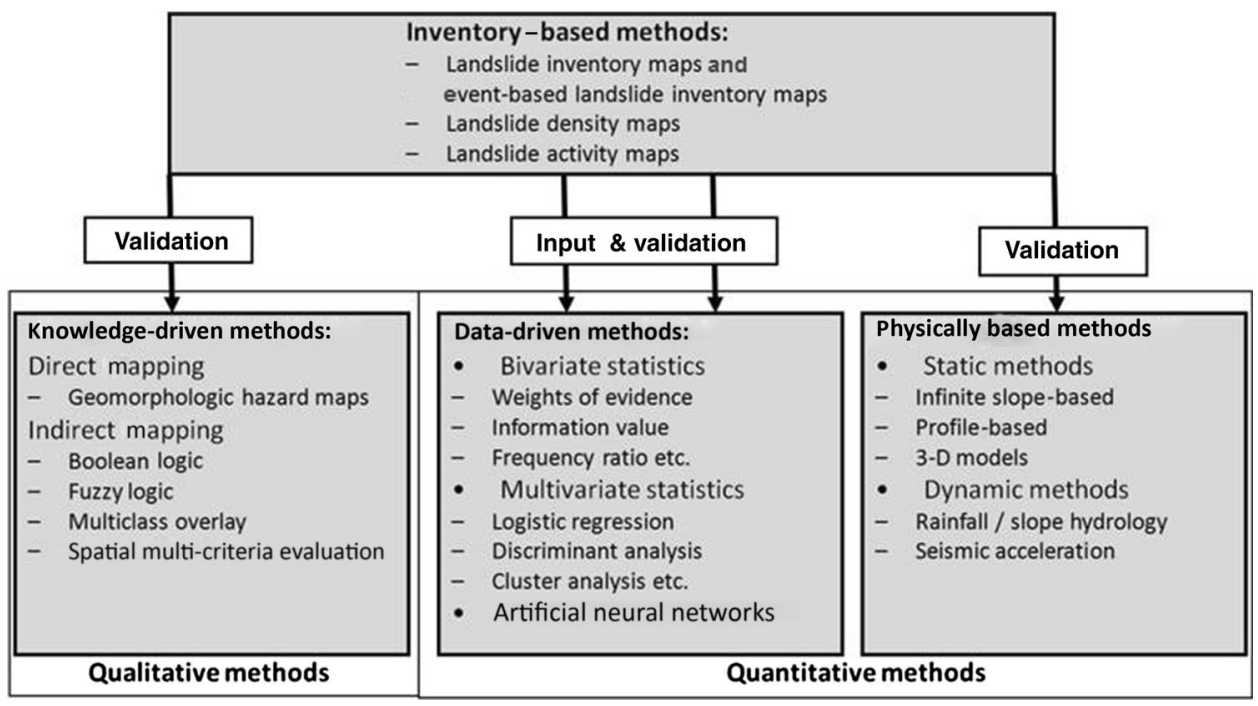

Table 4 Recommended methods for landslide inventory analysis

\begin{tabular}{ll}
\hline Approach & References \\
\hline $\begin{array}{l}\text { Landslide distribution maps based } \\
\text { on image interpretation. }\end{array}$ & $\begin{array}{c}\text { Wieczorek (1984), Crozier } \\
\text { (2005) }\end{array}$ \\
$\begin{array}{l}\text { Generation of event-based } \\
\text { inventories or multiple occurrence } \\
\text { of regional landslide events } \\
\text { (MORLE) }\end{array}$ \\
$\begin{array}{l}\text { Landslide activity maps based on } \\
\text { multi-temporal image }\end{array}$ & $\begin{array}{c}\text { Keefer (2002), Reid and Page } \\
\text { interpretation }\end{array}$ \\
$\begin{array}{l}\text { Generation of inventories based on } \\
\text { historical records }\end{array}$ & $\begin{array}{c}\text { Guzzetti et al. (2000), Jaiswal } \\
\text { and van Westen (2009) }\end{array}$ \\
$\begin{array}{l}\text { Landslide inventory based on radar } \\
\text { interferometry }\end{array}$ & $\begin{array}{c}\text { Squarzoni et al. (2003), } \\
\text { Colesanti and Wasowski }\end{array}$ \\
& (2006) \\
$\begin{array}{l}\text { Representation of landslide } \\
\text { inventory as density information, } \\
\text { representation of landslide } \\
\text { inventory as spatial density }\end{array}$ & $\begin{array}{c}\text { Coe et al. (2000), Bulut et al. } \\
\text { information }\end{array}$ \\
\hline
\end{tabular}

conditions are indicative of future conditions. Therefore, areas that have experienced landslides in the past are likely to experience them in the future too, as they maintain similar environmental settings (e.g. topography, geology, soil, geomorphology and land use).

- Methods used for landslide susceptibility analysis are usually based on the assumption that terrain units that have similar environmental settings (e.g. topography, lithology, engineering soils, geomorphology and land use) and were affected by landslides in the past are likely to experience landslides in the future. This approach emphasises the need to collect detailed landslide inventories before conducting any landslide susceptibility assessment.
- In terms of visualisation, landslide susceptibility maps should include

- Zones with different classes of susceptibility to landslide initiation and runout for particular landslide types; for the purpose of clarity, the number of classes should be limited to less than five

- An inventory of historic landslides, which allows the user to compare the susceptibility classes with actual historic landslides

- A legend with an explanation of the susceptibility classes, including information on expected landslide densities

As landslide susceptibility maps primarily provide a proposed ranking of terrain units in terms of spatial probability of occurrence, they do not explicitly convey information on landslide return periods.

Landslide susceptibility assessment

Overviews of the methods available for landslide susceptibility assessment (see Fig. 2) can be found in Soeters and Van Westen (1996), Carrara et al. (1999), Guzzetti et al. (1999), Aleotti and Chowdhury (1999), Dai et al. (2002), Chacón et al. (2006), and Fell et al. (2008a, b). The methods are qualitative (inventory-based and knowledgedriven methods) and quantitative (data-driven methods and physically based models), as shown in Fig. 2. Each one is defined and described in the following paragraph. Inventory-based methods are required as a prelude to all other methods, as they provide the most important input and are used to validate the resulting maps. An overview of these methods and some relevant references are given in Table 4 .

There is a difference between susceptibility assessment methods for areas where landslides have previously 
occurred and susceptibility assessment methods for areas where landslides might occur but no landslide has occurred previously. It should be noted that there is a direct relation between the scale of the zoning map and the complexity of the landslide susceptibility assessment method, with more complex methods being applied at larger scales due to the increased amount of data required. In knowledge-driven or heuristic methods, the landslide susceptibility map can be prepared directly in the field by expert geomorphologists, or created in the office as a derivative map of a geomorphological map. The method is direct, as the expert interprets the susceptibility of the terrain directly in the field, based on the observed phenomena and the geomorphological/geological setting. In the direct method, GIS is used as a tool for entering the final map without extensive modelling. Knowledge-driven methods can also be applied indirectly using a GIS, by combining a number of factor maps that are considered to be important for landslide occurrence. On the basis of his/her expert knowledge on past landslide occurrences and their causal factors within a given area, an expert assigns particular weights to certain combinations of factors. In knowledge-driven methods, susceptibility is expressed in a qualitative form. In the following, only quantitative methods are discussed.

\section{Data-driven landslide susceptibility assessment methods}

In data-driven landslide susceptibility assessment methods, the combinations of factors that have triggered landslides in the past are evaluated statistically, and quantitative predictions are made for current non-landslide-affected areas with similar geological, topographical and land-cover conditions. No information on the historicity of the terrain units in relation to multiple landslide events is considered.

The output may be expressed in terms of probability. These methods are termed "data-driven", as data from past landslide occurrences are used to obtain information on the relative importances of the factor maps and classes. Three main data-driven approaches are commonly used: bivariate, multivariate and active learning statistical analysis (Table 5). In bivariate statistical methods, each factor map is combined with the landslide distribution map, and weight values based on landslide densities are calculated for each parameter class. Several statistical methods can be applied to calculate weight values, such as the information value method, weights of evidence modelling, Bayesian combination rules, certainty factors, the Dempster-Shafer method, and fuzzy logic. Bivariate statistical methods are a good learning tool that the analyst can use to determine which factors or combination of factors play a role in the initiation of landslides. It does not take into account the interdependence of variables, and it has to serve as a guide when exploring the dataset before multivariate statistical
Table 5 Recommended methods for data-driven landslide susceptibility assessment

\begin{tabular}{lcl}
\hline & Method & References \\
\hline $\begin{array}{c}\text { Bivariate } \\
\text { statistical } \\
\text { methods }\end{array}$ & $\begin{array}{c}\text { Likelihood ratio } \\
\text { model (LRM) }\end{array}$ & Lee (2005) \\
& $\begin{array}{c}\text { Information } \\
\text { value method }\end{array}$ & Yin and Yan (1988) \\
& Weights of & van Westen (1993), Bonham- \\
& evidence & Carter (1994), Suzen and \\
& modelling & Doyuran (2004) \\
& Favourability & Chung and Fabbri (1993), Luzi \\
& functions & (1995) \\
Multivariate & Discriminant & Carrara (1983), Gorsevski et al. \\
statistical & analysis & (2000) \\
method & Logistic & Ohlmacher and Davis (2003), \\
& regression & Gorsevski et al. (2006a) \\
ANN & Artificial neural & Lee et al. (2004), Ermini et al. \\
& networks & (2005), Kanungo et al. (2006) \\
\hline
\end{tabular}

methods are used. Multivariate statistical models evaluate the combined relationship between a dependent variable (landslide occurrence) and a series of independent variables (landslide controlling factors). In this type of analysis, all relevant factors are sampled either on a grid basis or in slope morphometric units. For each of the sampling units, the presence or absence of landslides is determined. The resulting matrix is then analysed using multiple regression, logistic regression, discriminant analysis, random forest or active learning. The results can be expressed in terms of probability. Data-driven susceptibility methods can be affected by shortcomings such as (a) the general assumption that landslides occur due to the same combination of factors throughout a study area, (b) ignorance of the fact that the occurrence of certain landslide types is controlled by certain causal factors that should be analysed/ investigated individually, (c) the extent of control over some spatial factors can vary widely in areas with complex geological and structural settings, and (d) the lack of suitable expert opinion on different landslide types, processes and causal factors. These techniques have become standard in regional scale landslide susceptibility assessment.

\section{Physically based landslide susceptibility assessment methods}

Physically based landslide susceptibility assessment methods are based on the modelling of slope failure processes. The methods are only applicable over large areas when the geological and geomorphological conditions are fairly homogeneous and the landslide types are simple (Table 6). Most physically based models that are applied at a local scale make use of the infinite slope model and are 
Table 6 Examples of methods for physically based landslide susceptibility assessment (location of the slope failure)

\begin{tabular}{|c|c|c|}
\hline Type & Method & References \\
\hline \multirow{3}{*}{$\begin{array}{l}\text { GIS-based } \\
\text { limit } \\
\text { equilibrium } \\
\text { methods }\end{array}$} & $\begin{array}{l}\text { Static infinite slope } \\
\text { modelling }\end{array}$ & $\begin{array}{l}\text { Pack et al. (1998), } \\
\text { Dietrich et al. (1995) }\end{array}$ \\
\hline & $\begin{array}{l}\text { Dynamic infinite slope } \\
\text { modelling with } \\
\text { rainfall trigger }\end{array}$ & $\begin{array}{l}\text { Baum et al. (2002), Van } \\
\text { Beek (2002), Casadei } \\
\text { et al. (2003), Simoni } \\
\text { et al. (2008) }\end{array}$ \\
\hline & $\begin{array}{l}\text { Earthquake-induced } \\
\text { infinite slope } \\
\text { modelling (e.g. } \\
\text { Newmark) }\end{array}$ & $\begin{array}{l}\text { Jibson et al. (1998), } \\
\text { Wang and Lin (2010) }\end{array}$ \\
\hline $\begin{array}{l}\text { Kinematic } \\
\text { analysis for } \\
\text { rock slopes }\end{array}$ & $\begin{array}{l}\text { Stereonet plots, GIS- } \\
\text { based analysis of } \\
\text { discontinuities }\end{array}$ & Günther (2003) \\
\hline $\begin{array}{l}\text { 2-D limit } \\
\text { equilibrium } \\
\text { methods }\end{array}$ & $\begin{array}{l}\text { 2-D LEM with } \\
\text { groundwater flow and } \\
\text { stress analysis }\end{array}$ & GEO-SLOPE (2011) \\
\hline $\begin{array}{l}\text { 3-D limit } \\
\text { equilibrium } \\
\text { methods }\end{array}$ & $\begin{array}{l}\text { 3-D slope stability } \\
\text { analysis }\end{array}$ & $\begin{array}{l}\text { Hungr (1995), } \\
\text { Gitirana et al. (2008) }\end{array}$ \\
\hline \multirow[t]{2}{*}{$\begin{array}{l}\text { Numerical } \\
\text { modelling }\end{array}$} & Continuum modelling & $\begin{array}{l}\text { Hoek et al. (1993), Stead } \\
\text { et al. (2001) }\end{array}$ \\
\hline & $\begin{array}{l}\text { Discontinuum } \\
\text { modelling (e.g. } \\
\text { distinct element, } \\
\text { discrete element) }\end{array}$ & $\begin{array}{l}\text { Hart (1993), Stead et al. } \\
\text { (2001) }\end{array}$ \\
\hline
\end{tabular}

therefore only applicable for the analysis of shallow landslides (less than a few metres in depth). Physically based models for shallow landslides account for different triggers such as the transient groundwater response of the slopes to rainfall and/or the effect of earthquake excitation. Dynamic models are capable of making future temporal predictions by applying cause-and-effect-based rules to simulate temporal changes in the landscape. A dynamic landslide susceptibility model addresses the spatial and temporal variations in landslide initiation. Physically based models are also applicable to areas with incomplete landslide inventories. The parameters used in such models are most often measurable and are considered state variables that have a unique value at a given point in time and space. Most physically based models are dynamic in nature, implying that they run forward (or backward) in time, constantly calculating the values of the state variables based on the equations incorporated. If implemented in a spatial framework (a GIS model), such models are also able to calculate the changes in the values over time for every unit of analysis (pixel). The results of such models are more concrete and consistent than those of heuristic and statistical models, given the white-box approach of describing the underlying physical processes leading up to the phenomena being modelled. They have a higher
Table 7 Recommended quantitative methods for landslide susceptibility analysis at different scales

\begin{tabular}{lll}
\hline & \multicolumn{2}{l}{ Quantitative methods } \\
\cline { 2 - 3 } & $\begin{array}{l}\text { Data-driven } \\
\text { statistical } \\
\text { methods }\end{array}$ & $\begin{array}{l}\text { Deterministic } \\
\text { physically based } \\
\text { methods }\end{array}$ \\
\hline $\begin{array}{l}\text { National scale } \\
(<1: 250,000)\end{array}$ & No & No \\
$\begin{array}{c}\text { Regional scale } \\
(1: 25,000-1: 250,000)\end{array}$ & Yes & No \\
$\begin{array}{c}\text { Local scale } \\
(1: 5,000-1: 25.000)\end{array}$ & Yes & Yes \\
$\begin{array}{c}\text { Site-specific } \\
(>1: 5,000)\end{array}$ & No & Yes \\
\hline
\end{tabular}

predictive capability and are the most suitable for quantitatively assessing the influences of individual parameters that contribute to shallow landslide initiation. However, the parameterisation of these models can be a complicated task because of difficulties in getting access to critical parameters such as the distribution of soil depths or in simulating transient slope hydrological processes such as macropore flows and temporal changes in hydraulic properties. The advantage of these models is that they are based on slope stability models, allowing the calculation of quantitative values of stability (safety factors or probability of failure). The main drawbacks of this method are the degree of simplification involved and the need for large amounts of reliable input data.

\section{Selection of the most appropriate analytical method}

For landslide susceptibility analysis, there is a clear link between the scale of analysis and the type of method that can be used, which is mainly related to the possibility of obtaining the required input data (Table 7).

There are several aspects that should be considered when selecting the most appropriate method:

- The selection should suit the available data and the scale of the analysis; for instance, the selection of a physically based modelling approach at small scales with insufficient geotechnical and soil depth data is not recommended. This will either lead to large simplifications in the resulting hazard and risk map or to endless data collection.

- The use of data of a scale, or with details, that are inappropriate for the hazard assessment method selected should be avoided.

- Different landslide types are controlled by different combinations of environmental and triggering factors, and this should be reflected in the analysis. The 
Table 8 Empirical methods for assessing runout distance

\begin{tabular}{ll}
\hline Activity & References \\
\hline $\begin{array}{l}\text { Geomorphological } \\
\text { Map old and recent landslide }\end{array}$ & Hoblitt et al. (1998) \\
deposits from aerial photos, & \\
satellite images and/or surface & \\
mapping. Assess limit (greatest & \\
likely travel distance for each & \\
landslide type) & \\
$\begin{array}{l}\text { Geometrical } \\
\text { Use empirical methods based on }\end{array}$ & $\begin{array}{l}\text { Corominas et al. (2003), Ayala } \\
\text { reach angle, shadow angle or }\end{array}$ \\
$\begin{array}{l}\text { average channel slope to assess } \\
\text { travel distance (maximum reach) }\end{array}$ & $\begin{array}{l}\text { Labiouse (2003), Prochaska } \\
\text { et al. (2008) }\end{array}$ \\
$\begin{array}{l}\text { Use empirical methods based on } \\
\text { reach angle or shadow angle to }\end{array}$ & Copons and Vilaplana (2008) \\
$\begin{array}{l}\text { assess travel distance while } \\
\text { accounting for uncertainty } \\
\text { (probability of reach) }\end{array}$ & \\
$\begin{array}{l}\text { Planimetric areas of lahar and } \\
\text { debris flow inundated valleys are } \\
\text { obtained from statistical } \\
\text { analyses (volume-area relations) } \\
\text { of previous paths }\end{array}$ & Rickenmann (1999), Berti and \\
$\begin{array}{l}\text { Volume-change method } \\
\text { Runout calculated by imposing a } \\
\text { balance between the volume } \\
\text { entrained and that deposited }\end{array}$ & Fannin and Wise (2001) \\
\hline & \\
\hline
\end{tabular}

landslide inventory should be subdivided (when possible) into several subsets, each related to a particular failure mechanism, and linked to a specific combination of causal factors.

- The use of factor maps that are not from the period of the landslide occurrence should be avoided. For instance, in order to be able to correlate landslides with changes in land use/land cover, it is important to map the situation that existed when the landslide occurred, not the situation that resulted after the landslide.

- Finally, many landslide susceptibility assessments are based on the assumption that "the past is the key to the future", and that historical landslides and their causal relationships can be used to predict future ones. However, one could also follow the analogy of the investment market in stating that "results obtained in the past are not a guarantee for the future". While landslides may have occurred in the past under particular conditions, conditions change, and susceptibility maps are developed for the present situation. When there are changes in the causal factors (e.g. a road with steep cuts is constructed in a slope which was considered to have a low hazard previously, or the yearly rainfall or the distribution of rainfall per month changes significantly due to climate change), the susceptibility information needs to be adapted.

\section{Landslide runout}

This section describes the methods available for assessing landslide runout (travel distance) for different landslide types in quantitative terms, and their applicability to different scales of work. Given the low resolution of regional scale analyses, runout assessment is seldom performed for maps at the regional scale or smaller, except for very large events (Horton et al. 2008). Landslide magnitude (e.g. volume), propagation mechanism and path characteristics are the main factors that affect the landslide runout.

Methods for determining landslide runout may be classified into empirical and rational (Hungr et al. 2005). Both of these are widely used, as they can be integrated into GIS platforms.

\section{Empirical}

Empirical methods are based on field observations and on an analysis of the relationship between morphometric parameters of the landslide (e.g. the volume), characteristics of the path (i.e. local morphology, presence of obstacles) and the distance travelled by the landslide mass. Empirical approaches are based on simplifying assumptions, and their applicability to quantitative analysis may be restricted. Methods for predicting landslide runout can be classified into geomorphological, geometrical and volumechange methods. A nonexhaustive list is presented in Table 8. Uncertainties associated with the source, size and mobility of future events preclude the definition of the precise locations of the hazard zone boundaries.

Geomorphological evidence The mapping of landslide deposits provides direct measurements of the distance travelled by landslides in the past. The extents of both ancient and recent landslide deposits are used to define future travel distances. Geomorphological analysis can be used to determine (a) the farthest distances reached by previous landslide events and (b) whether a sufficient number of landslide events are inventoried as well as the statistics of distances reached and their associated probabilities.

The complete identification of historical landslide deposits is not always possible. Old deposits may have been buried by new events, removed by erosion (either totally or partially), or masked by depositional features from other processes. The geomorphological approach is appropriate for the analysis of high-magnitude, low-frequency events that, due to their abnormally large sizes, 
may persist for a long period of time and may define the maximum extent of runout that similar events might achieve in the future. However, the uncertainties associated with the sources, sizes, and mobilities of future events preclude the definition of the precise locations of the hazard zone boundaries. Furthermore, the slope geometry may have changed and the full set of causative circumstances associated with past landslides may not be present anymore. Therefore, results obtained in a given place cannot be extrapolated to other locations.

Geometrical approaches Runout assessment can be carried out by analysing the geometrical relations between landslide parameters and distance travelled (Domaas 1994). The most commonly used indices are the angle of reach or travel distance angle (Hsü 1975) and the shadow angle (Evans and Hungr 1993). The angle of reach is the angle of the line connecting the highest point of the landslide crown scarp to the distal margin of the displaced mass. Empirical observations show a volume dependence for the angle of reach $(\alpha)$. A plot of the tangent of the reach angle (the ratio between the vertical drop, $H$, and the horizontal component of the runout distance, $L$ ) against the landslide volume shows that large landslides display lower angles of reach than smaller ones (Scheidegger 1973). This relation may be expressed by a regression equation that takes the following form:

$\log (\tan \alpha)=A+B \log V$

where $A$ and $B$ are constants and $V$ is the volume.

The runout length can also be obtained graphically by considering the angle of reach to the potential landslide volume, for which a line can be traced from the source. The intersection with the topographic surface will give both $H$ and $L$ (Finlay et al. 1999; Corominas et al. 2003; Copons et al. 2009).

The rockfall shadow is the area beyond the toe of a talus slope that falling boulders can reach by bouncing and rolling. Hungr and Evans (1988) and Evans and Hungr (1993) have used the concept of the shadow angle $(\beta)$ to determine the maximum travel distance of a rockfall. This is defined as the angle of the line linking the talus apex with the farthest block. The application of this method also requires the presence of a talus slope, since the shadow angle is delineated from the talus apex, and the talus toe is used as the reference point beyond which the distance travelled by the fallen blocks is determined.

For debris flows, empirical methods have been developed that predict travel distances and inundation areas in fans. Volume, elevation and channel slope have been used to estimate the total travel distance (Rickenmann 1999, 2005) or have been determined on the basis of the average channel slope (Prochaska et al. 2008). Volume balance criteria have been considered that delineate cross-sectional and inundated planimetric areas (Iverson et al. 1998; Crosta et al. 2003; Berti and Simoni 2007).

These empirical methods can be implemented in a GIS for local and site-specific analyses (Jaboyedoff et al. 2005; Berti and Simoni 2007; Scheidl and Rickenmann 2010). Using envelopes to the most extreme observed events is conservative but not unrealistic because they are based on observed cases. This seems appropriate for preliminary studies of runout distance assessment. If enough data are available, it is possible to model the uncertainty in the runout distance by tracing the lines that correspond to the different percentiles $(99,95,90 \%$, etc.) of the spatial probability (Copons et al. 2009). Such approaches may be applied to local scale landslide susceptibility and hazard maps but, as they do not provide kinematic parameters (velocity, kinetic energy), they are not really suitable for application to site-specific analyses.

Volume-change method The volume-change method (Fannin and Wise 2001) estimates the potential travel distance of a debris flow by imposing a balance between the volumes of the entrained and deposited masses. The path is subdivided into "reaches", and the length, width and slope of each reach are measured. The model considers confined, transitional and unconfined reaches, and imposes the conditions that there is no deposition for flow in confined reaches and no entrainment for flow in transitional reaches. Using the initial volume as input and the geometry of consecutive reaches, the model establishes an averaged volume-change formula by dividing the volume of mobilised material by the length of the debris trail. The initial mobilised volume is then progressively reduced during downslope flow until the movement stops (i.e. the volume of actively flowing debris becomes negligible). The results provide the probability of exceeding the travel distance, which is compared with the travel distances of two observed events.

\section{Rational methods}

Rational methods are based on the use of analytical or numerical models with different degrees of complexity. They can be classified as discrete or continuum-based models.

Discrete models These models are used in cases where the granularity of the landslide is important, i.e. where the structure of the material is granular, so that it is possible to represent grains as individual discrete elements. The simplest case is that of a block which falls on a slope. Its geometry can be modelled with precision or approximated by a simpler form. The model checks 
Table 9 Rational methods for landslide runout assessment

\begin{tabular}{|c|c|c|}
\hline & Type of landslide & References \\
\hline \multicolumn{3}{|l|}{ Discrete models } \\
\hline Lumped & Rockfalls & $\begin{array}{l}\text { Agliardi and Crosta } \\
\text { (2003), Dorren and } \\
\text { Seijmonsbergen } \\
(2003)\end{array}$ \\
\hline Hybrid/rigid body & Rockfalls & $\begin{array}{l}\text { Crosta et al. (2004), } \\
\text { Azzoni et al. (1995) }\end{array}$ \\
\hline $\begin{array}{l}\text { Discrete-element- } \\
\text { based models }\end{array}$ & Rock avalanches & Calvetti et al. (2000) \\
\hline \multicolumn{3}{|c|}{ Continuum-based models } \\
\hline $\begin{array}{l}\text { Infinite landslide } \\
\text { models and sliding- } \\
\text { consolidation } \\
\text { model }\end{array}$ & $\begin{array}{c}\text { Avalanches, debris } \\
\text { flows, mudflows, } \\
\text { lahars, flowslides }\end{array}$ & Hutchinson (1986) \\
\hline $\begin{array}{l}\text { Multi-sliding block } \\
\text { models } \\
\text { (thermomechanical) }\end{array}$ & $\begin{array}{l}\text { Fast-propagating } \\
\text { landslides }\end{array}$ & $\begin{array}{l}\text { Alonso and Pinyol } \\
\text { (2010), Pinyol and } \\
\text { Alonso (2010) }\end{array}$ \\
\hline $\begin{array}{l}\text { Depth-integrated } \\
\text { models }\end{array}$ & $\begin{array}{c}\text { Avalanches, debris } \\
\text { flows, mudflows, } \\
\text { lahars, flowslides }\end{array}$ & $\begin{array}{l}\text { Savage and Hutter } \\
\text { (1991), McDougall } \\
\text { and Hungr (2004), } \\
\text { Pastor et al. (2009), } \\
\text { Iverson and Denlinger } \\
\text { (2001) }\end{array}$ \\
\hline 3D models & $\begin{array}{l}\text { Avalanches, debris } \\
\text { flows, mudflows, } \\
\text { lahars, flowslides }\end{array}$ & $\begin{array}{l}\text { Sosio et al. (2008), } \\
\text { Quecedo et al. (2004) }\end{array}$ \\
\hline
\end{tabular}

for impacts with the basal surface, applying a suitable coefficient of restitution. This approach is used for rockfall modelling, with either a lumped (Piteau and Clayton 1976; Stevens 1998; Guzzetti et al. 2002a, b), hybrid (Pfeiffer and Bowen 1989; Jones et al. 2000; Crosta et al. 2004) or rigid-body (Bozzolo and Pamini 1986; Azzoni et al. 1995) approach employed. At the other extreme, discrete elements have been used to model rock avalanches. The avalanche is approximated by a set of particles with simple geometrical forms (spheres, circles) and ad hoc laws are used to describe the contact forces. The number of material parameters is generally small (friction, initial cohesion, and elastic properties of the contact). In many cases, it is not feasible to reproduce all of the blocks of the avalanche, so it is approximated with a smaller number of blocks. The spheres (3D) or disks (2D) can be combined to form more complex shapes, and various granulometries can be generated. The main advantage of these methods is their ability to reproduce effects, such as inverse segregation, that are far beyond the capabilities of continuum-based models (Calvetti et al. 2000). Discrete element models are suitable for the simulation of rock avalanches, but their use is not recommended in other situations (flowslides, lahars, mudflows, etc.) because of the complex rheology of the flowing material.
Continuum-based models Such models are based on continuum mechanics, and can include the coupling of the mechanical behaviour with hydraulics and thermomechanics. The following four groups are considered (Table 9):

(a) 3D models based on mixture theory. The most complex model category includes all of the phases present in the flowing material as solid particles, fluid and gas. Here, relative movements can be large, and this group of models can be applied to the most general case. Due to the large number of unknowns and equations involved in such models, they have only been used when the mixture is considered, which is the correct approach for mudflows and rock avalanches. As the geometry is rather complex, there is no analytical solution and it is necessary to discretise the equations using a suitable numerical model. These models are very expensive in terms of computing time, but must be used in situations where 3D effects are important, as in the case of waves generated by landslides or the impact of the flowing material with structures and buildings (Quecedo et al. 2004). This kind of model can be applied to all types of movement, with the exception of those where the granularity of the mixture is an important influence.

(b) Velocity-pressure models (Biot-Zienkiewicz). In many cases, the movement of pore fluids relative to the soil skeleton can be assumed to be small, and the model can be cast in terms of the velocity of the solid particles and the pore pressures of the interstitial fluids. This is the classical approach used in geotechnical engineering (Sosio et al. 2008), and it can be applied to avalanches and debris flows. The resulting model is $3 \mathrm{D}$, and the computational effort required to solve it is large (Crosta et al. 2008). One important point is that pore pressures can be fully described.

(c) Considering the geometries of most fast-propagating landslides, it is possible to use a depth integration approximation. This method has been used in hydraulics and coastal engineering to describe flow in channels, long waves, tides, etc. In the context of landslide analysis, they were introduced by Savage and Hutter (1991). Since then, they have been widely used by engineers and earth scientists. It is also possible to include information on the basal pore pressure (e.g. Iverson and Denlinger 2001; Pastor et al. 2009). It is important to note that, even if the results obtained by these models can be plotted in 3D, giving the impression that it is a full 3D simulation, the model is $2 \mathrm{D}$. Moreover, pressures and forces over structures are hydrostatic. Therefore, if this information is needed, it is necessary to couple the $2 \mathrm{D}$ 
depth-integrated model with the full 3D model in the proximity of the obstacle. Depth-integrated models represent an excellent compromise between computer time and accuracy. They have been used to describe rock avalanches, lahars, mudflows, debris flows and flowslides (Agliardi and Crosta 2003; Hungr 1995; McDougall and Hungr 2004; Pastor et al. 2002, 2009; Quecedo et al. 2004; Savage and Hutter 1991; Sosio et al. 2008, Laigle and Coussot 1997).

(d) Depth-integrated models can be simplified still further, as in the case of so-called infinite landslide approaches. Indeed, the block analysis performed in many cases consists of a succession of infinite landslides evolving over a variable topography. Pore pressure dissipation can be included in such models (e.g. Hutchinson 1986).

\section{Landslide hazard assessment}

Hazard assessment aims to determine the spatial and temporal probability of occurrence of landslides in the target area, along with their mode of propagation, size and intensity. A complete analysis has to take into account all of the possible failure mechanisms, the reactivation of dormant landslides, and the acceleration of active ones. A well-known definition of landslide hazard refers to the probability of occurrence of a landslide of a given magnitude (Varnes 1984). The magnitude is the measure of the landslide size, which is usually expressed as either an area or volume. However, the landslide magnitude is not an appropriate hazard descriptor. Even though it may be expected that the larger the landslide, the higher the potential for damage, this does not hold true in all cases. A large creeping landslide mobilizing hundreds of millions of cubic metres at a rate of displacement of a few $\mathrm{mm} / \mathrm{year}$ would cause only slight damage to buildings or infrastructure, and a negligible threat to people. In contrast, a rockfall of a few hundreds of cubic metres travelling at tens of $\mathrm{m} / \mathrm{s}$ has the capacity to cause significant damage to structures and loss of life.

Landslide destructiveness is best represented by its intensity (Hungr 1997). Intensity is expressed differently depending on the propagation mechanism. For landslides that cause localised impacts, such as rockfalls, the velocity of the event coupled with its volume or the kinetic energy can be used. For slow-moving landslides, the differential displacement or the total displacement (which may cause damage or disturbance to structural elements) is used. The depth of debris, the peak discharge per unit of width, or the impact pressure can be used to characterise the intensities of flow-like movements. Assessing landslide intensity is not a straightforward task, because it is not an intrinsic characteristic of the landslide. It changes along the path and must be either measured or computed using dynamic models that take the landslide volume as an input parameter. In areas affected by slow-moving landslides, magnitude has been used as a proxy for the landslide intensity (Guzzetti et al. 2005). Although it is not conceptually correct, it may be a practical way to decide between different land-use planning options.

Irrespective of the scale of work, hazard assessment must specify a time frame for the occurrence of all potential landslide types and their intensities at any considered location. This is the most difficult part of the assessment because (a) different landslide types may occur within different time frames, (b) the target area may be affected by landslides originating from different source areas, (c) the landslide frequency observed at any given location or section will change with the distance from the landslide source. Further discussion of these issues can be found in the "Landslide hazard evaluation" section.

\section{Temporal occurrence of landslides}

The temporal occurrence of landslides is normally expressed in terms of frequency, return period, or exceedance probability. The frequency represents the number of events in a certain time interval (e.g. annual frequency), and it can conveniently be assessed from empirical data. The return period is the inverse of the annual probability, and refers to the average time interval in which an event of a certain magnitude is expected to occur. The exceedance can be considered the probability that one or more events will occur in a certain period, regardless of the magnitude of the events (Crovelli 2000). Otherwise, if the magnitude of the events is accounted for, the exceedance probability can be considered the probability that an event with a magnitude equal to or larger than a certain value will occur in a certain period. The exceedance probability is preferable as a measure of the temporal occurrence of landslides for a quantitative probabilistic hazard analysis, and can be derived from the frequency (or return period) using an appropriate probabilistic model, such as a binomial or Poisson model (Crovelli 2000) or a power-law distribution (Dussauge-Peisser et al. 2002).

Frequency may be absolute or relative (Corominas and Moya 2008). Absolute frequency expresses the number of observed events in a terrain unit (i.e. slope, debris fan, watershed, etc.). It may consist of either the repeated occurrence of first-time slope failures, reactivation events of dormant landslides, or acceleration episodes (surges) of active landslides. Rockfalls and debris flows are typical 
landslide types treated as repetitive events. Relative frequency is a normalised frequency. It is usually expressed as the ratio of the number of observed landslide events to the unit area or length (i.e. landslides $/ \mathrm{km}^{2} /$ year). The relative frequency of landslides is appropriate when working with large areas and/or at small scales, and particularly when dealing with multiple-occurrence regional landslide events or MORLE (Crozier 2005). Maps prepared at scales smaller than 1:25,000 cannot effectively address the frequency of individual small-sized landsides (up to a few several thousands of cubic metres) because they are too small to be mapped and treated individually.

The approaches traditionally followed to assess the probability of occurrence of landslides are now described.

\section{Heuristic methods (judgemental approach)}

Heuristic methods are based on the expert judgements of a group of specialists, whose opinions may be quantified by assigning probabilities. One of the ways to systematise heuristic evaluation is through event trees. An event tree analysis is a graphical representation of all of the events that can occur in a system. Using a logic model, the probabilities of the possible outcomes following an initiating event may be identified and quantified. As the number of possible outcomes increases, the figure spreads out like the branches of a tree (Wong et al. 1997b). The branching node probabilities have to be determined in order to quantify the probabilities of the different alternatives. The probability of a path giving a particular outcome, such as a slope failure, is simply the product of the respective branching node probabilities (Lee et al. 2000; Budetta 2002; Wong 2005).

\section{Rational methods (geomechanical approach)}

The probability of slope failure may be determined by means of stability analysis and numerical modelling. It is important to point out that the outputs for these methods can be implemented on GIS platforms and used to prepare maps showing the potential for landslide occurrence from hillslope source areas. However, they are not intended to depict landslide paths or landslide deposition areas.

The geomechanical approach considers slope failure to be dependent on space, time and stresses within the soil. This allows the calculation of the factor of safety, or the probability of failure. The latter is assumed to be the probability of the factor of safety being less than unity. Several methods have been developed to estimate this probability, such as the first-order second moment (FOSM) method, point estimate methods and Monte Carlo simulations (Wu et al. 1996; Haneberg 2004; Wu and Abdel-Latif 2000). These methods take the uncertainties in the input parameters into account. In order to assign a probability of occurrence, it is necessary to explicitly couple the stability analysis to a triggering factor with a known probability.

Slope stability may be coupled with hydrological models to simulate the effect of rainfall on slope stability. For single landslides at either the local or regional scale, transient hydrogeological 2D or 3D finite-element or difference models can be applied (Miller and Sias 1998; Tacher et al. 2005; Malet et al. 2005; Shrestha et al. 2008). For shallow landslides, it is possible to implement regional scale analyses by using simplified hydrological methods that can be implemented in a spatially distributed GIS analysis (Montgomery and Dietrich 1994; Pack et al. 1998; Iverson 2000; Crosta and Frattini 2003; Baum et al. 2005; Godt et al. 2008).

\section{Empirical probability}

Probabilistic models may be developed based upon the observed frequency of past landslide events. This approach is implemented in a similar manner to the hydrological analyses, and the annual probability of occurrence is obtained. In this case, landslides are considered recurrent events that occur randomly and independently. These assumptions do not hold completely true for landslides, particularly that the events are independent, and that external (e.g. climatic) conditions are static. However, they may be accepted as a first-order approach and, quite often, frequency analysis is the only feasible method of estimating the temporal probability of occurrence of landslides.

The binomial or the Poisson distribution is typically used to obtain the probability of landsliding (Crovelli 2000). The binomial distribution can be applied to the cases in which discrete time intervals are considered and only one observation is made per interval (usually per year), as is typically the case in flood frequency analysis. The annual probability of a landslide event of a given magnitude which occurs on average once every $T$ years is

$P(N=1 ; t=1)=\frac{1}{T}=\lambda$,

where $T$ is the return period of the event and $\lambda$ is the expected frequency of future occurrences.

The Poisson distribution arises as a limit case of the binomial distribution when the increments of time are very small (tending to 0), which is why the Poisson distribution is said to be a continuous-time distribution. The annual probability of having $n$ landslide events for a Poisson model is

$P(N=n ; t=1)=\frac{(\lambda t)^{n}}{n !} e^{-\lambda t}$,

where $\lambda$ is the expected frequency of future landslides. On the other hand, the probability of occurrence of one or more landslides in $t$ years is 
$P(N \geq 1 ; t)=1-e^{-\lambda t}$,

which strongly depends on the magnitude of the landslide events. Consequently, magnitude-frequency (M-F) relations should be established in order to carry out the quantitative assessment of the landslide hazard. It must be taken into account that different landslide types occur with different temporal patterns. In the event that the same location is potentially affected by the arrival of different landslide types from different sources, an increase in the probability of occurrence will result, and the combined frequency must be calculated.

\section{Indirect approaches}

The definition of landslide-triggering rainfall and earthquake thresholds has been a topic of great interest in recent decades. Plotting rainfall intensity versus rainfall duration for observed landslide events allows the construction of region-specific curves which identify precipitation intensity-durations that cause shallow landslides and debris flows (Guzzetti et al. 2007, 2008).

Once the critical rainfall (or the earthquake) magnitude has been determined, the return period of the landslides is assumed to be that of the critical trigger. These types of relationships give an estimate of how often landslides occur in the study area, but not which slopes will fail; nor do they indicate the size of the failure. In this case, the probability of occurrence of the landslide triggering rainfall allows the calculation of the relative frequency of landslides (i.e. the number of landslides $/ \mathrm{km}^{2} /$ year), which is useful for regional analyses of homogeneously sized landslides (Reid and Page 2003).

Regional landslide triggering events might co-exist with other regional triggers (e.g. snow melt), and with other landslide triggers occurring at a local scale (e.g. river erosion). In this case, the return period obtained from the regional landslide trigger is only a minimum estimate of the landslide frequency.

\section{Magnitude-frequency relations}

The landslide magnitude-frequency relation is the basis of quantitative hazard assessment. Without a sound assessment of the landslide occurrence probability, expressed in terms of the expected annual frequency of landslide events of a given magnitude, or exceeding a magnitude threshold, a quantitative assessment of landslide hazard is not feasible. In this case, the problem can only be dealt with in terms of susceptibility (e.g. spatial probability; Brabb 1984).

Specific relationships between the frequency of events falling in different magnitude classes (i.e. magnitude- frequency relationships) have been observed for different natural hazards (e.g. earthquakes, floods). The first wellestablished magnitude-frequency relationship was proposed in seismology, where a relation between earthquake magnitude and cumulative frequency was observed (the Gutenberg-Richter equation), which is expressed as

$\log N(m)=a-b M$,

where $N(m)$ is the cumulative number of earthquake events with magnitudes equal or greater than $M$, and $a$ and $b$ are constants.

The probability density function according to the Gutenberg-Richter relation can be calculated as the derivative of the corresponding cumulative density function. In practice, when simulating earthquakes, bounded versions of the Gutenberg-Richter relation are used that account for a lower cutoff for earthquake magnitude of completeness as well as an expected upper one (Kramer 1996).

Early analyses of landslides (Hovius et al. 1997; Pelletier et al. 1997) found that magnitude versus cumulative frequency of the number of landslides is scale invariant and that, for a wide range of landslide magnitudes, the relation follows a power law which is formally equivalent to the Gutenberg-Richter equation:

$N_{\mathrm{CL}}=C A_{\mathrm{L}}^{-\alpha}$,

where $N_{\mathrm{CL}}$ is the cumulative number of landslide events with magnitudes equal or greater than $A$, and $A_{\mathrm{L}}$ is the landslide magnitude (usually expressed as its size: volume or area), while $C$ and $\alpha$ are constants.

A similar distribution may be used for the noncumulative distribution of landslides (Guzzeti et al. 2002b):

$N_{\mathrm{L}}=C^{\prime} A_{\mathrm{L}}^{-\beta}$,

where $N_{\mathrm{L}}$ is the noncumulative number of landslide events with magnitudes equal or greater than $A$, and $A_{\mathrm{L}}$ is the landslide magnitude (usually expressed as its size: volume or area), while $C^{\prime}$ and $\beta$ are constants.

The construction and interpretation of frequency-magnitude relations have been discussed by several researchers (e.g. Guzzetti et al. 2002b; Brardinoni and Church 2004; Malamud et al. 2004; Guthrie et al. 2008; Brunetti et al. 2009). Power laws can usually be adjusted to the frequency distribution of events in a given magnitude class above a particular magnitude threshold. Below this threshold, a characteristic "rollover" effect may occur, resulting in a deviation from the power law and an unrealistic underestimation of smaller events. While some researchers consider that the rollover effect is usually not observed in complete inventories, and that flattening of the magnitudefrequency curves towards small magnitude values is related to censoring effects (Hungr et al. 1999; Stark and Hovius 
Table 10 Activities required to prepare non-spatially explicit magnitude-frequency relations for landslides

\begin{tabular}{|c|c|}
\hline Methodologies and data sources & References \\
\hline \multicolumn{2}{|c|}{ Occurrence of multiple-landslide-triggering events } \\
\hline $\begin{array}{l}\text { Landslide density is related to the } \\
\text { intensity of the landslide- } \\
\text { triggering storm }\end{array}$ & Reid and Page (2003) \\
\hline $\begin{array}{l}\text { Landslide density (magnitude) is } \\
\text { related to the intensity of the } \\
\text { landslide-triggering earthquake }\end{array}$ & Keefer (2002) \\
\hline $\begin{array}{l}\text { Factor relating safety to rainfall or } \\
\text { piezometric level }\end{array}$ & Salciarini et al. (2008) \\
\hline \multicolumn{2}{|c|}{ Cumulative occurrence of landslides over known time intervals } \\
\hline $\begin{array}{l}\text { Analysis of landside records and } \\
\text { historical archives }\end{array}$ & Jaiswal and Van Westen (2009) \\
\hline $\begin{array}{l}\text { Identification and inventory of } \\
\text { landslides from aerial } \\
\text { photographs or satellite images }\end{array}$ & $\begin{array}{l}\text { Hungr et al. (1999), Guthrie and } \\
\text { Evans (2004) }\end{array}$ \\
\hline $\begin{array}{l}\text { Landslide series completed by } \\
\text { dating landslide deposits and } \\
\text { field work }\end{array}$ & $\begin{array}{l}\text { Schuster et al. (1992), Bull et al. } \\
\text { (1994), Bull and Brandon } \\
\text { (1998) }\end{array}$ \\
\hline $\begin{array}{l}\text { Landslide series completed using } \\
\text { proxy data such as silent } \\
\text { witnesses (e.g. tree damage) }\end{array}$ & Van Steijn (1996) \\
\hline
\end{tabular}

2001; Malamud et al. 2004), others consider that rollover is the result of actual physiographic limitations (Pelletier et al. 1997; Guthrie et al. 2008) or the effect of cohesion (Van Den Eeckhaut et al. 2007).

\section{Derivation of $M-F$ relations}

Different approaches may be followed depending on whether $\mathrm{M}-\mathrm{F}$ relations have been derived at a regional scale or at particular locations. Lists of possible works on how to prepare M-F relationships using different approaches or different datasets are given in Tables 10 and 11 . Landslide magnitude may be expressed in terms of either MORLE or individual landslide size.

In regional scale analyses, a relation may be established between the intensity of the trigger (accumulated rainfall, rainfall intensity, earthquake magnitude) and the magnitude of the MORLE, which is given by either the total number of landslides or, preferably, by landslide areal density (i.e. number of landslides $/ \mathrm{km}^{2}$ ) (Frattini et al. 2009). Such a relation has been obtained in some documented cases for storms (Reid and Page 2003) and earthquakes (Keefer 2002). M-F relations can also be prepared from the analysis of aerial photographs or satellite images obtained at known time intervals. These M-F relations may be valid at a regional level, but not for any particular slope or subregion. It is important to note that, in the aforementioned regional approaches,
Table 11 Activities required to prepare spatially explicit magnitudefrequency relations for landslides

\begin{tabular}{|c|c|}
\hline Methodologies and data sources & References \\
\hline \multicolumn{2}{|l|}{ Source area } \\
\hline $\begin{array}{l}\text { Landslide reactivation event } \\
\text { series prepared by dating the } \\
\text { associated landslide } \\
\text { reactivation features }\end{array}$ & Agliardi et al. (2009a) \\
\hline Sizes of landslide scars & Pelletier et al. (1997) \\
\hline $\begin{array}{l}\text { Probabilistic analysis of cliff } \\
\text { recession rates }\end{array}$ & Lee et al. (2002) \\
\hline \multicolumn{2}{|l|}{ Reference section or location } \\
\hline $\begin{array}{l}\text { Incident databases of roads and } \\
\text { railway maintenance teams }\end{array}$ & $\begin{array}{l}\text { Bunce et al. (1997), Hungr et al. } \\
\text { (1999), Chau et al. (2003) }\end{array}$ \\
\hline $\begin{array}{l}\text { Spatial probability of occurrence } \\
\text { combined with the expected } \\
\text { probability of occurrence at } \\
\text { each slope }\end{array}$ & Guzzetti et al. (2005) \\
\hline $\begin{array}{l}\text { Landslide series completed using } \\
\text { proxy data such as silent } \\
\text { witnesses (e.g. tree damage) }\end{array}$ & $\begin{array}{l}\text { Jakob and Friele (2010), Stoffel } \\
\text { (2010), Corominas and Moya } \\
\text { (2010), Lopez Saez et al. } \\
\text { (2012) }\end{array}$ \\
\hline $\begin{array}{l}\text { Landslide series completed by } \\
\text { dating landslide deposits and } \\
\text { field work }\end{array}$ & $\begin{array}{l}\text { Van Dine et al. (2005), Jakob } \\
(1996,2012)\end{array}$ \\
\hline \multicolumn{2}{|l|}{ Integrated approach } \\
\hline $\begin{array}{l}\text { Landslide frequency at the source } \\
\text { area combined with runout } \\
\text { models to obtain frequencies of } \\
\text { different landslide magnitudes } \\
\text { at a given control section }\end{array}$ & Corominas et al. (2005) \\
\hline $\begin{array}{l}\text { Landslide frequency at the source } \\
\text { area combined with runout } \\
\text { models to obtain spatial } \\
\text { distributions of different } \\
\text { landslide magnitudes }\end{array}$ & Agliardi et al. (2009b) \\
\hline
\end{tabular}

landslide runout is not considered in the analyses (Table 10).

In local scale analysis, the F-M relation calculated at the source area can be significantly different from that calculated further downhill, as the volume of the landslide influences the travel distance and the area covered by the deposit. Consequently, the landslide frequency at any terrain unit is due to both the occurrence of a slope failure and the probability of being affected by landslides from neighbouring areas.

The probability that a given slope unit is affected by a landslide thus depends on the frequency of initiation, which must be scaled according to the frequency of reach, which in turn depends on the landslide dynamics, as simulated by suitable models (Crosta and Agliardi 2003). For hazard zoning purposes, such scaling may be regarded as negligible for short-runout landslides, and hazard can be evaluated with respect to the 
landslide source. Conversely, when coping with longrunout landslides at the local or site-specific scale, M-F relations derived at the landslide source must be combined with runout models to obtain the areal frequencies of different landslide magnitudes (Tables 10 and 11).

\section{Restrictions on $M-F$ relations}

M-F curves must be applied with care. Limitations on their validity and practical applicability include statistical reliability and the degree to which the processes used to determine them are fully representative of the physical process in play. The statistical reliability of M-F curves is affected by the fact that historical databases and inventories of landslide events (the preferred source of M-F information) are rarely available, and also by the reality that site-specific data collection may not be feasible for large areas or when there are budget constraints. Moreover, landslide size values reported in historical databases may be incomplete or estimated (Jakob 2012) at the order-of-magnitude level of accuracy (Hungr et al. 1999). Data may be incomplete in both space (i.e. data sampling was only performed in specific subareas) and time (i.e. data were only recorded for specific time windows). Undersampling of low-magnitude events may be related to the existence of a detection cutoff threshold (e.g. for rockfalls along roads, very small blocks may not be considered "landslide events"; or, even if they are, they may not be reported) or to "systemic censoring" due to factors affecting the physical processes involved in landsliding (e.g. effective countermeasures upslope of the sampling area). M-F curves derived from inventories prepared from a single aerial photogram or image, or from a single field campaign, should be discouraged. These types of inventories do not reflect the actual frequencies of different landslide magnitudes, as many small landslides have disappeared due to erosion, and they do not adequately account for the reactivation events that can affect large landslides (Corominas and Moya 2008).

A key question is whether the rate of occurrence of small landslides in a region can be extrapolated to predict the rate of occurrence of large landslides, and vice versa. The answer to this question is not evident. As stated by Hungr et al. (2008), based on the analysis of debris flows and debris avalanches, an $\mathrm{M}-\mathrm{F}$ derived from a region would underestimate the magnitudes if it was applied to a smaller subregion of relatively tall slopes, and overestimate them in a nearby subregion with lower relief. An even greater error could result if one was to attempt to estimate the probability of slides of a certain magnitude on a specific slope segment of known height.
Landslide intensity-frequency relation

Combinations of magnitude-frequency pairs do not yield landslide hazard data because landslide magnitude values are not suitable for use in vulnerability curves for risk analysis. In order to assign a probability or frequency to events leading to a certain degree of damage (assessed through vulnerability curves), it is therefore necessary to assess intensity. The intensity parameter that should be chosen depends on the typology of the landslides and the nature of the element at risk. For instance, kinetic energy is the most frequently used parameter for rockfalls (Corominas et al. 2005; Agliardi et al. 2009b), whereas peak discharge (Jakob 2005), velocity (Hungr 1997; Bovolin and Taglialatela 2002; Calvo and Savi 2009), depth (Borter 1999; Fuchs et al. 2007), and velocity squared multiplied by depth (Jakob et al. 2012) are used for debris flows. For large slides and earthflows, the displacement or the displacement rate (Saygili and Rathje 2009; Mansour et al. 2011) can be suitable parameters.

Techniques to derive intensity-frequency relationships for each location along the slope can vary as a function of the typology of the landslide and the scale of the analysis. For local scale analysis of single landslides, it is possible to simulate various scenarios with different volumes and associated probabilities (e.g. M-F relationships) through numerical models in order to determine the spatial distribution of intensity during landslide movement (Archetti and Lamberti 2003; Jaboyedoff et al. 2005; Friele et al. 2008). Hence, for each location on the slope, it is possible to build the intensity-frequency curves by adopting the frequency values of $\mathrm{M}-\mathrm{F}$ relationships and the intensities calculated by the models (Jakob et al. 2012).

For slopes which are potentially affected by landslides that can fail at different source areas, the intensity at each location along the slope is not a single value for each frequency scenario but a distribution of values. A simple statistic of the distribution is normally used to characterise this distribution, such as the arithmetic average (Agliardi et al. 2009b) or the maximum value (Gentile et al. 2008; Calvo and Savi 2009), and the intensity-frequency curves are derived using this value of intensity and the frequency derived from M-F relationships.

However, this approach introduces a strong assumption about the distribution of intensity, because the arithmetic mean is appropriate only for normally distributed intensities, and the maximum value only consider outliers of the distribution, strongly overestimating the actual hazard.

An alternative approach for the calculation of intensityfrequency relationships for rockfalls is to consider the probability distribution of kinetic energy for a given location and volume scenario (Jaboyedoff et al. 2005). Using 3D rockfall models, it is also possible to analyse the 
convergence of different trajectories in the same location, thus characterising the frequency distribution of kinetic energy (Frattini et al. 2012).

Landslide hazard evaluation

\section{The object of the hazard analysis}

The purpose of a landslide hazard analysis determines the scale, the methodology and its results. The hazard analysis may have different target areas and spatial arrangements (Corominas and Moya 2008), including the following:

- Areal analysis is usually performed for either regional or local planning zoning. The potential for slope failure is evaluated at every single terrain unit (pixel, cell, polygon, basin), and the temporal occurrence may be expressed in relative terms as the number of landslides (of a given magnitude) per unit area $\left(\mathrm{km}^{2}\right.$, pixel, etc.) per year, or as an exceedance probability. The intensity may later be integrated by combining the outputs with runout analysis.

- Linear analysis is performed for infrastructure and facilities (motorways, railways, pipelines, etc.) with a linear layout. The analysis may be performed at the source area (Michoud et al. 2012), but it usually focuses on the landslides that (potentially) affect the infrastructure. The hazard may be expressed as the number of landslides of a given magnitude that reach the infrastructure per unit length and per year, or as the total number of landslides per year across the whole stretch. In both cases, frequency is expressed in relative terms and should be determined for segregated landslide volumes (e.g. Jaiswal and Van Westen 2009; Jaiswal et al. 2010).

- Object-oriented (point-like) hazard analysis is performed at specific sites such as debris fans, talus slopes, or for an element or set of exposed elements. Hazard analysis is restricted to landslides that (potentially) affect the site. Frequency may be expressed in absolute terms as the number of landslides of a given magnitude that reach the site per year, or as the return period (the inverse).

Depending on whether the exact location of the slope failure is shown, the landslide runout is shown, or both are shown, the analyses are considered to be spatially or nonspatially explicit.

\section{Consideration of landslide runout}

Areal hazard analysis can be addressed with or without the mobility of the landslides. Short-displacement landslides are well contained geographically and remain at or very close to the initiation zone. In this case, hazard assessment and mapping considers the potential for slope failure or landslide reactivation at each terrain unit, but intensity is not calculated (Cardinali 2002). Long-runout landslides can travel considerable distances from the source area. In this case, besides the potential for slope failure, landslide frequency (and consequently intensity level) must be determined along the path (spatially explicit analysis). Different landslide magnitudes will result in different travel distances and intensities.

Two approaches to including landslide runout may be considered (Roberds 2005). In the first, the probability of failure of each slope is first determined, propagation is calculated separately, and then they are combined mathematically. To achieve this, a magnitude-frequency relation is required for each slope or land unit and, afterwards, the estimation of the runout distance for each landslide magnitude. Alternatively, hazard is calculated directly for each combination of slope instability mode and runout as, for instance, the magnitude-frequency of a rockfall at a road based on the statistics of past rockfall events (i.e. Bunce et al. 1997; Hungr et al. 1999) or on a debris fan (Van Dine et al. 2005).

\section{Non-spatially explicit hazard analyses}

National and regional maps in which the scale usually does not allow accurate slope stability and runout analyses to be performed are non-spatially explicit. Hazard assessment is not fully achieved because intensity is not considered. This analysis is typically performed for shallow landslides, which are assumed to be recurrent events that occur within a region as failures scattered throughout the study area over time or are generated by particular landslide-triggering events (i.e. rainstorms or earthquakes) acting over a large area (MORLE).

Hazard over defined time intervals can be assessed based on landslide inventories prepared from successive aerial photographs or images. Landslide frequency is calculated by counting the number of new landslides between photographs. Landslide hazard is expressed as the number of landslides that occur per unit area in a given time span. This method provides valid estimates of the short-term average frequency. It may only be used for a medium- and long-term average frequency if the sampling period includes the average distribution of landslide-producing events (Corominas and Moya 2008).

For MORLE, a relationship must first be established between the occurrence of landslide events and the trigger, either storm precipitation (e.g. Guzzetti et al. 2008) or seismic events (e.g. Keefer 1984; Jibson et al. 1998). Given sufficient spatial resolution of records of storm rainfall or earthquake magnitude, knowledge of the distribution of 
Table 12 Regional hazard assessment (non-spatially explicit)

\begin{tabular}{|c|c|c|}
\hline Methodology & $\begin{array}{l}\text { Hazard } \\
\text { descriptor }\end{array}$ & References \\
\hline $\begin{array}{l}\text { Recurrence of landslides is } \\
\text { obtained from sets of aerial } \\
\text { photographs and/or satellite } \\
\text { images taken at known time } \\
\text { intervals. Landslide } \\
\text { frequency is then obtained }\end{array}$ & $\begin{array}{l}\text { No. of } \\
\text { landslides/ } \\
\mathrm{km}^{2} / \text { year } \\
\text { No. of } \\
\text { landslides/ } \\
\text { pixel/year } \\
\text { Total slide } \\
\text { area/km²/ } \\
\text { year }\end{array}$ & $\begin{array}{l}\text { Remondo et al. } \\
\text { (2005), Guzzetti } \\
\text { et al. (2005) }\end{array}$ \\
\hline $\begin{array}{l}\text { Landslide-triggering events } \\
\text { of different magnitudes are } \\
\text { related to landslide density. } \\
\text { Return periods or the } \\
\text { exceedance probability of } \\
\text { the trigger are then } \\
\text { calculated }\end{array}$ & $\begin{array}{l}\text { Probability of } \\
\text { having } \\
\text { No. of } \\
\text { landslides/ } \\
\mathrm{km}^{2} \\
\text { No. of } \\
\text { landslides/ } \\
\text { pixel } \\
\text { Total slide } \\
\text { area/km }{ }^{2}\end{array}$ & $\begin{array}{l}\text { Reid and Page } \\
\text { (2003) }\end{array}$ \\
\hline $\begin{array}{l}\text { Seismic shaking probability } \\
\text { for given time intervals } \\
\text { combined with the } \\
\text { probability of landsliding } \\
\text { based on Newmark models }\end{array}$ & $\begin{array}{l}\text { Probability of } \\
\text { landslide } \\
\text { occurrence }\end{array}$ & $\begin{array}{l}\text { Del Gaudio et al. } \\
\text { (2003) }\end{array}$ \\
\hline
\end{tabular}

landslides over the area should make it possible to establish rainfall intensity/landslide density or epicentral distance/ landslide density functions. In a second step, the exceedance probability of either the rainfall intensity or earthquake magnitude can be related to the landslide density (e.g. number of landslides $/ \mathrm{km}^{2}$ ) (Reid and Page 2003; Keefer 2002). However, in some areas, landslide density changes nonlinearly with rainfall, and a reliable relationship cannot be established (Govi and Sorzana 1980). This type of relationship allows us to estimate how often landslides occur in the study area, but not where the slopes will fail. However, if it is combined with landslide susceptibility or probability maps, it is then possible to identify areas where landslides are expected to occur, given threshold-exceeding rainfall (Baum and Godt 2010).

Hazard calculated from the frequency of landslide triggers, at least for supply-unlimited watersheds, does not require a complete record of past landslides, but it is necessary to determine a reliable relation between the trigger, its magnitude and the occurrence of the landslides. It is important to account for the fact that regional landslide triggering events may co-exist with other regional triggers (e.g. snow melt or rain-on-snow events, or landslide dam failures on creeks prone to debris flows and debris floods) and with local landslide activity (e.g. river erosion). Consequently, return periods obtained from regional landslide triggers are only a minimum estimate of the landslide frequency. The opposite may occur if landslides remove the mantle of susceptible material, leaving an essentially stable residual surface-a process referred to as event resistance or supply limitation (Crozier and Preston 1999). Some authors propose a minimum "safety" threshold for rainfall that has historically produced few landslides and an "abundant" threshold for rainfall that triggers many landslides (Wilson 2004).

Selected works on the aforementioned approaches for non-spatially explicit hazard analyses are given in Table 12.

\section{Spatially explicit hazard analysis}

On local and site-specific scales, the resolution of the DEM usually allows the probability of landslide occurrence to be calculated at each analysed unit (e.g. pixel). The analyses may be performed by either including or excluding the runout analysis and the subsequent intensity calculation (Table 13):

Hazard assessment without intensity calculation This type of analysis is usually carried out for geographically contained landslides (e.g. slow-moving, short-runout landslides) with displacements that cannot be represented outside the analysed spatial unit (e.g. cell or pixel). It is also performed for linear or point-like features located far from the landslide source in which landslide hazard is determined based on the observation of past events. In both cases, intensity is not calculated and risk is assessed assuming simplifying assumptions for the vulnerability of the exposed elements.

a. Hazard analysis for geographically contained landslides.

Combined spatially distributed hydrological and stability models are used in either regional or local scale analyses to calculate the probability of landslides in land units (e.g. pixel, basin) containing both the landslide source and deposition area. Hazard is expressed as the annual probability of either failure or reactivation at each terrain unit. More specifically, hazard is calculated as the conditional probability of slope failure once a landslide trigger (e.g. a critical rainfall or earthquake event) occurs. The factor of safety of the slope is computed at each terrain unit using an infinite slope stability model in which the probability of failure is obtained as the annual exceedance probability of a critical rainfall event (Savage et al. 2004; Baum et al. 2005; Salciarini et al. 2008). For earthquake-induced failures, a conventional seismic hazard analysis is used to determine the peak 
Table 13 Spatially explicit landslide hazard analyses

\begin{tabular}{|c|c|c|c|c|c|}
\hline & Methodology & $\begin{array}{l}\text { Magnitude/ } \\
\text { intensity }\end{array}$ & Frequency & Hazard descriptor & References \\
\hline \multicolumn{6}{|c|}{ Landslide intensity not considered } \\
\hline \multirow[t]{2}{*}{$\begin{array}{l}\text { Areal } \\
\text { analysis }\end{array}$} & $\begin{array}{l}\text { Combining spatial probability } \\
\text { (susceptibility) with the } \\
\text { probability of a landslide of a } \\
\text { given magnitude and } \\
\text { probability of occurrence }\end{array}$ & $\begin{array}{l}\text { Landslide } \\
\text { size (area, } \\
\text { volume) }\end{array}$ & $\begin{array}{l}\text { Frequency of } \\
\text { landslides is } \\
\text { averaged based on } \\
\text { the time span } \\
\text { between sets of } \\
\text { images }\end{array}$ & $\begin{array}{l}\text { Exceedance probability } \\
\text { of occurrence of a } \\
\text { landslide of a given } \\
\text { magnitude during an } \\
\text { established period }\end{array}$ & Guzzetti et al. (2005) \\
\hline & $\begin{array}{l}\text { Stability models combined with } \\
\text { spatially distributed } \\
\text { hydrological models and the } \\
\text { probability of the critical } \\
\text { trigger }\end{array}$ & $\begin{array}{l}\text { Landslide } \\
\text { density }\end{array}$ & $\begin{array}{l}\text { Return periods or the } \\
\text { exceedance } \\
\text { probability of the } \\
\text { trigger magnitude }\end{array}$ & $\begin{array}{l}\text { Exceedance probability } \\
\text { of the landslide trigger } \\
\text { during an established } \\
\text { period }\end{array}$ & $\begin{array}{l}\text { Savage et al. (2004), } \\
\text { Baum et al. (2005), } \\
\text { Salciarini et al. (2008) }\end{array}$ \\
\hline \multirow[t]{2}{*}{$\begin{array}{l}\text { Object- } \\
\text { oriented } \\
\text { analysis } \\
\text { (linear or } \\
\text { point-like) }\end{array}$} & $\begin{array}{l}\text { Hazard assessment performed at } \\
\text { a reference section (e.g. road } \\
\text { segment) }\end{array}$ & $\begin{array}{l}\text { Landslide } \\
\text { magnitude }\end{array}$ & $\begin{array}{l}\text { Frequency of } \\
\text { landslide } \\
\text { magnitude classes } \\
\text { is averaged based } \\
\text { on the recorded } \\
\text { time span }\end{array}$ & $\begin{array}{l}\text { Probability of } x \\
\text { landslides of a given } \\
\text { size per year (this may } \\
\text { be normalised based on } \\
\text { length) }\end{array}$ & $\begin{array}{l}\text { Bunce et al. (1997), } \\
\text { Hungr et al. (1999), } \\
\text { Jaiswal et al. (2010), } \\
\text { Ferlisi et al. (2012) }\end{array}$ \\
\hline & $\begin{array}{l}\text { Hazard assessment performed at } \\
\text { a reference location (i.e. where } \\
\text { the exposed element is located) }\end{array}$ & $\begin{array}{l}\text { Landslide } \\
\text { magnitude/ } \\
\text { extent }\end{array}$ & $\begin{array}{l}\text { From historical } \\
\text { catalogues }(\mathrm{M}-\mathrm{F} \\
\text { relations) }\end{array}$ & $\begin{array}{l}\text { Or debris flow magnitude } \\
\text { and for established } \\
\text { periods }\end{array}$ & Van Dine et al. (2005) \\
\hline \multicolumn{6}{|c|}{ Landslide intensity calculated } \\
\hline $\begin{array}{l}\text { Areal } \\
\text { analysis }\end{array}$ & $\begin{array}{l}\text { Combining the probability of } \\
\text { occurrence at identified } \\
\text { sources with empirical runout } \\
\text { models }\end{array}$ & $\begin{array}{l}\text { Volume/ } \\
\text { kinetic } \\
\text { energy/ } \\
\text { extent }\end{array}$ & $\begin{array}{l}\text { From historical } \\
\text { catalogues }(\mathrm{M}-\mathrm{F} \\
\text { relations) }\end{array}$ & $\begin{array}{l}\text { Kinetic energy limits for } \\
\text { different rockfall } \\
\text { magnitudes and for } \\
\text { established periods }\end{array}$ & $\begin{array}{l}\text { Guzzetti et al. (2003), } \\
\text { Jaboyedoff et al. } \\
\text { (2005), Blahut et al. } \\
\text { (2010a), Jaboyedoff } \\
\text { and Labiouse (2011) }\end{array}$ \\
\hline \multirow{2}{*}{$\begin{array}{l}\text { Object- } \\
\text { oriented } \\
\text { analysis } \\
\text { (linear } \\
\text { intensity or } \\
\text { point-like) }\end{array}$} & $\begin{array}{l}\text { Combining the probability of } \\
\text { occurrence with empirical- } \\
\text { statistical runout models }\end{array}$ & $\begin{array}{l}\text { Block } \\
\text { volume }\end{array}$ & $\begin{array}{l}\text { From slope angle } \\
\text { frequency } \\
\text { distributions }\end{array}$ & $\begin{array}{l}\text { Number of events } \geq \text { a } \\
\text { given magnitude per } \\
\text { year }\end{array}$ & $\begin{array}{l}\text { Corominas et al. (2005), } \\
\text { Agliardi et al. (2009b), } \\
\text { Michoud et al. (2012) }\end{array}$ \\
\hline & $\begin{array}{l}\text { Combining the probability of } \\
\text { occurrence with physically } \\
\text { based runout models }\end{array}$ & $\begin{array}{l}\text { Debris } \\
\text { volume/ } \\
\text { velocity }\end{array}$ & $\begin{array}{l}\text { From historical } \\
\text { catalogues }(\mathrm{M}-\mathrm{F} \\
\text { relations) }\end{array}$ & & $\begin{array}{l}\text { Hürlimann et al. (2006, } \\
\text { 2008) }\end{array}$ \\
\hline
\end{tabular}

ground accelerations (PGA) for different return periods, and the stabilities of slopes subjected to earthquakes of varying return periods are examined using a pseudo-static analysis (Dai et al. 2002).

Alternatively, the probability of landslide occurrence may be calculated based on the observed frequency of past landside events (Catani et al. 2005). An example of the latter is provided by Guzzetti et al. (2005), who defined geomorphohydrological units and obtained the probability of spatial occurrence of landslides for each unit by discriminant analysis.

b. Hazard analysis performed at a reference section or point-like object.

A runout calculation is not required for a hazard analysis that focuses on specific sections or locations. This is typically performed for transportation corridors in which landslide records are available and the exposed elements (cars and people) are highly vulnerable to low-intensity landslides. It such cases, neither the velocity nor the kinetic energy are computed. The magnitude of the event is used to determine, for instance, the number of affected lanes or the width of the landslide mass, and to calculate the encounter probability (Bunce et al. 1997; Hungr et al. 1999; Jaiswal and Van Westen 2009; Jaiswal et al. 2010; Ferlisi et al. 2012). Hazard values may be expressed in either relative terms (i.e. annual probability of occurrence of a given magnitude event per unit length) or in absolute terms (i.e. number of events per year).

Combined landslide initiation and runout hazard analyses This type of analysis takes into account the spatial distribution of the landslide intensity. A given rockfall 
volume will produce a changing velocity profile along its path, and the kinetic or impact energy will change as well (Crosta and Agliardi 2003). Rockfall intensity is not dependent solely on rockfall size (magnitude), as similar kinetic energy values can result from different combinations of volumes and velocities. Therefore, rockfall hazard mapping must be performed with the aid of runout models that calculate the potential rockfall paths, the locations of obstructions that may stop blocks, the velocities and kinetic energies of the blocks, and the spatial distribution of the kinetic energy.

A critical issue is the definition of the characteristic rockfall volume. In the case of fragmented rockfalls (Evans and Hungr 1993), the hazard is caused by individual blocks that follow more or less independent trajectories. However, magnitude-frequency relationships, which are the usual output of rockfall inventories, often link the frequency to the volume of the initial detached mass, not to the sizes of the individual blocks that finally reach the reference section, and this may result in an overestimate for the impact energy and an underestimate for the impact probability. Unfortunately, at present, most of the codes available do not consider the rockfall fragmentation process. If a rockfall event is treated as an individual block in the runout analysis, it should be representative of the most likely future events. The representative block size can be determined from the geometric characteristics (i.e. length, spacing) of the main discontinuity sets observed on the rock face, and/or from the size distribution of the fragments on the slope (Agliardi et al. 2009b; Abbruzzese et al. 2009).

In debris flows, as in rockfalls, the intensity is not directly correlated with the mobilised debris volume. Every debris flow event will produce a different distribution of intensity and probability of impact, based on its dynamics. According to Hungr (1997), the hazard intensity map must therefore present a scale of pairings of intensity and impact probability values for various flow types and magnitude classes. Two different approaches are typically used for debris flow hazard assessment at the site-specific scale: (1) assess the probability that a particular debris volume will fail to generate a debris flow, and use a physically based (2D or $3 \mathrm{D}$ ) runout model to define the affected area and the intensity parameters (Hürlimann et al. 2006, 2008); (2) assess the probabilities of occurrence of debris flows of different magnitudes at particular locations below the debris source (i.e. reference sections, debris fans) using M-F relations (Van Dine et al. 2005). Using the different probabilities of occurrence, hazard maps for debris flows can then be created for specific return periods (e.g. 100-, 500- and perhaps 2,500-year return periods).
Landslide multi-hazard assessment

The term "multi-hazard" is frequently used in the literature (Lewis 1984; Granger et al. 1999) as an adjective to indicate multiple sources of hazard that are analysed in parallel and finally integrated into a multi-risk analysis. Multi-hazard assessment should, sensu stricto, refer to the joint probability of independent events occurring in the same area in a given time span. In practice, however, multi-hazard assessment is often considered solely in conjunction with risk analysis, as an assessment of expected losses. This is due to the fact that vulnerability depends on landslide typology and intensity, and combining occurrence probabilities at the hazard stage into a single hazard value may hinder the correct determination of risk during subsequent stages.

When multiple noninteracting sources of hazard are analysed, a hazard assessment is performed independently for each source following specific guidance. In this sense, a true multi-hazard assessment is not performed, and the integration of different sources of hazard is done at the level of risk (e.g. combining $\mathrm{F}-\mathrm{N}$ curves, summing expected losses).

Multi-hazard assessment becomes relevant when hazard sources can interact, giving rise to a domino effect that occurs when a hazard event triggers a secondary event. Examples of such sequences include a landslide damming a valley bottom and the consequent failure of the dam.

In the literature, there are several examples of applications that consider the combined effects of different natural (or man-made) hazards on given sets of elements at risk (Van Westen et al. 2002; Lacasse et al. 2008; Kappes et al. 2010; Schmidt et al. 2011). Marzocchi et al. (2012) proposes the following equation for two interacting hazards with occurrences of $E_{1}$ and $E_{2}$ (and where $H_{1}$ is the probability of occurrence of $E_{1}$ ):

$H_{1}=p\left(\mathrm{E}_{1}\right)=p\left(\left(E_{1} \mid E_{2}\right) p\left(E_{2}\right)+p\left(E_{1} \mid \bar{E}_{2}\right) p\left(\bar{E}_{2}\right)\right)$,

where $p$ represents a probability or a probability distribution, and $\bar{E}_{2}$ means that event $E_{2}$ does not occur. The generalisation of Eq. 9 to more than two events does not pose any particular conceptual problem, even though it may require cumbersome calculations (Marzocchi et al. 2012).

Although the severe consequences of such domino sequences are well known, there is, as yet, no well-established and widely accepted methodology for the identification and quantitative assessment of hazard from domino effects. Several qualitative criteria have been proposed in the literature to check for the possibility of domino events, whereas only a few pioneering studies have addressed the problem of the quantitative assessment of risk due to domino effects-usually in relation to earthquakes (e.g. Keefer 1984; Romeo et al. 2006). 
Methodologies for the assessment of domino hazards involving natural events (e.g. landslides, floods, tsunamis, etc.) can be derived and adapted from those proposed for technological hazards. In particular, the methodology proposed by Cozzani and Zanelli (2001) is useful for this purpose. The frequency of the secondary event $B$ is calculated as

$f_{B}=f_{A} P_{\mathrm{d}}$,

where $f_{B}$ is the expected frequency of the secondary event $B, f_{A}$ is the expected frequency (events/year) of the first event $A$, and $P_{\mathrm{d}}$ is the propagation probability, expressed as

$P_{d}=P(B \mid A)$,

where $P(B \mid A)$ is the conditional probability of $B$ given $A$.

A fundamental tool for dealing with interconnected probabilities-widely recognised as a standard in environmental impact assessment and industrial risk analysisis the event tree or cause-effect network. In a sentence, an event tree (ET) is a graphical or logical scheme that is able to represent direct and indirect chains of cause-effect as a consequence of a starting event, usually called the first impact. There are various typologies of ET, ranging from purely categorical (in which the descriptive sequence of events is reproduced with all predictable branching) to quantitative ETs, where a numerical representation of the conditional probability or return time of every single chain node is calculated using suitable methods (Lee and Jones 2004). The most commonly used ET based on conditional probability is the Bayesian event tree (BET).

The different approaches to assessing the relative/ absolute probability of multiple sources of hazard can be broadly grouped into the following classes:

a. Joint probability. According to the fundamentals of probability theory, the concurrent occurrence of events can be calculated by combining their respective probabilities using suitable rules and methods. This is a very basic yet essential tool that does not account for spatial dimensions, cascade effects or system dynamics.

b. Event tree-Bayesian event tree. This category includes descriptive event trees, Bayesian event trees and general cause-effect propagation networks. Branching can be multiple or binary. Each branch can be assigned a conditional probability (Bayesian ET). This approach explicitly considers cascading higher order effects, but does not fully account for the spatial dimensionality of probability pathways. For this reason, in the context of hazard analysis, such methods should be more appropriately called scenario-based BETs. c. Spatially averaged ET-BET. A specific, spatially aware version of BET can be envisaged when dealing with multiple multi-hazard paths over a given geographic space. Depending on the level of spatial and temporal knowledge of the single hazards, this can be:

1. Spatial distribution of single independent BETs: when the hazard map provides an indication of the given probability of occurrence $H(I)$ in a given time span at specific locations.

2. Spatial averaging of BET probabilistic outcomes with statistical averaging: when the hazard map provides a spatially averaged (or statistically deduced) degree of hazard in terms of either relative probability or probability over time.

3. Spatial lumping of BETs: this is when the required data are only known for discrete areas with constant values.

d. Spatially averaged BET with functional behaviour. Here, the physical objects in geographical space interact dynamically and show behaviours that vary over time as a consequence of system evolution. This is not explicitly accounted for using the previous methods, but can be included in multi-hazard analysis by resorting to techniques that are able to dynamically modify the event trees according to functional behaviour rules (Eveleigh et al. 2006, 2007). This is a new and challenging approach that has been virtually unattempted in landslide studies. It obviously requires that an unusually large amount of data is available, which makes it more suitable for local scale studies at the present stage.

In practical terms, when dealing with hazard assessment, four different scenarios concerning multiple sources of landslide hazard are possible:

1. Multiple types of landslides. Multiple types of landslides occur at the same location but do not interact with each other and cause a cascade or domino effect, and do not necessarily occur at the same time

2. Composite landslides: According to Cruden and Varnes (1996), a composite landslide exhibits at least two types of movement simultaneously in different parts of the displacing mass

3. Complex landslides: According to Cruden and Varnes (1996), a complex landslide exhibits at least two types of movement in a temporal sequence, yielded a kind of cascade effect

4. Multiple interacting landslides. Multiple types of landslides (or several landslides of the same type) that occur at the same location or at different locations interact, so that there is a point in time and space (the 
Table 14 Suggested methods for multi-hazard assessment at the regional scale

\begin{tabular}{|c|c|c|c|c|}
\hline $\begin{array}{l}\text { Regional } \\
\text { scale }\end{array}$ & Magnitude & Frequency & Hazard descriptor & $\begin{array}{l}\text { Multi-hazard methods and } \\
\text { recommendations }\end{array}$ \\
\hline \multirow{10}{*}{$\begin{array}{l}\text { Areal } \\
\text { analysis }\end{array}$} & Landslide density & \multirow{4}{*}{$\begin{array}{l}\text { Frequency of landslides is calculated based on } \\
\text { the average time span between sets of images }\end{array}$} & No. of landslides/ & \multirow{4}{*}{$\begin{array}{l}\text { Spatially averaged joint } \\
\text { probability and scenario-based } \\
\text { BETs }\end{array}$} \\
\hline & Landslide size (area, & & & \\
\hline & & & $\begin{array}{l}\text { No. of landslides/ } \\
\text { pixel/year }\end{array}$ & \\
\hline & & & $\begin{array}{l}\text { Total slide area/ } \\
\mathrm{km}^{2} / \text { year }\end{array}$ & \\
\hline & \multirow[t]{4}{*}{$\begin{array}{l}\text { Landslide density (i.e. } \\
\text { landslides } / \mathrm{km}^{2} \text { ) }\end{array}$} & \multirow[t]{4}{*}{$\begin{array}{l}\text { Return periods or the exceedance probability of } \\
\text { the trigger magnitude }\end{array}$} & $\begin{array}{l}\text { Probability of } \\
\text { having }\end{array}$ & $\begin{array}{l}\text { Spatially averaged joint } \\
\text { probability and BETs }\end{array}$ \\
\hline & & & $\begin{array}{l}\text { No. of landslides/ } \\
\mathrm{km}^{2}\end{array}$ & Spatially based BETs \\
\hline & & & $\begin{array}{l}\text { No. of landslides/ } \\
\text { pixel }\end{array}$ & \\
\hline & & & $\begin{array}{l}\text { Total slide area/ } \\
\mathrm{km}^{2}\end{array}$ & \\
\hline & \multirow[t]{2}{*}{$\begin{array}{l}\text { Number of landslides } \\
\text { (normalised by } \\
\text { distance) }\end{array}$} & \multirow[t]{2}{*}{$\begin{array}{l}\text { Return periods or the exceedance probability of } \\
\text { seismic shaking }\end{array}$} & \multirow[t]{2}{*}{$\begin{array}{l}\text { Probability of } \\
\text { landslide } \\
\text { occurrence }\end{array}$} & $\begin{array}{l}\text { Spatially averaged joint } \\
\text { probability and BETs }\end{array}$ \\
\hline & & & & Spatially based BETs \\
\hline
\end{tabular}

Table 15 Suggested methods for multi-hazard assessment at the local scale

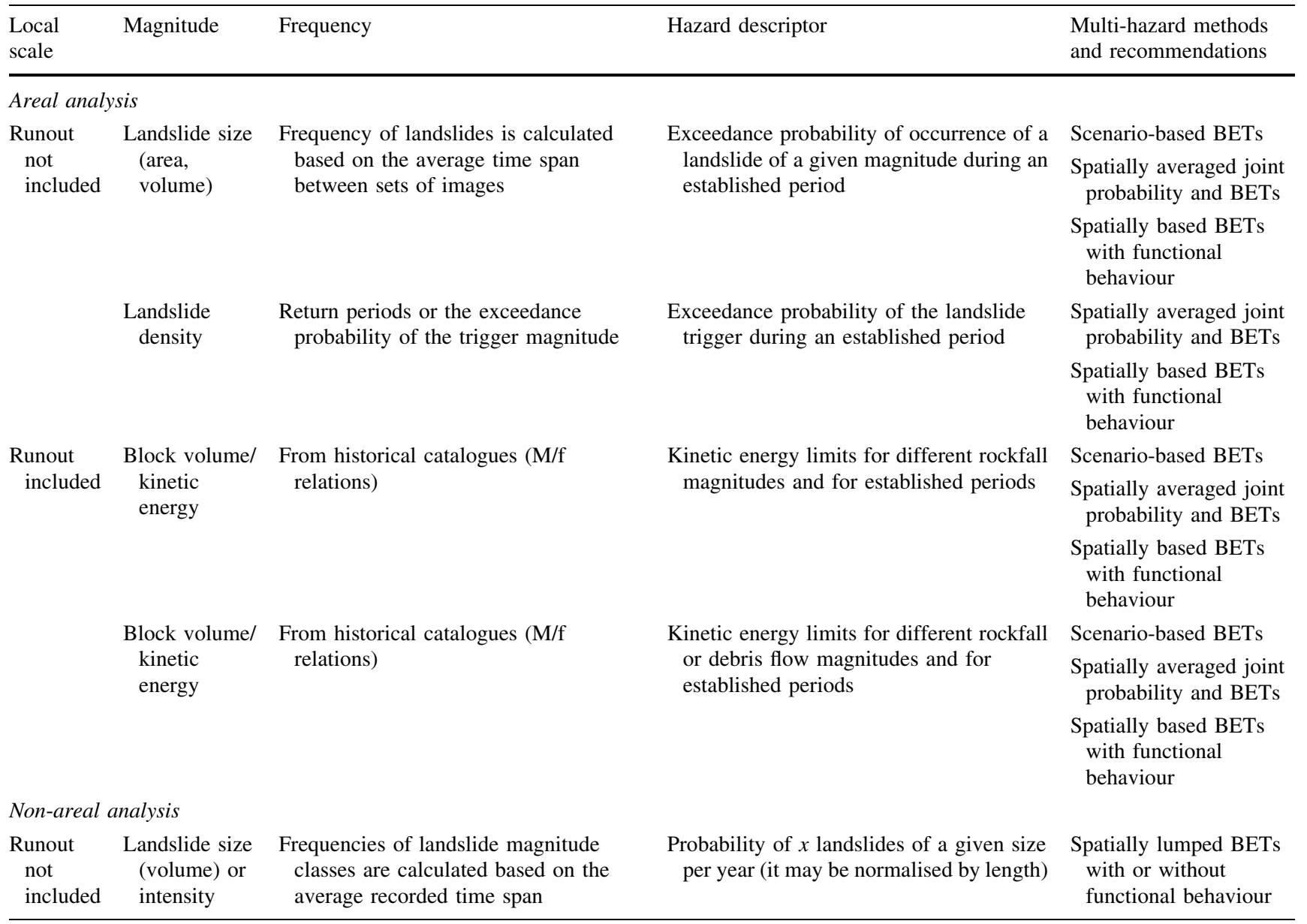



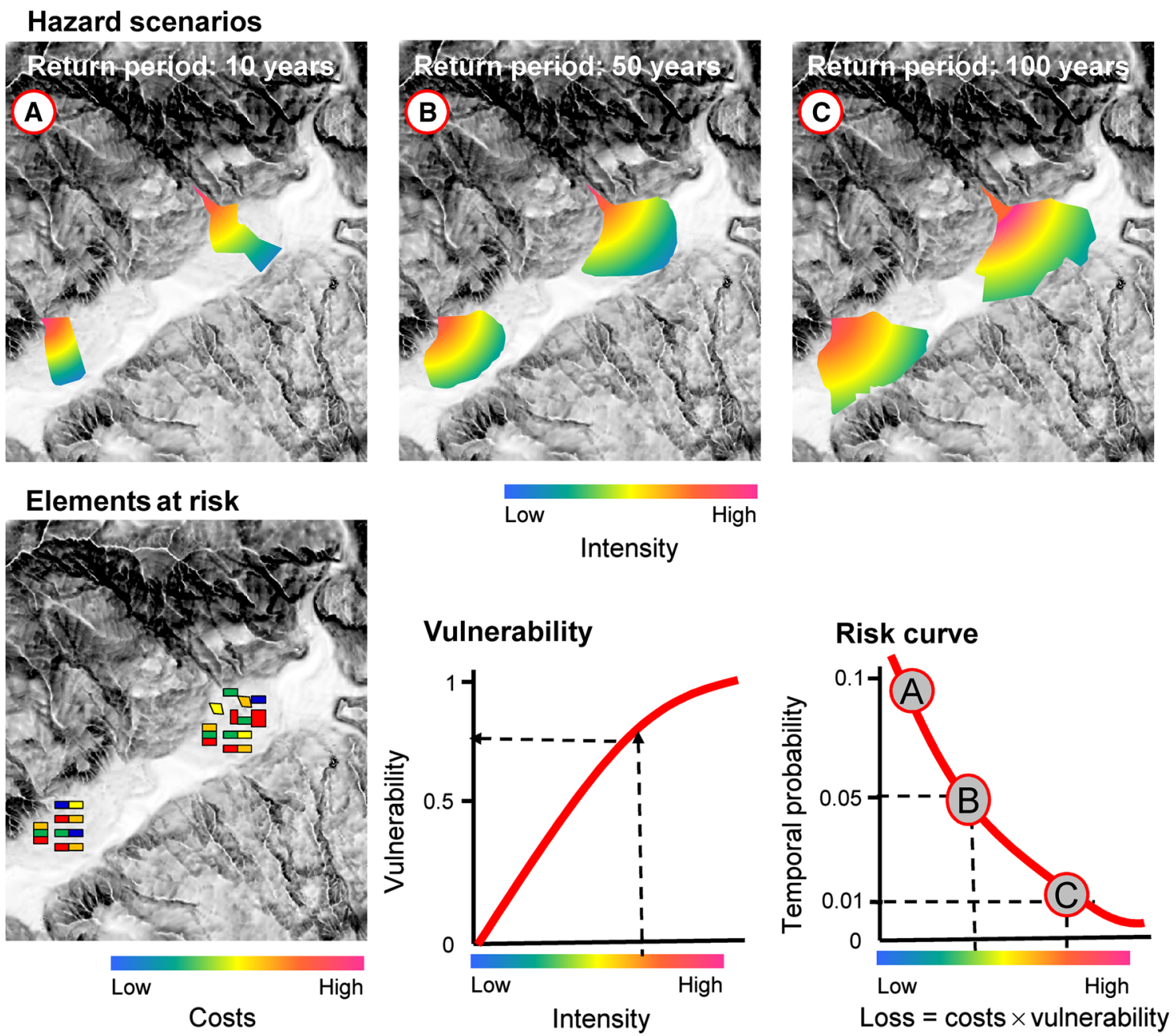

Fig. 3 Example of a risk curve plotting the temporal probabilities of different landslide scenarios with various return periods against loss. Each of the scenarios yields intensity maps (e.g. of impact pressure). Each element at risk (e.g. a building) is characterised by its type, location and replacement cost. The vulnerability of each exposed element at risk is determined using a vulnerability curve for that

confluence point) where the effects are cumulated using suitable concepts

For the first case, the hazard assessment is undertaken independently for each type of landslide, and the results are merged only at the risk level. For composite landslides, the joint probability approach can be considered for multihazard assessment. When complex landslides occur, providing a cascade effect such as a slide evolving into a flow, the ET or BET can be used. The fourth case requires the distributed use of ETs or BETs or a single ET/BET to account for the cumulated/cascading effects down-valley of the confluence point. The best ET or BET to use among those listed above depends on the scale of analysis and on the hazard descriptors selected. particular structural type and the intensity for the particular hazard scenario. The losses are determined by multiplying the vulnerabilities by the replacement costs for all exposed elements at risk. After defining a number of points, a risk curve can be drawn. The area under the risk curve represents the annualised losses

Tables 14 and 15 show the suggested methods for landslide hazard assessment at different scales and typologies, based on the broad categories of methods just listed.

\section{Suggested methods for quantitative landslide risk analysis}

This section is dedicated to QRA with landslide hazard as an input. It often necessary to calculate all of the parameters in Eq. 1 for each magnitude class, as each class has a specific probability of occurrence, travel distance, intensity, and impact probability. The global risk for an area can then be obtained by aggregating the specific risks for 
different landslide magnitudes or intensities and for all of the exposed elements. However, for regional (or smaller) scale analyses, this approach cannot be applied because of a lack of detailed input data, so the risk equation is simpler and more general.

Besides the direct risk (involving, for example, the physical loss of property or fatalities), the indirect risk must also be included (e.g. disruption of economic activities, evacuation of the areas...), but this is beyond the scope of this paper, which mostly focuses on direct losses.

Risk descriptors vary according to the goal of the assessment, the nature and type of each exposed element, as well as the terms that are used to describe the extent of the loss.

Landslide risk descriptors may be:

- Univariate, such as $€ 1,000,000 /$ year

- Multivariate, such as a (cumulative) probability of 0.0001 for a given level of loss

For the second risk descriptor, representative risk scenarios should be established. Risk descriptors for an object or an area can be shown diagrammatically by plotting (cumulative) frequency (or probability)-consequence curves (Fig. 3) or single values.

Two alternative types of analysis may be used to calculate risk: deterministic or probabilistic. Deterministic risk analysis uses the average or least favourable values (worst case scenario) of the risk components (variables of the risk equation), and it yields a univariate result expressing the average or maximum risk, respectively. In contrast, for the probabilistic analysis, all or some of the risk components are assumed to conform with a probability distribution, so the results are presented in probabilistic terms, using pairs or plots of (cumulative) probability and consequences. Monte Carlo simulations may facilitate the probabilistic calculation of the risk when the probability density functions that best fit the distributions of the risk components are known.

\section{Vulnerability assessment}

While there has been extensive research into quantifying landslide hazard, research into consequence analysis and vulnerability assessment has been limited. In the following, various types of landslide damage are described for different landslide types and elements at risk. Directions for selecting appropriate vulnerability assessment methods are provided with respect to the exposed element, the landslide type and the scale of analysis.

\section{Types of vulnerability}

Different disciplines use multiple definitions and different conceptual frameworks for vulnerability. From a natural sciences perspective, vulnerability may be defined as the degree of loss of a given element or set of elements within the area affected by the landslide hazard. For property, the loss will be the value of the damage relative to the value of the property. For people, it will be the probability of fatalities. Vulnerability can also refer to the propensity for loss (or the probability of loss) and not the degree of loss. In the social sciences, there are multiple definitions and aspects of the term "vulnerability", depending on the scale and the purpose of the analysis. Some are reviewed in Fuchs et al. (2007) and Tapsell et al. (2010).

The quantified vulnerability can be expressed in monetary terms (absolute or relative to the value of the exposed elements), as a percentage of the per capita gross domestic product, as the number of fatalities, or using other types of indicator scales (the latter is especially true for social vulnerability, as described in King and MacGregor 2000). The degree of loss due to an event is the sum of the direct and indirect losses.

Here, we consider either (a) physical vulnerability or (b) the vulnerability of people:

a. Physical vulnerability refers to the direct damage to buildings, utilities and infrastructure. The monetary impact of damage to a building or to infrastructure can be readily assessed and is easily understood. Furthermore, the vulnerability of physical elements can be expressed in terms of the extent of damage or the cost of recovery as a result of a given event.

b. Vulnerability of people (fatalities, injuries) relates to whether or not a landslide event will result in injury or fatalities. Again, monetary values can be assigned in cases of injury or loss of life (in terms of insurance value) or reduced quality of life. Models that are used to assign such monetary values generally consider the cost of rescue, hospitalisation and treatment, and the loss of earning potential (in both the short term in the case of injury, and in the long term). Other impacts of the loss of life or injury due to a landslide include social implications that do not readily lend themselves to quantification.

An overview of potential landslide damage types, which are delineated according to landslide type, elements at risk and the location of the exposed element in relation to the landslide, is presented by Van Westen et al. (2005).

Vulnerability of buildings Experience indicates that the extent of damage to buildings due to landslides varies considerably according to the characteristics of the building, the landslide mechanism, and the magnitude and intensity. The vulnerability may be expressed in terms of damage states varying from nonstructural damage to extensive collapse. Damage may be structural or nonstructural with damage caused to utility systems. 
The typology of the exposed elements is a key factor in a vulnerability assessment methodology. The structural system, geometry, material properties, state of maintenance, levels of design codes, foundation and superstructure details, number of floors, and other factors are among typical typological parameters which determine the capacity of buildings to withstand landslide actions. The cost of the damage varies with the type of the structure, its location and use. In order to facilitate data collection at local and regional scales, it is convenient in many cases to consider more aggregated levels in the form of homogeneous units. These should consist of groups of buildings, characterised by relative homogeneity of structural type, construction materials, age, number of floors and land-use distribution.

An additional important factor is the geographic location of the exposed elements within the landslide body (crest, transport zone, toe, runout zone, etc.), given the variation of the movement and the consequent interaction with the structures and infrastructure. Another parameter is the impact location on the structure and the importance of the impacted members to the stability of the building. The main impact locations are the roof of a building, its façade (including structural and nonstructural elements) and its foundation. For small scales, the simplification that events of a similar magnitude produce the same level of damage can be made due to the resolution of the analysis. For detailed scales, especially in the case of rockfalls and debris flow, the impact point on the building-particularly on elements which are important for its stability-should be taken into consideration. This applies especially to frame structures, where, for example, damage to a column may initiate a cascade of failures. For masonry structures, the damage is usually local, as alternative load paths are easily found due to the inherent hyperstatic load-bearing system.

The "resistance hierarchies" between the main structural and the secondary nonstructural elements are among the main parameters that may significantly influence building damage in the case of debris flow.

While damage to the built environment resulting from the occurrence of rapid landslides such as debris flow and rockfalls is generally the greatest and most severe, as it may lead to the complete destruction of any structure within the affected area, slow-moving slides also have adverse effects on affected facilities (Mansour et al. 2011).

The damage caused by a slow-moving landslide to a building is mainly attributed to the cumulative permanent (absolute or differential) displacement and the fact that it is concentrated within the unstable area. The type of response of a building to permanent total and differential ground deformation depends primarily on the type of foundations present. Deep foundations are less vulnerable than shallow foundations. Rigid foundations that permit the rotation of the building as a rigid body may be less vulnerable than flexible foundations (Bird et al. 2006).

Vulnerability of roads, railways and vehicles The vulnerability of a road or railway system may be attributed to both the partial or complete blockage of the road or track as well as structural damage, including damage to the surfacing, which is associated with the level of serviceability. Information regarding the type (e.g. highway, main road, or unpaved road), width, and traffic volume is necessary to assess the vulnerability of transportation infrastructure and vehicles (due to traffic interruption) to various landslide hazards. The annual average daily traffic (AADT), which is representative of the typical traffic flow, can be used to this end.

For moving elements such as vehicles, an accurate assessment of vulnerability requires a good historical record of landslide events and related damage (Dai et al. 2002). The vulnerability of a vehicle on the road depends on its position with respect to the landslide at a specific time and whether the vehicle is directly impacted by the landslide, whether the vehicle crashes into it, or whether the vehicle is derailed due to damage to the infrastructure. Furthermore, important contributing factors are the type of vehicle (in relation to its average speed), the magnitude of the landslide, and the density of vehicles (traffic volume) at a particular time and along a particular section of road. Hence, vehicle vulnerability to landslides is space and time dependent, and can be quantified using statistical data and/ or stochastic approaches.

Vulnerability of people The physical vulnerability of people refers to the probability that a particular life will be lost, given that the person is affected by the landslide (AGS 2007). It depends on many factors, such as the landslide type, size and intensity; the resistance and mobility of the individuals affected by the landslide hazard; and their relative positions in the exposed area. The resistance of a person to landslides is believed to also be a function of the person's intellectual maturity (e.g. perception of the risk) and physical ability (e.g. age) (Uzielli et al. 2008). This type of vulnerability may be quite important for a fastmoving landslide (debris flow, rockfall), but is generally negligible for slow-moving landslides. Due to the complex and dynamic nature of a human population, vulnerability changes over time. Considering the large uncertainties and complexities associated with the physical vulnerability of people to landslides, all existing methodologies are based on expert judgement and empirical data. 
Table 16 Judgemental/heuristic methods for assessing vulnerability

\begin{tabular}{|c|c|c|c|c|}
\hline Exposed elements & $\begin{array}{l}\text { Landslide } \\
\text { mechanism }\end{array}$ & $\begin{array}{l}\text { Application } \\
\text { scale }\end{array}$ & Methodology & References \\
\hline $\begin{array}{l}\text { Buildings, roads and infrastructures, people } \\
\text { inside and outside buildings }\end{array}$ & $\begin{array}{l}\text { Debris flow, } \\
\text { rockfalls }\end{array}$ & $\begin{array}{l}\text { Local, } \\
\text { regional }\end{array}$ & $\begin{array}{l}\text { Direct attribution of fixed values for events } \\
\text { with different return periods }\end{array}$ & $\begin{array}{l}\text { Bell and Glade } \\
\text { (2004) }\end{array}$ \\
\hline People in open spaces, vehicles or buildings & $\begin{array}{l}\text { Debris flow, } \\
\text { rockfalls }\end{array}$ & $\begin{array}{l}\text { Local, } \\
\text { regional }\end{array}$ & $\begin{array}{l}\text { Fixed values from observations of historic } \\
\text { records in Hong Kong }\end{array}$ & $\begin{array}{l}\text { Finlay and Fell } \\
\text { (1996) }\end{array}$ \\
\hline Roads & Debris flow & Regional & $\begin{array}{l}\text { Statistical analysis of inventory data to } \\
\text { construct vulnerability curves }\end{array}$ & $\begin{array}{l}\text { Winter et al. } \\
\text { (submitted) }\end{array}$ \\
\hline
\end{tabular}

Table 17 Data-driven methods for assessing vulnerability

\begin{tabular}{|c|c|c|c|c|}
\hline $\begin{array}{l}\text { Exposed } \\
\text { elements }\end{array}$ & $\begin{array}{l}\text { Landslide } \\
\text { mechanism }\end{array}$ & $\begin{array}{l}\text { Application } \\
\text { scale }\end{array}$ & Methodologies & References \\
\hline Buildings & Rockfalls & $\begin{array}{l}\text { Site- } \\
\text { specific, } \\
\text { local }\end{array}$ & $\begin{array}{l}\text { Back analysis of real event damage data. Vulnerability } \\
\text { associated with impact energy and expressed by a sigmoid } \\
\text { function }\end{array}$ & Agliardi et al. (2009a, b) \\
\hline Buildings & $\begin{array}{c}\text { Debris } \\
\text { flow }\end{array}$ & $\begin{array}{l}\text { Site } \\
\text { specific, } \\
\text { local }\end{array}$ & $\begin{array}{l}\text { Back analysis using damage data coupled with the } \\
\text { information from modelling outputs. Vulnerability } \\
\text { associated with height of accumulation or impact pressure } \\
\text { or kinematic viscosity and expressed by a sigmoid function }\end{array}$ & $\begin{array}{l}\text { Quan Luna et al. (2011), Jakob et al. } \\
\text { (2012) }\end{array}$ \\
\hline $\begin{array}{l}\text { Buildings, } \\
\text { people }\end{array}$ & $\begin{array}{c}\text { Various } \\
\text { types }\end{array}$ & Regional & $\begin{array}{l}\text { Probabilistic analysis based on first-order second moment } \\
\text { approximation of uncertainties. A vulnerability value is } \\
\text { obtained }\end{array}$ & $\begin{array}{l}\text { Uzielli et al. (2008), Uzielli and } \\
\text { Lacasse (2007), Kaynia et al. } \\
\text { (2008), Li et al. (2010) }\end{array}$ \\
\hline Buildings & $\begin{array}{c}\text { Debris } \\
\text { flow }\end{array}$ & $\begin{array}{l}\text { Local, } \\
\text { regional }\end{array}$ & $\begin{array}{l}\text { Calculation of a single function obtained by regression of real } \\
\text { event data and correlation with debris height }\end{array}$ & $\begin{array}{l}\text { Fuchs et al. (2007), Fuchs (2008), } \\
\text { Papathoma-Köhle et al. (2012), } \\
\text { Akbas et al. (2009) }\end{array}$ \\
\hline
\end{tabular}

\section{Quantification of vulnerability}

The vulnerability of an element at risk can be quantified using either vulnerability indices or fragility curves. The vulnerability index expresses the degree of damage on a relative scale from 0 (no damage) to 1 (total damage). Vulnerability curves express the conditional probability of reaching or exceeding a certain damage state (e.g. slight, moderate, extensive, complete) due to a landslide event of a given type and intensity. In this way, it is possible to explicitly include both epistemic and aleatory uncertainties in the vulnerability modelling approach (such as those for structural typology, resistance of materials, age, state of maintenance, etc.). Most procedures for developing vulnerability curves in the literature (e.g. ATC 1985; Shinozuka et al. 2000; Cornell et al. 2002; Nielson and DesRoches 2007; Porter et al. 2007, etc.) were initially proposed for earthquakes, but they can also be modified so that they can be applied to landslides. A two-parameter lognormal distribution function is usually adopted, due to its simple parametric form, to represent a fragility curve for a predefined damage/limit state (Koutsourelakis 2010; Fotopoulou and Pitilakis 2013a).
The methodologies used for the quantification of vulnerability can be classified according to the type of input data and the evaluation of the response parameters into judgemental/heuristic (Table 16), data-driven (using data from past events; Table 17) or analytical (using physical models; Table 18). The existence and quality of the input data also play fundamental roles.

Judgemental/heuristic methods Judgemental/heuristic methods usually provide discrete values for a range of landslide intensities. Based on the economic value of the buildings, roads and infrastructure in a given area, Bell and Glade (2004) established fixed vulnerability values as a function of the return period of debris flow and rockfalls. In the same way, they attributed vulnerability values to people inside and outside buildings. Further values for people present in open spaces, vehicles or buildings in landslide areas that could be applied for risk assessment in Hong Kong were proposed by Finlay and Fell (1996), based on the observation of real events.

Winter et al. (submitted) presented a methodology for physical damage to roads due to debris flow based on the statistical analysis of data obtained by questionnaires 
Table 18 Analytical/physical model-based methods for assessing vulnerability

\begin{tabular}{|c|c|c|c|c|}
\hline Exposed elements & $\begin{array}{l}\text { Landslide } \\
\text { mechanism }\end{array}$ & $\begin{array}{l}\text { Application } \\
\text { scale }\end{array}$ & Methodologies & References \\
\hline $\begin{array}{l}\text { Buildings (RC } \\
\text { frames) }\end{array}$ & Rockfalls & $\begin{array}{l}\text { Site-specific, } \\
\text { local }\end{array}$ & $\begin{array}{l}\text { Evaluation of column resistance. Application of the finite element } \\
\text { method for the progressive collapse potential. Yields a vulnerability } \\
\text { matrix and v curves associated with the impact energy and the } \\
\text { uncertainty of the impact location }\end{array}$ & $\begin{array}{l}\text { Mavrouli and } \\
\text { Corominas } \\
(2010 \mathrm{a}, \mathrm{b})\end{array}$ \\
\hline $\begin{array}{l}\text { Buildings ( } \mathrm{RC} \\
\text { frames) }\end{array}$ & $\begin{array}{l}\text { Slow- } \\
\text { moving }\end{array}$ & Site-specific & $\begin{array}{l}\text { Calculation of damage from earthquake-induced landslides using a finite } \\
\text { slope model and the finite difference method. Parametric analysis and } \\
\text { statistical evaluation for the construction of fragility curves }\end{array}$ & $\begin{array}{l}\text { Fotopoulou and } \\
\text { Pitilakis (2013a, } \\
\text { b) }\end{array}$ \\
\hline $\begin{array}{l}\text { Buildings (RC } \\
\text { frames) }\end{array}$ & $\begin{array}{l}\text { Slow- } \\
\text { moving }\end{array}$ & Site-specific & $\begin{array}{l}\text { Use of numerical simulations and earthquake analysis concepts for the } \\
\text { calculation of vulnerability curves associated with differential } \\
\text { settlements }\end{array}$ & $\begin{array}{l}\text { Negulescu and } \\
\text { Foerster (2010) }\end{array}$ \\
\hline Buildings & $\begin{array}{c}\text { Debris } \\
\text { flow }\end{array}$ & $\begin{array}{l}\text { Site-specific, } \\
\text { local, } \\
\text { regional }\end{array}$ & $\begin{array}{l}\text { Uses the principles of the dynamic responses of simple structures to } \\
\text { earthquake excitation. Vulnerability curves associated with the impact } \\
\text { force }\end{array}$ & $\begin{array}{l}\text { Haugen and } \\
\text { Kaynia (2008) }\end{array}$ \\
\hline $\begin{array}{l}\text { Buildings (RC } \\
\text { frames and } \\
\text { masonry) }\end{array}$ & $\begin{array}{l}\text { Debris } \\
\text { flow }\end{array}$ & $\begin{array}{l}\text { Site-specific, } \\
\text { local, } \\
\text { regional }\end{array}$ & $\begin{array}{l}\text { Probabilistic evaluation of damage by calculating element resistance, } \\
\text { using the Monte Carlo method for various structural typologies. } \\
\text { Calculation of fragility curves }\end{array}$ & $\begin{array}{l}\text { Zuccaro et al. } \\
\text { (2011) }\end{array}$ \\
\hline
\end{tabular}

(completed by recognised experts in the field of debris-flow hazard and risk assessment) to calculate vulnerability curves.

Data-driven methods Data-driven methods for vulnerability assessment are the most frequently used vulnerability assessment methods, as they offer both simplicity and reliability, although they also introduce a degree of subjectivity. Their sophistication and the incorporation of uncertainties vary significantly, and their applicability is limited by the need for inventory data for the study area to be available. Vulnerability is calculated as a function of the landslide intensity.

Agliardi et al. (2009b) proposed the back analysis of real event damage data to obtain correlations between rockfall intensity and building vulnerability by regression. The result was a site-specific empirical vulnerability function obtained by fitting damage and impact energy values using a sigmoid function. In the same way, Quan Luna et al. (2011) used inventoried building damage from debris flow to calculate a sigmoid function that could be used to obtain vulnerability as a function of the height of accumulation, the impact pressure and the kinematic viscosity.

Uzielli and Lacasse (2007) and Uzielli et al. (2008) incorporated uncertainties into the quantification of the vulnerability. They suggested its probabilistic evaluation by means of an approach relying on the first-order second moment (FOSM) approximation of uncertainty, which was also applied by Kaynia et al. (2008). A similar probabilistic model was also proposed by $\mathrm{Li}$ et al. (2010).

For debris flows, Fuchs et al. (2007), Fuchs (2008), Papathoma-Köhle et al. (2012) and Akbas et al. (2009) developed a vulnerability function that links intensity (debris depth) to vulnerability values. Jakob et al. (2012) developed a debris flow intensity index that considers the flow height and velocity in order to calculate the probability of damage.

Analytical methods Analytical methods are used less frequently because of their complexity in comparison to the methods described above and the lack of detailed input data. When implementing such methods, a distinction is usually made between buildings with different structural typologies.

Vulnerability to the impact of rockfalls at the base of a reinforced concrete structure may be analysed using the methodology developed by Mavrouli and Corominas (2010a, b). This methodology considers the potential for progressive collapse when key elements are destroyed by rockfall impact (analysed using the finite element method). It yields discrete probabilistic vulnerability values for different intensities and fragility curves incorporating the uncertainty of the impact location.

Fotopoulou and Pitilakis (2013a, b) developed an analytical methodology for assessing the vulnerabilities of reinforced concrete buildings subjected to earthquaketriggered slow-moving slides. The fragility curves were estimated by determining the peak ground acceleration or permanent ground displacement at the "seismic bedrock" and the probability of exceeding each limit state, based on a two-step uncoupled numerical modelling approach. The developed method is applicable to different soil types, slope geometries and building configurations, allowing explicit consideration of various sources of uncertainty. Negulescu and Foerster (2010) also calculated vulnerability curves as a function of the differential settlements of a reinforced concrete frame building. 
Vulnerability curves may be produced for unreinforced masonry structures and reinforced masonry structures that are subjected to debris flows using the method proposed by Haugen and Kaynia (2008), which implements the HAZUS software package (NIBS 2004). This method uses the principles of the dynamic response of a simple structure to earthquake excitation. Additionally, Zuccaro et al. (2011) presented another analytical method for calculating vulnerability curves that is based on the resistances of a reinforced concrete $\mathrm{RC}$ frame and the infill wall, in probabilistic terms, and uses Monte Carlo simulation. The resistance hierarchy among the distinct elements is taken into consideration.

\section{Risk analysis}

The risk-in a similar manner to the hazard-may refer to a single object, a linear feature or an area. Areal analysis is usually required by local and regional governments for the purposes of land planning or the design of protection measures. It is very demanding in terms of the data required to calculate the hazard and the vulnerability parameters, and it imposes many restrictions on the detailed runout analysis that can be performed as well as the incorporation of landslide kinematics. The areal analysis is typically performed at a regional scale and implemented in GIS platforms, with maps being used to illustrate the risk (Agliardi et al. 2009b). The latter may be expressed as the annual monetary loss per pixel or area unit, or as the probability of a given risk scenario (Remondo et al. 2005).

Risk analysis for linear features, for example roads or railways, is a very common procedure. The risk may be calculated either for the entire line or some selected parts, specifically those that are most at risk. This analysis does not necessarily require an assessment of the frequency at the source area, but the inventory of the events that reach the infrastructure should be as complete as possible. On the other hand, if the landslide occurrence is evaluated at the source, propagation analysis is needed (Roberds 2005). Even though the landslide intensity best expresses the damage potential of the landslide, it is rarely considered in this type of analysis (Bunce et al. 1997; Hungr et al. 1999).

Object-orientated analysis is performed for buildings, road cuts or specific facilities. Landslide analysis is usually undertaken using analytical and/or numerical models, and includes the calculation of the spatial parameters that influence the probability of a landslide of a given magnitude or velocity reaching the exposed element(s). Restrictions in this case may stem from the scarcity of the data needed to properly assess the probability or frequency of occurrence. Risk may be expressed as the annual monetary loss per object or the annual probability of property damage or loss of life for different risk scenarios.

\section{Exposure}

Exposure is an attribute of people, property, systems or other elements present in areas that are potentially affected by landslides. It is calculated as the temporal and spatial probability that an element at risk is within the landslide path, and it also needs to be incorporated into the risk equation. The calculation of the exposure depends mainly on the scale of the analysis and the type of element potentially exposed. Whether an element is exposed or not is determined by its location with respect to the landslide path, which varies according to the landslide mechanism. For exposure, there is an important distinction between static elements (buildings, roads, other infrastructure, etc.) and moving elements (vehicles, persons, etc.).

Static elements In the case of rockfalls, the affected elements are located within the rockfall path. Exposed elements for fragmented rockfalls have limited spatial intersections, while the intersections are larger for rock avalanches and rockslides. For fragmented rockfalls, and at small scales with low resolution, all of the elements next to rockfall-prone cliffs are assumed to be exposed. At sitespecific and local scales, and when the trajectory is included in the analysis, this is limited to only the elements that are situated within the potential rockfall path. In the latter case, the exposure component varies as a function of the block size.

The impact probability may be obtained by considering the percentage of the area that contains structures in one or more reference sections reached by the rockfall path (Corominas et al. 2005; Corominas and Mavrouli 2011b). For large-scale analyses, where detailed information on the spatial probability of a block reaching a building is required, the probabilities of individual block trajectories may be computed. Some rockfall sources produce paths that have a higher probability of affecting some buildings than others do, and this has to be taken into account.

Debris flows can affect larger areas than rockfalls, due to their increased mobility and possibility of inundation. In some cases, deposition affects an entire urban area. The spatial exposure of an area can be calculated as the ratio of the affected area to the total area. Whether the latter is calculated as a function of the flow kinematics (e.g. discharge rate) or not depends on the availability of propagation information at the scale of analysis considered, as previously mentioned.

For slow-moving landslides, the exposed elements may be located on it, next to the landslide scarp or in the landslide runout zone. Because of this, the actions applied and the damage caused may vary. Again, the exposure of each element may be calculated as a function of the 
landslide kinematics if the scale and the resolution of the analysis permit this.

Kinematic analysis is required to calculate the exposures of linear elements such as roads and railways when the frequency or probability of landslide occurrence is calculated at the source. If it is calculated to intersect directly with the infrastructure, the exposure is equal to 1 .

Moving elements Quantification of the temporal and spatial probabilities of moving elements must take into account the characteristics of their movement. Vehicles may be exposed to landslides in different ways. They may be affected while stationary or moving. They may be hit by a rock or soil mass, or they may crash into a rock or soil mass that is obstructing or blocking the road. Vehicles that are buried or become entrained in the debris flow or landslide, and thus become part of the moving mass, should also be considered.

The impact probability can be calculated for the direct impact of rocks or soil on vehicles. This depends, amongst other factors, upon the frequency of the vehicles, the size of the fragmented rock or the geometrical characteristics of the debris flow or landslide, and the lengths of the vehicles. Basic simplifying assumptions that are usually made for the exposure of vehicles are that they are uniformly distributed temporally and spatially, and that all vehicles have the same length (Bunce et al. 1997).

The temporal and spatial probability that a moving rock or soil mass will intersect with a particular stationary vehicle is proportional to the length of the infrastructure occupied by the vehicle. For multiple events, the probability that no vehicle is hit is equal to

$P(S)=1-(1-P(S: H))^{N_{\mathrm{r}}}$,

where $P(S: H)$ is the probability that a vehicle occupies the portion of the road affected by a landslide, and $N_{\mathrm{r}}$ is the number of events.

For a particular moving vehicle, the temporal probability of intersection is also calculated as a function of the occupying time, which depends on the frequency of the moving vehicle as well as its average length and speed. The width of the rock or the soil mass is usually neglected.

People are also affected by landslides in open spaces and while occupying buildings and vehicles. In this context, the temporal and spatial probability of intersection of a person is calculated as a function of the exposure of the building or vehicle the person is occupying and the percentage of time and/or space that they spend in it (Fell et al. 2005). Thus, for people inside buildings, the probability of intersection depends on their usage of the building and their occupancy of it during specific time spans. In some cases (ski resorts for example) where the population varies between seasons, the seasonal exposure should also be taken into account.
Risk analysis can be performed for either the most exposed people or for those with the average exposure.

\section{Risk calculation}

Examples of the applications of QRA are summarised in Table 19; although the risk components are not calculated in a strictly quantitative manner in some of these applications, the proposed methodologies do yield quantitative results.

Practical examples at site-specific and local scales are provided in the literature for people inside vehicles during rockfalls (Fell et al. 2005) and debris flows (Archetti and Lamberti 2003; Budetta 2002). Wilson et al. (2005) consider both the direct impact of debris on vehicles and the risk of the vehicles running into the debris. The case study of Jakob and Weatherly (2005) also describes the calculation of frequency-fatality curves for people; in that work, vulnerability is calculated empirically from past data as a function of the debris discharge rate. The procedure presented by Bell and Glade (2004) can be used at a regional scale for risk analyses of buildings in relation to both debris flows and rockfalls; this procedure is mainly based on judgemental and empirical data.

If we consider more detailed scales, Agliardi et al. (2009a, b) developed an analytical procedure for QRA relating to rockfalls based on data from the back analysis of a real rockfall event, which included data on the damage to buildings. Corominas et al. (2005) showed an example of the quantification of the risk of blocks hitting people inside buildings. A methodology for the analysis of rockfall risk for buildings for application at the site-specific scale was proposed by Corominas and Mavrouli (2011a), which included the analytical probabilistic vulnerability of buildings as a function of the location of rock block impact. Ferlisi et al. (2012) provided a methodology for calculating the risk taken by people moving along a road while inside vehicles.

For slow-moving landslides (amongst other types), Catani et al. (2005) proposed a methodology that yields results in terms of the expected economic losses relating to buildings, which used remote sensing techniques.

Finally, Ho et al. (2000) and Lee and Jones (2004) presented practical cases of risk calculation for a range of landslide types and exposed elements, with emphasis placed on the calculation of $\mathrm{F}-\mathrm{N}$ curves.

Risk scenarios

In a study area of a particular geo-environmental context, the different stages of movement of existing or potential landslide phenomena of a given type are controlled by mechanisms that are often interrelated (Leroueil et al. 
Table 19 Examples of the application of QRA

\begin{tabular}{|c|c|c|c|}
\hline $\begin{array}{l}\text { Landslide } \\
\text { mechanism }\end{array}$ & $\begin{array}{l}\text { Exposed } \\
\text { elements }\end{array}$ & $\begin{array}{l}\text { Specific } \\
\text { characteristics }\end{array}$ & References \\
\hline \multicolumn{4}{|c|}{ Debris flow and shallow slides } \\
\hline \multirow{2}{*}{$\begin{array}{l}\text { Intensity is } \\
\text { not } \\
\text { accounted } \\
\text { for }\end{array}$} & $\begin{array}{l}\text { People, linear } \\
\text { infrastructure } \\
\text { and buildings }\end{array}$ & $\begin{array}{l}\text { Risk is } \\
\text { calculated at } \\
\text { each pixel }\end{array}$ & $\begin{array}{l}\text { Jaiswal et al. } \\
\text { (2011), Zêzere } \\
\text { et al. (2008) }\end{array}$ \\
\hline & $\begin{array}{l}\text { People inside } \\
\text { vehicles }\end{array}$ & $\begin{array}{l}\text { Risk is } \\
\text { calculated in } \\
\text { relation to } \\
\text { specific road } \\
\text { sections in } \\
\text { terms of } \\
\text { probability }\end{array}$ & $\begin{array}{l}\text { Archetti and } \\
\text { Lamberti } \\
\text { (2003), } \\
\text { Budetta } \\
\text { (2002), Wilson } \\
\text { et al. (2005) }\end{array}$ \\
\hline \multirow[t]{2}{*}{$\begin{array}{l}\text { Intensity is } \\
\text { accounted } \\
\text { for }\end{array}$} & $\begin{array}{l}\text { Buildings, } \\
\text { people }\end{array}$ & $\begin{array}{l}\text { Judgemental or } \\
\text { empirical } \\
\text { evaluation of } \\
\text { risk } \\
\text { parameters }\end{array}$ & $\begin{array}{l}\text { Bell and Glade } \\
\text { (2004), Tsao } \\
\text { et al. (2010) }\end{array}$ \\
\hline & People & $\begin{array}{l}\text { Vulnerability is } \\
\text { a function of } \\
\text { the debris } \\
\text { discharge rate }\end{array}$ & $\begin{array}{l}\text { Jakob and } \\
\text { Weatherly } \\
(2005)\end{array}$ \\
\hline
\end{tabular}

\section{Rockfalls}

Intensity is accounted for

Buildings,
people inside
buildings

Buildings

$\begin{array}{ll}\text { Intensity is } & \begin{array}{c}\text { Moving } \\ \text { not }\end{array} \\ \text { accounted } & \text { (persons, } \\ \text { for } & \text { vehicles) }\end{array}$

Slow moving

Intensity is Buildings
accounted
for

Various types

$\begin{array}{ll}\text { Intensity is } & \text { People, linear } \\ \text { not } & \text { infrastructure } \\ \text { accounted } & \text { and buildings } \\ \text { for } & \end{array}$

Practical Fell et al. (2005), examples at Ghosh et al. the site- (2011), Ho and specific, local Ko (2009), and regional Remondo et al. scales
Therefore, regardless of the scale of landslide risk analysis and zoning adopted, it is necessary to understand the landslide mechanisms that may occur in the study area. Thus, several landslide hazard scenarios can be considered (not necessarily the worst case), along with their potential consequences, so that the respective direct and indirect risk components can be estimated quantitatively.

The total risk must be summed from the risks associated with a number of landslide hazards (Amatruda et al. 2004; Fell et al. 2005). Summing different risk values from several scenarios implies the hypothesis that each scenario considered occurs independently. Based on this, it is often accepted that similar landslide mechanisms with very different magnitudes and probabilities of occurrence produce different scenarios.

A general scenario-based risk formulation is given by Roberds (2005), with a particular emphasis placed on the analysis of consequences; examples relating to this topic are provided by Hungr (1997) and Roberds and Ho (1997).

\section{Evaluation of the performance of landslide zonation maps}

Evaluating the uncertainties, robustness and reliability of a landslide zonation map is a challenging task. As landslide susceptibility, hazard and risk maps predict future events, the best evaluation method would be to "wait and see", and test the performance of the zoning based on events that happened after the maps had been prepared. However, this is not a practical solution, although subsequent events can provide a qualitative degree of confidence for users of the maps, provided that the limitations of the inevitably very short time period considered are understood. Testing the performance of models is a multi-criteria problem encompassing (1) the adequacy (conceptual and mathematical) of the model at describing the system, (2) the robustness of the model to small changes in the input data (e.g. data sensitivity), and (3) the accuracy of the model in predicting the observed data (Davis and Goodrich 1990; Begueria 2006).

In practice, model performance is evaluated using a landslide inventory for a given time period and by testing the result with another inventory from a later period. However, the landslide inventory maps themselves may contain high levels of uncertainty (Van Den Eeckhaut et al. 2006; Guzzetti et al. 2012). Another way of assessing model performance is to compare maps of the same area made independently by different teams, although this has proven to be a rather difficult exercise (Van Westen et al. 1999; Van Den Eeckhaut et al. 2009). To characterise the predictive power of a zonation map, the landslide inventory should be separated into two populations (one of which is
1996). Their geometrical and kinematical characteristics may, in turn, differ depending on the factors that drive and accompany the slope instability processes (Leroueil 2001; Cascini et al. 2009), leading to different risk scenarios. 
used to generate the zonation map, and the second to analyse the accuracy). This can be done by using a random selection of landslides, or by using two temporally different inventory maps. Comparing zonation maps created by different methods may also give a good idea of the accuracy of the prediction.

This section provides an overview of the methods that can be used to evaluate the performance of landslide susceptibility and hazard maps. The term "performance" is used here to indicate whether the zonation maps make a correct distinction between potentially landslide-free and landslide-prone areas.

Uncertainties in and robustness of zonation maps

The nature of uncertainties and the trend towards the use of more complex models (e.g. by moving from heuristic to statistical and process-based models) motivates the need for enhanced model identification and evaluation tools (Saltelli et al. 2004; van Asch et al. 2007) to prove that increased complexity does indeed provide better model results.

Aleatory and epistemic uncertainties are commonly considered for the assessment of landslide models. An aleatoric uncertainty is presumed to be the intrinsic randomness of a phenomenon. An epistemic uncertainty is presumed to be caused by a lack of knowledge or data. Differences in the interpretation of the data by experts participating in the zonation belong to the latter.

The term "robustness" characterises the change in the accuracy of the classification due to perturbations in the modelling process (Alippi et al. 2004). Often, robustness analyses focus only on disturbances to model performance due to errors in the input parameters (Melchiorre et al. 2011). In this context, the term "sensitivity" (Homma and Saltelli 1996) is used to identify the key uncertain parameters that influence the output uncertainty the most (e.g. global sensitivity) and to emphasise the parameters that exert the greatest effect on the output itself but not its uncertainty (local sensitivity analysis).

For landslide zoning assessments, quantitative variancebased methods for global sensitivity analyses (e.g. to investigate the influence of the scale and shape of the distribution of parameters) and graphical methods for local sensitivity analyses may be considered (Melchiorre and Frattini 2012). To introduce perturbations into the different input parameters, probabilistic techniques based on the moment theory are used, as these allow input parameters to to be expressed as mathematical functions instead of unique values (Baecher and Christian 2003). Such approaches allow outcomes based on several theoretical input data sets to be determined and confidence intervals encompassing these return paths to be derived.
Table 20 Contingency table used to evaluate landslide zoning model performance

\begin{tabular}{llll}
\hline $\begin{array}{l}\text { Model } \\
\text { prediction } \\
\text { observations }\end{array}$ & $\begin{array}{l}\text { True (unstable } \\
\text { terrain unit) }\end{array}$ & $\begin{array}{l}\text { False (stable } \\
\text { terrain unit) }\end{array}$ & \\
\hline $\begin{array}{c}\text { Positive } \\
\text { (landslide) }\end{array}$ & True positive & False positive & $\begin{array}{c}\rightarrow \text { Positive } \\
\text { predictive } \\
\text { value }\end{array}$ \\
$\begin{array}{c}\text { Negative (stable } \\
\text { terrain unit) }\end{array}$ & $\begin{array}{c}\text { False } \\
\text { negative } \downarrow\end{array}$ & $\begin{array}{c}\text { True } \\
\text { negative } \downarrow\end{array}$ & $\begin{array}{c}\rightarrow \text { Negative } \\
\text { predictive } \\
\text { value }\end{array}$ \\
& Sensitivity & Specificity & \\
\hline
\end{tabular}

Table 21 Commonly used accuracy statistics

\begin{tabular}{ll}
\hline Accuracy statistics & Formula \\
\hline Efficiency & $\frac{t_{\mathrm{p}}+t_{\mathrm{n}}}{T}$ \\
$\quad$ (accuracy or & \\
percent correct) & \\
True-positive rate & $\frac{t_{\mathrm{p}}}{t_{\mathrm{p}}+F_{\mathrm{n}}}=\frac{t_{\mathrm{p}}}{P}=1-F n$ \\
$\quad$ (sensitivity) & $\frac{f_{\mathrm{p}}}{f_{\mathrm{p}}+t_{\mathrm{n}}}=\frac{f_{\mathrm{p}}}{N}=1-T n$ \\
False-positive rate & (specificity) \\
Threat score & $\frac{t_{\mathrm{p}}}{t_{\mathrm{p}}+f_{\mathrm{n}}+f_{\mathrm{p}}}$ \\
(critical success & \\
rate) & \\
Peirce skill score & $\frac{t_{\mathrm{p}}}{t_{\mathrm{p}} \cdot f_{n}}-\frac{f_{\mathrm{p}}}{f_{\mathrm{p}}+T n}$ \\
$\quad$ (true skill statistic) & $\frac{t_{\mathrm{p}}+t_{\mathrm{n}}-E}{T-E}$ \\
Heidke skill score & where \\
(Cohen's kappa) & $E=\frac{1}{T}\left[\left(t_{\mathrm{p}}+f_{\mathrm{n}}\right)\left(t_{\mathrm{p}}+f_{\mathrm{p}}\right)+\left(t_{\mathrm{n}}+f_{\mathrm{n}}\right)\left(t_{\mathrm{n}}+f_{\mathrm{p}}\right)\right]$ \\
(Heidke 1926) & \\
Odds ratio & $\frac{t_{\mathrm{p}} \cdot t_{\mathrm{n}}}{f_{\mathrm{n}} \cdot f_{\mathrm{p}}}$ \\
Odds ratio skill & $\frac{t_{\mathrm{p}} \cdot t_{\mathrm{n}}-f_{\mathrm{p}} \cdot f_{\mathrm{n}}}{t_{\mathrm{p}} \cdot t_{\mathrm{n}}+f_{\mathrm{p}} \cdot f_{\mathrm{n}}}$ \\
score (Yule's Q) & \\
\hline
\end{tabular}

$t_{\mathrm{p}}=$ true positives, $t_{\mathrm{n}}=$ true negatives, $f_{\mathrm{p}}=$ false positives (type $\mathrm{I}$ error), $f_{\mathrm{n}}=$ false negatives (type II error), $P=$ positive prediction $\left(t_{\mathrm{p}}+f_{\mathrm{n}}\right), N=$ negative prediction $\left(f_{\mathrm{p}}+t_{\mathrm{n}}\right), T=$ total number of observations (see also Table 20)

Sensitivity analysis of input parameters in landslide zoning assessments at site-specific and local scales have been performed by Gray and Megahan (1981), Malet et al. (2004, 2005), and Hürlimann et al. (2008). At the regional scale, sensitivity analysis is possible for both multivariate statistical models and process models. Coupled hydrological and slope stability models that apply bootstrapping indicate that physical modelling based on mean values may not always be practical (Blijenberg 2007). Other examples are given by van Beek (2002), Gorsevski et al. (2006b) and Melchiorre and Frattini (2012). For multivariate statistical models, only a few papers deal with robustness evaluation by performing ensembles of models calibrated for different samples of landslides from the same inventory (Guzzetti 
et al. 2006; Van Den Eeckhaut et al. 2009; Rossi et al. 2010) or by calibrating models for different landslide inventories of the same region (Blahut et al. 2010b). A few studies have investigated the impact of, for example, different classifications of the independent variables derived from lithological, soil or land-cover maps (Thiery et al. 2007). For instance, Melchiorre et al. (2011) defined a robustness index showing sensitivity to variations in the data set of independent (predictor) variables.

\section{Accuracy of the zonation maps}

None of the techniques presented in the literature to assess the accuracy of landslide zoning models account for the economic costs of misclassification, which become important when landslide zoning is adopted in practice for land planning. This is a significant limitation on landslide susceptibility analysis, as the costs of misclassification vary depending on the type of error:

- A type I error (false positive) means that a unit without landslides is classified as unstable, and therefore limited in its use and economic development. Hence, the falsepositive misclassification cost represents the loss of economic value of these terrain units. This cost differs for each terrain unit as it is a function of environmental and socio-economic characteristics.

- A type II error (false negative) means that a terrain unit with landslides is classified as stable, and can consequently be used without restrictions. The false negative misclassification cost is equal to the loss of elements at risk that can be impacted by landslides in these units.

In landslide zoning models, costs relating to type II errors are normally much larger than those relating to type I errors. For example, siting a public facility such as a school building in a terrain unit that is incorrectly identified as stable (type II error) could lead to very large social and economic costs.

In the following, different techniques for the evaluation of landslide model performance are presented.

\section{Cutoff-dependent accuracy statistics}

The accuracy is assessed by analysing the agreement between the model outputs and the observations. Since the observed data comprise the presence/absence of landslides within a certain terrain unit, a simpler method of assessing the accuracy is to compare these data with a binary classification of susceptibility into stable and unstable units. This classification requires a cutoff value in susceptibility that divides terrains into stable (which have a susceptibility less than the cutoff) and unstable (which have a susceptibility greater than the cutoff). A comparison of the observed data and model results after they have been reclassified into these two classes is represented using contingency tables (Table 20). Accuracy statistics assess model performance by combining correctly and incorrectly classified positives (e.g. unstable areas) and negatives (e.g. stable areas) (Table 21).

The efficiency, which measures the percentage of observations that are correctly classified by the model, is unreliable because it is heavily influenced by the most common class, usually "stable terrain unit", and it is not equitable (e.g. it gives the same score for different types of unskilled classifications), and this must be taken into account. The true-positive (TP) rate and the false-positive (FP) rate are insufficient performance statistics because they ignore false positives and false negatives, respectively. They are not equitable, and they are useful only when used in conjunction (such as in ROC curves). The threat score (Gilbert 1884) measures the fraction of observed and/or classified events that were correctly predicted. Because it penalises both false negatives and false positives, it does not distinguish the source of classification error. Moreover, it depends on the event frequency (and thus poorer accuracy scores are derived for rarer, i.e. usually larger-in-magnitude, events), since some true positives can occur purely due to random chance. Alternatively, Peirce's skills score (Peirce 1884) or the odds ratio (Stephenson 2000) may be used.

Accuracy statistics require the division of the classified objects into a few classes by defining specific values of the susceptibility index that are called cutoff values. For statistical models, there is a statistically significant probability cutoff ( $p$ [cutoff]) that is equal to 0.5 . When the groups of stable and unstable terrain units are equal in size and they approximate a normal distribution, this value maximises the number of correctly predicted stable and unstable units. However, the cutoff value used to define the susceptibility classes is chosen arbitrarily and, unless a cost criterion is adopted (Provost and Fawcett 1997), depends on the objective of the map, the number of classes and the type of modelling approach employed.

A first solution to this limitation consists of evaluating model performance over a large range of cutoff values using cutoff-independent performance criteria. Another option consists of finding the optimal cutoff by minimising the costs.

\section{Cutoff-independent accuracy statistics: ROC curves and SR curves}

The most commonly used cutoff-independent performance techniques for landslide zoning models are receiver operating characteristic (ROC) curves and success-rate curves (SR). 

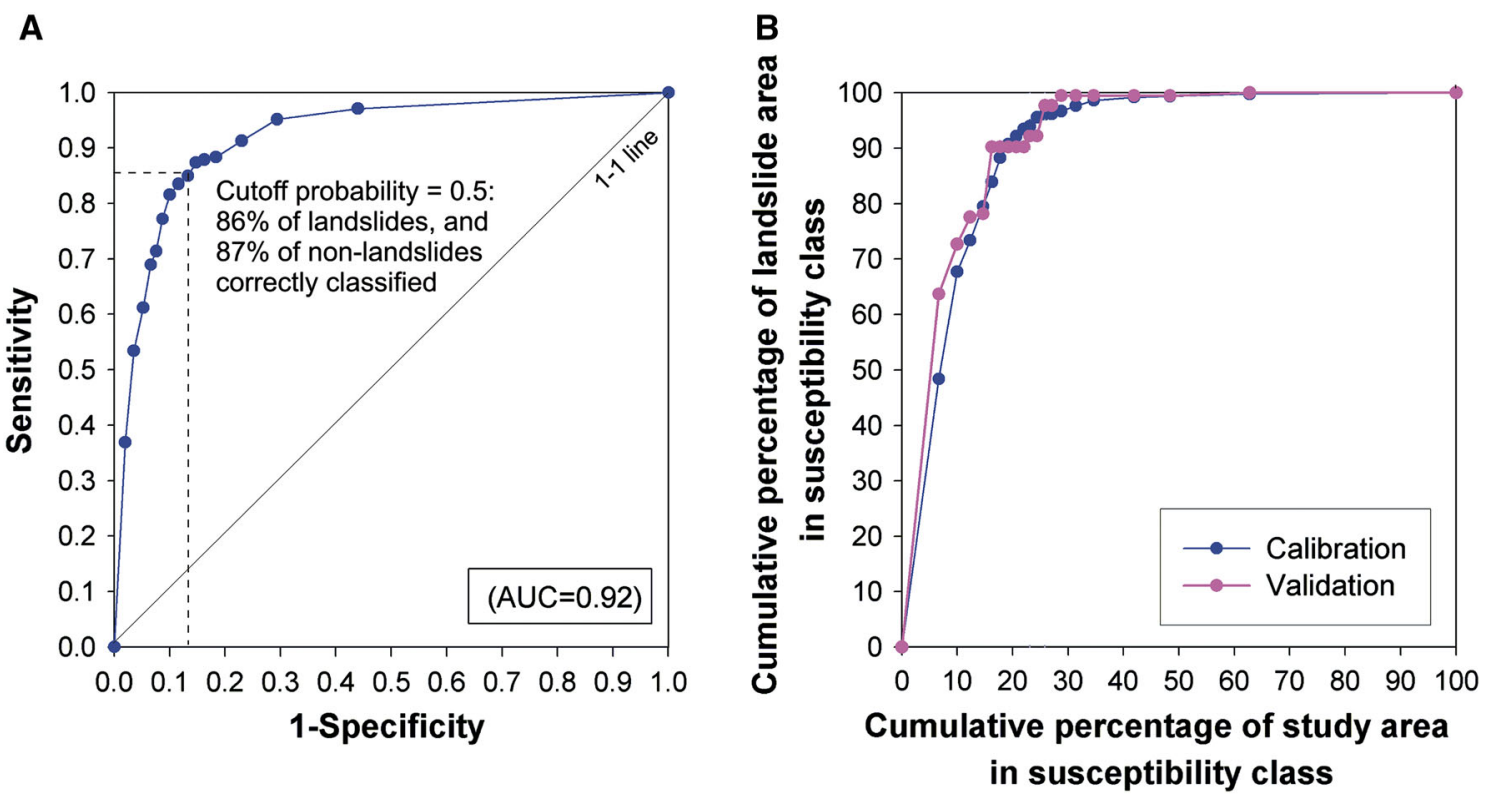

Fig. 4a-b Examples of an ROC curve (a) and a success-rate curve (b) (after Van Den Eeckhaut et al. 2009)

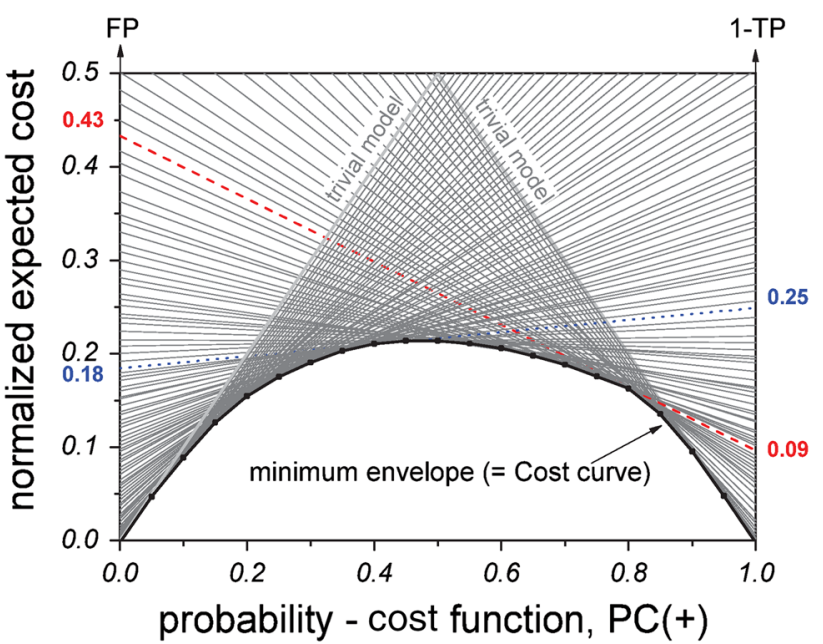

Fig. 5 Example of a cost curve. Each straight line corresponds to a point on the ROC curve. The red line shows, for example, the line of a point with a sensitivity (TP) of 0.91 and (1 - specificity; FP) of 0.43 (Frattini et al. 2010)

ROC analysis was developed to assess the performance of radar receivers in detecting targets, but it has since been adopted in various scientific fields (Adams and Hand 1999; Provost and Fawcett 2001). The area under the ROC curve [area under curve (AUC)] can be used as a metric to assess the overall quality of a model (Hanley and McNeil 1982): the larger the area, the better the performance of the model over the whole range of possible cutoffs. The points on the ROC curve represent (FP, TP) pairs derived from different contingency tables created by applying different cutoffs (Fig. 4). Points closer to the upper right corner correspond to lower cutoff values. One ROC curve is better than another if it is closer to the upper left corner. The range of values for which the ROC curve is better than a trivial model (e.g. a model which classifies objects by chancerepresented in the ROC space by a straight line joining the lower left and the upper right corners; e.g. the 1-1 line) is defined as the operating range. When the model's accuracy is evaluated using data that were not used to develop the model, it is a good model when it has ROC curves for the evaluation and production data sets that are located close to each other in the ROC graph, and has AUC values $>0.7$ (moderately accurate) or even $>0.9$ (highly accurate; Swets 1988).

Success-rate curves (Zinck et al. 2001; Chung and Fabbri 2003; Fig. 4) plot the percentage of correctly classified objects (e.g. terrain units) on the $y$-axis against the percentage of area classified as positive (e.g. unstable) on the $x$-axis. For landslide zoning assessments, the $y$-axis is normally considered to be the number of landslides that are correctly classified (or the percentage of the landslide area that is correctly classified). In the case of grid-cell units where landslides correspond to single grid cells and all of the terrain units have the same area, the $y$-axis corresponds to TP (analogous to the ROC space), and the $x$-axis corresponds to the number of units classified as positive.

\section{Cost curves}

It is possible to account for misclassification costs when evaluating model performance with ROC curves using an additional procedure (Provost and Fawcett 1997), but the results are difficult to visualise and assess. Cost curves (Drummond and Holte 2006) represent the normalised 
expected cost as a function of a probability-cost function (Fig. 5), where the expected cost is normalised by the maximum expected cost that occurs when all cases are incorrectly classified (e.g. when FP and FN are both 1). The maximum normalised cost is 1 and the minimum is 0 .

A single classification model, which would be a single point (FP, TP) in the ROC space, is thus a straight line in the cost curve representation (Fig. 5). The lower the cost curve, the better the accuracy of the model, and the difference between two models is simply the vertical distance between the curves.

In order to implement cost curves, it is necessary to define a value for the probability-cost function, which depends on both the a priori probability and the misclassification costs. For landslide zoning models, given the uncertainty in the observed distribution of the landslide population, a condition of equal probability is a reasonable choice (Frattini et al. 2010).

Misclassification costs are site-specific and vary significantly within the study area. A rigorous analysis would estimate them at each terrain unit independently, and evaluate the total costs arising from the adoption of each model by summing these costs. This requires contributions from the administrators and policy makers of local (municipality) and national authorities. In order to estimate the average cost of false negatives and false positives, a land-use map can be used to calculate both the area occupied by elements potentially at risk (e.g. contributing to false-negative costs) and the area potentially suitable for building development (e.g. contributing to false-positive costs) (Frattini et al. 2010).

For this reason, the predicted susceptibility maps must be carefully analysed and critically reviewed before disseminating the results. The tuning of statistical techniques and independent validation of the results are already recognised to be fundamental steps in any natural hazard study to assess model accuracy and predictive power. Validation may also permit the the degree of confidence in the model to be established and a comparison of the results from different models. For this reason, the spatial agreement among susceptibility maps produced by different models should also be tested, especially if these models have similar predictive powers.

\section{Limits on the use of accuracy statistics}

The application of each statistic is only reliable under specific conditions (e.g. rare events or frequent events) that should be evaluated case by case in order to select the most appropriate method (Stephenson 2000). This is a limitation on their general application to landslide zoning assessments. For statistical models, the application of cutoffdependent accuracy statistics is straightforward and scientifically correct because the cutoff value is statistically significant. This is true only when assuming equal a priori probabilities and equal misclassification costs-conditions that are normally violated by landslide models. For other kinds of zoning models (heuristic, physically based), there is no theoretical reason to select a certain cutoff, and the application of accuracy statistics is therefore not feasible.

Evaluating the performance of landslide zonation maps with cutoff-independent criteria has the advantage that an a priori cutoff value is not required, and the performance can be assessed over the entire range of cutoff values. ROC and SR curves give different results, because the ROC curve is based on an analysis of the classification of the statistical units, and describes the ability of the statistical model to discriminate between two classes of objects, while the SR curve is based on an analysis of spatial matching between actual landslides and zonation maps. Thus, it considers the areas of both the landslides and the terrain units, and not only the number of units correctly or incorrectly classified.

SR curves present some theoretical problems when they are applied to grid-cell models. The number of true positives actually contributes to both the $x$ - and $y$-axes. An increase in true positives causes an upward shift (toward better performance) and a rightward shift (toward worse performance) of the curve. In some cases, the rightward shift can be faster than the upward one, causing an apparent loss of performance with increasing true positives, and this is clearly a misleading evaluation of model performance. Moreover, the SR curve is sensitive to the initial proportions of positives and negatives. Hence, the application of SR curves to areas with a low degree of hazard (e.g. flat areas with small, steep portions of the landscape) will always give better results than their application to areas with a high hazard (e.g. mountain valleys with steep slopes), even if the quality of the classification is exactly the same.

An important restriction is that the abovementioned statistics are not spatially explicit, meaning that similar shapes of ROC and SR curves may reflect different spatial patterns of stable and unstable predicted landscape units (Sterlacchini et al. 2011).

\section{Summary}

This paper reviewed the key components of QRA for landslide hazards, which allows scientists and engineers to quantify risk in an objective and reproducible manner and to compare the results from one location (site, region, etc.) with those from another. It is important to understand that estimates of risk are only estimates. Limitations on the available information and the use of numbers may conceal 
potentially significant errors. In that respect, QRA is not necessarily more accurate than qualitative estimations as, for example, probability may be calculated based on personal judgement. However, QRA facilitates communication between geoscience professionals, land owners and decision makers.

Recommended methodologies for the quantitative analysis of the landslide hazard, vulnerability and risk at different scales (site-specific, local, regional and national) have been presented, as well as verification and validation methods.

The methodologies described here focus on the evaluation of the probabilities of occurrence of different landslide types with certain characteristics. Methods to determine the spatial distribution of landslide intensity, the characterisation of the elements at risk, the assessment of the potential degree of damage and the quantification of the vulnerability of the elements at risk, as well as the QRA, are also described.

The paper is intended for use by scientists and practising engineers, geologists and other landslide experts.

Acknowledgments The authors are grateful for the support of the SafeLand project (grant agreement 226479) funded by the European Commission within its Seventh Framework Programme.

Open Access This article is distributed under the terms of the Creative Commons Attribution License which permits any use, distribution, and reproduction in any medium, provided the original author(s) and the source are credited.

\section{Appendix: Definitions and terminology}

Most of the terms used in this document are consistent with landslide hazard and risk definitions proposed by international committees such as Fell et al. (2008a), TC32 (2004) and UN-ISDR (2004).

Consequence The outcomes or potential outcomes arising from the occurrence of a landslide, expressed qualitatively or quantitatively in terms of loss, disadvantage or gain; damage, injury or loss of life.

Danger The natural phenomenon that could lead to damage, described in terms of its geometry and mechanical and other characteristics. The danger can be an existing one (such as a creeping slope) or a potential one (such as a rock fall). The characterisation of a danger does not include any forecasting.

Elements at risk The population, buildings and engineering structures, economic activities, public services, utilities, infrastructure, cultural and environmental features in the area potentially affected by landslides.
Exposure The presence of people, structures, property, systems, or other elements in zones that may be impacted by landslides.

Frequency A measure of likelihood expressed as the number of occurrences of an event in a given time. See also "likelihood" and "probability".

Hazard A condition with the potential for causing an undesirable consequence. The characterisation of landslide hazard should include the location, volume (or area), classification and velocity of the potential landslides and any resultant detached material, and the probability of their occurrence within a given period of time.

Hazard zoning The subdivision of the terrain into zones that are characterised by the temporal probability of occurrence of landslides of a particular intensity within a given period of time. Landslide hazard maps should indicate the zones where landslides may occur as well as the runout zones.

Individual risk to life The risk of fatality or injury to any identifiable individual who is within the zone impacted by the landslide, or who follows a particular pattern of life that might subject him or her to the consequences of the landslide.

Landslide inventory A record of recognised landslides in a particular area combined with attribute information. These attributes should ideally contain information on the type of landslide, date of occurrence or relative age, size and/or volume, current activity, and causes. Landslide inventories are either continuous in time, or provide socalled event-based landslide inventories, which are inventories of landslides that happened as a result of a particular triggering event (rainfall, earthquake).

Landslide activity The stage of development of a landslide; pre-failure, when the slope is strained throughout but is essentially intact; failure, characterised by the formation of a continuous surface of rupture; post-failure, which includes movement from just after failure to when it essentially stops; and reactivation, when the slope slides along one or several pre-existing surfaces of rupture. Reactivation may be occasional (e.g. seasonal) or continuous (in which case the slide is "active").

Landslide hazard assessment The estimation of the zones where landslides of a particular type, volume, runout and intensity may occur within a given period of time.

Landslide hazard map A map showing the subdivision of the terrain into zones that are characterised by the probability of occurrence of landslides of a particular intensity. Landslide hazard maps should indicate the zones where landslides may occur as well as the runout zones. 
Landslide intensity A set of spatially distributed parameters related to the destructive power of a landslide. The parameters may be described quantitatively or qualitatively, and may include maximum movement velocity, total displacement, differential displacement, depth of the moving mass, peak discharge per unit width or kinetic energy per unit area.

Landslide magnitude The measure of the landslide size. It may be quantitatively described by its volume or (indirectly) by its area. The latter descriptors may refer to the landslide scar, the landslide deposit, or both.

Landslide probability In the framework of landslide hazard, the following types of probability are important:

- Spatial probability: the probability that a given area is hit by a landslide

- Temporal probability: the probability that a given triggering event will cause landslides

- Size/volume probability: the probability that the slide has a given size/volume

- Reach probability: the probability that the slide will travel a certain distance downslope.

Landslide risk map A map showing the subdivision of the terrain into zones that are characterised by different probabilities of losses that might occur due to landslides of a given type within a given period of time. It is usually calculated as

- The expected losses in a particular area struck by a landslide of a given magnitude (intensity) in a given year,

- A recurrence interval, i.e. the expected losses in a particular area struck by the 100-year landslide event, or

- The cumulative losses during a given time interval due to landslides with different return periods.

Landslide susceptibility assessment A quantitative or qualitative assessment of the classifications, volumes (or areas) and spatial distribution of landslides which exist or potentially may occur in an area.

Landslide susceptibility map A map showing the subdivision of the terrain into zones that have a different likelihood of a landslide of a given type occurring. It should indicate the zones where landslides may occur as well as the runout zones.

Likelihood Used as a qualitative description of probability or frequency.

Population at risk All of the people who would be directly exposed to the consequences of landslides.
Probability A measure of the degree of certainty. This measure has a value between zero (impossibility) and 1.0 (certainty). It is an estimate of the likelihood of the magnitude of the uncertain quantity, or the likelihood of the occurrence of the uncertain future event.

Qualitative risk analysis An analysis which uses wordform, descriptive or numerical scales to describe the magnitude of potential consequences and the likelihood that those consequences will occur.

Quantitative risk analysis An analysis based on numerical values of the probability, vulnerability and consequences, and resulting in a numerical value of the risk.

Recurrence interval The long-term average elapsed time between landslide events at a particular site or in a specified area. Also known as "return period".

Reach probability/runout probability The probability that a specified landslide will reach a certain distance.

Residual risk The degree of risk that exists given the presence of risk-mitigation measures.

Risk A measure of the probability and severity of an adverse effect to health, property or the environment. Risk is often defined as the probability of the landslide event multiplied by the consequences.

Risk analysis The use of available information to calculate the risk to individuals, population, property or the environment from hazards. Risk analyses generally contain the following steps: scope definition, hazard identification, vulnerability evaluation and risk estimation.

Risk assessment The process of making a recommendation on whether existing risks are acceptable and present risk control measures are adequate, and if they are not, whether alternative risk control measures are justified or will be implemented. Risk assessment incorporates the risk analysis and risk evaluation phases.

Risk control/risk treatment The process of decision making for managing risk, and the implementation or enforcement of risk mitigation measures and the re-evaluation of its effectiveness from time to time, using the results of risk assessment as one input.

Risk evaluation The stage at which values and judgements enter the decision process, explicitly or implicitly, including consideration of the importance of the estimated risks and the associated social, environmental and economic consequences, in order to identify a range of alternatives for managing the risks.

Risk management The complete process of risk assessment and risk control. 
Societal risk The risk of multiple fatalities, injuries, or disruption of activities in society as a whole: one where society would have to carry the burden of a landslide causing a number of deaths, injuries, financial, environmental, and other losses.

Spatiotemporal probability of the element at risk The probability that the element at risk is in the path of the landslide at the time of its occurrence. It is the quantitative expression of the exposure.

Validation The process of determining the degree to which a model is an accurate representation of the real world from the perspective of the intended uses of the model.

Verification The process of determining that the implementation of the model accurately represents the developer's conceptual description of the model and its solution.

Vulnerability The degree of loss of a given element or set of elements exposed to the occurrence of a landslide of a given magnitude/intensity. It is expressed on a scale of 0 (no loss) to 1 (total loss).

Zoning The act of dividing land into homogeneous areas or domains and then ranking them according to degrees of actual or potential landslide susceptibility, hazard or risk.

It is important that those carrying out landslide mapping use consistent terminology to classify and characterise landslides. It is recommended that the classification and terminology are based on well-known schemes such as Cruden and Varnes (1996), Hungr et al. (2001, 2012), and IAEG (1990).

\section{References}

Abbruzzese JM, Sauthier C, Labiouse V (2009) Considerations on Swiss methodologies for rock fall hazard mapping based on trajectory modelling. Nat Hazards Earth Syst Sci 9:1095-1109

Adams NM, Hand DJ (1999) Comparing classifiers when the misallocations costs are uncertain. Pattern Recogn 32: $1139-1147$

Agliardi F, Crosta GB (2003) High resolution three-dimensional numerical modelling of rockfalls. Int $\mathrm{J}$ Rock Mech Min Sci 40:455-471

Agliardi F, Crosta GB, Zanchi A, Ravazzi C (2009a) Onset and timing of deep-seated gravitational slope deformations in the eastern Alps, Italy. Geomorphology 103:113-129

Agliardi F, Crosta GB, Frattini P (2009b) Integrating rockfall risk assessment and countermeasure design by 3D modelling techniques. Nat Hazards Earth Syst Sci 9:1059-1073

AGS (2000) Landslide risk management concepts and guidelines. Australian Geomechanics Society. Aust Geomech 35(1):49-92

AGS (2007) Guidelines for landslide susceptibility, hazard and risk zoning for land use management. Australian Geomechanics Society Landslide Taskforce Landslide Zoning Working Group. Aust Geomech 42(1):13-36
Akbas SO, Blahut J, Sterlacchini S (2009) Critical assessment of existing physical vulnerability estimation approaches for debris flows. In: Malet JP, Remaitre A, Bogaard T (eds) Proceedings of landslide processes: from geomorphologic mapping to dynamic modelling. CERG Editions, Strasburg, pp 229-233

Amatruda G et al (2004) A key approach: the IMIRILAND project method. In: Bonnard Ch, Forlati F, Scavia C (eds) Identification and mitigation of large landslides risks in Europe. IMIRILAND PROJECT_European Commission-Fifth Framework Program. A.A. Balkema, Amsterdam, pp 13-43

Aleotti P, Chowdhury R (1999) Landslide hazard assessment: summary review and new perspectives. Bull Eng Geol Environ 58:21-44

Alexander ED (2005) Vulnerability to landslides. In: Glade T, Anderson MG, Crozier MJ (eds) Landslide risk assessment. Wiley, London, pp 175-198

Alippi C, Sana D, Scotti F (2004) A training-time analysis of robustness in feed-forward neural networks. In: Proceedings of the International Joint Conference on Neural Networks IJCNN04, Budapest, Hungary. IEEE, New York, pp 2853-2858

Alonso EE, Pinyol NM (2010) Criteria for rapid sliding I: a review of the Vaiont case. Eng Geol 114:198-210

Archetti R, Lamberti A (2003) Assessment of risk due to debris flow events. Nat Hazards Rev 4(3):115-125

Ardizzone F, Cardinali M, Carrara A, Guzzetti F, Reichenbach P (2002) Impact of mapping errors on the reliability of landslide hazard maps. Nat Hazards Earth Syst Sci 2:3-14

Ardizzone F, Cardinali M, Galli M, Guzzetti F, Reichenbach P (2007) Identification and mapping of recent rainfall-induced landslides using elevation data collected by airborne Lidar. Nat Hazards Earth Syst Sci 7:637-650

Asselen SV, Seijmonsbergen AC (2006) Expert-driven semi-automated geomorphological mapping for a mountainous area using a laser DTM. Geomorphology 78(3-4):309-320

ATC (1985) ATC-13: Earthquake damage evaluation data for California. Applied Technology Council, Redwood City

Ayala FJ, Cubillo S, Álvarez A, Domínguez MJ, Laín L, Laín R, Ortíz G (2003) Large scale rockfall reach susceptibility maps in La Cabrera Sierra (Madrid) performed with GIS and dynamic analysis at 1:5,000. Nat Hazards 30:325-340

Azzoni A, La Barbera G, Zaninetti A (1995) Analysis and prediction of rock falls using a mathematical model. Int J Rock Mech Min Sci Geomech Abstr 32:709-724

Baecher GB, Christian JT (2003) Reliability and statistics in geotechnical engineering. Wiley, New York

Bakker MM, Govers G, Kosmas C, Vanacker V, van Oost K, Rounsevell M (2005) Soil erosion as a driver of land-use change. Agric Ecosyst Environ 105(3):467-481

Bathurst JC, Moretti G, El-Hames A, Begueria S, Garcia-Ruiz JM (2007) Modelling the impact of forest loss on shallow landslide sediment yield, Ijuez river catchment, Spanish Pyrenees. Hydrol Earth Syst Sci 11(1):569-583

Baum RL, Godt JW (2010) Early warning of rainfall-induced shallow landslides and debris flows in the USA. Landslides 7:259-272

Baum RL, Savage WZ, Godt JW (2002) TRIGRS-a FORTRAN program for transient rainfall infiltration and grid-based regional slope stability analysis. US Geological Survey Open-File Report 02-0424. Available via http://pubs.usgs.gov/of/2002/ofr-02-424/

Baum R, Coe JA, Godt JW, Harp EL, Reid ME, Savage WZ, Schulz WH, Brien DL, Chleborad AF, McKenna JP, Michael JA (2005) Regional landslide-hazard assessment for Seattle, Washington, USA. Landslides 2:266-279

Begueria S (2006) Validation and evaluation of predictive models in hazard assessment and risk management. Nat Hazards 37(3): 315-329 
Bell R, Glade T (2004) Quantitative risk analysis for landslidesexamples from Bíldudalur, NW-Iceland. Nat Hazard Earth Syst Sci 4(1):117-131

Berardino P, Fornaro G, Lanari R, Sansosti E (2002) A new algorithm for surface deformation monitoring based on small baseline differential interferograms. IEEE Trans Geosci Remote Sens 40(11):2375-2383

Berti M, Simoni A (2007) Prediction of debris flow inundation areas using empirical mobility relationships. Geomorphology 90:144161

Bird JF, Bommer JJ, Crowley H, Pinho R (2006) Modelling liquefaction-induced building damage in earthquake loss estimation. Soil Dyn Earthq Eng 26(1):15-30

Blahut J, Horton P, Sterlacchini S, Jaboyedoff M (2010a) Debris flow hazard modelling on medium scale: Valtellina di Tirano, Italy. Nat Hazards Earth Syst Sci 10:2379-2390

Blahut J, van Westen CJ, Sterlacchini S (2010b) Analysis of landslide inventories for accurate prediction of debris-flow source areas. Geomorphology 119(1-2):36-51

Blijenberg HM (2007) Application of physical modelling of debris flow triggering to field conditions: limitations posed by boundary conditions. Eng Geol 91(1):25-33

Bonham-Carter GF (1994) Geographic information system for geoscientists: modelling with GIS. Pergamon, Oxford, p 398

Borghuis AM, Chang K, Lee HY (2007) Comparison between automated and manual mapping of typhoon-triggered landslides from SPOT-5 imagery. Int J Remote Sens 28:1843-1856

Borter P (1999) Risikoanalyse bei gravitativen Naturgefahren. Bundesamt für Umwelt, Wald und Landschaft, Bern

Bovolin V, Taglialatela L (2002) Proceedings Scritti in onore di Lucio Taglialatela. CNR-GNDCI publ. no. 2811. CNR-GNDCI, Perugia, pp 429-437

Bozzolo D, Pamini R (1986) Simulation of rock falls down a valley side. Acta Mech 63:113-130

Brabb EE (1984) Innovative approaches to landslide hazard mapping. In: 4th Int Symp on Landslides, Toronto, Canada, 16-21 Sept 1984, 1:307-324

Brabb EE, Pampeyan EH, Bonilla MG (1972) Landslide susceptibility in San Mateo County, California. Misc. Field Studies, map MF360 (scale 1:62,500). US Geological Survey, Reston

Brand EW (1988) Special lecture: landslide risk assessment in Hong Kong. In: Proceedings of the V International Symposium on Landslides, Lausanne, Switzerland. A.A. Balkema, Amsterdam, 2:1059-1074

Brardinoni F, Church M (2004) Representing the landslide magnitude-frequency relation, Capilano River Basin, British Columbia. Earth Surf Proc Land 29:115-124

Brenner C (2005) Building reconstruction from images and laser scanning. Int J Appl Earth Obs Geoinf 6(3-4):187-198

Brunetti MT, Guzzetti F, Rossi M (2009) Probability distributions of landslide volumes. Nonlinear Process Geophys 16:179-188

Budetta PB (2002) Risk assessment from debris flows in pyroclastic deposits along a motorway, Italy. Bull Eng Geol Environ 61(4):293-301

Bull WB, Brandon MT (1998) Lichen dating of earthquake-generated regional rockfall events, Southern Alps, New Zealand. GSA Bull 110:60-84

Bull WB, King J, Kong F, Moutoux T, Philips WM (1994) Lichen dating of coseismic landslide hazards in alpine mountains. Geomorphology 10:253-264

Bulut F, Boynukalin S, Tarhan F, Ataoglu E (2000) Reliability of isopleth maps. Bull Eng Geol Environ 58:95-98

Bunce CM, Cruden DM, Morgenstern NR (1997) Assessment of the hazard from rock fall on a highway. Can Geotech J 34:344-356

Calvetti F, Crosta G, Tatarella M (2000) Numerical simulation of dry granular flows: from the reproduction of small-scale experiments to the prediction of rock avalanches. Rivista Italiana di Geotecnica 2000:21-38

Calvo B, Savi F (2009) A real-world application of Monte Carlo procedure for debris flow risk assessment. Comput Geosci 35(5):967-977

Cardinali M (2002) A geomorphological approach to the estimation of landslide hazards and risk in Umbria, Central Italy. Nat Hazards Earth Syst Sci 2:57-72

Carrara A (1983) Multivariate models for landslide hazard evolution. Math Geol 15:403-427

Carrara A, Guzzetti F, Cardinali M, Reichenbach P (1999) Use of GIS technology in the prediction and monitoring of landslide hazard. Nat Hazards 20(2-3):117-135

Casadei M, Dietrich WE, Mille NL (2003) Testing a model for predicting the timing and location of shallow landslide initiation on soil mantled landscapes. Earth Surf Proc Land 28(9):925-950

Cascini L (2008) Applicability of landslide susceptibility and hazard zoning at different scales. Eng Geol 102:164-177

Cascini L, Bonnard Ch, Corominas J, Jibson R, Montero-Olarte J (2005) Landslide hazard and risk zoning for urban planning and development-state of the art report. In: Hungr O, Fell R, Couture R, Eberhardt E (eds) Landslide risk management. A.A. Balkema, Amsterdam, pp 199-235

Cascini L, Cuomo S, Ferlisi S, Sorbino G (2009) Detection of mechanisms for destructive landslides in Campania regionsouthern Italy. In: Picarelli L, Tommasi P, Urciuoli G, Versace P (eds) Proceedings of the Workshop on Rainfall-Induced Landslides: Mechanisms, Monitoring Techniques and Nowcasting Models for Early Warning Systems, vol 1, Naples, 8-10 June 2009. Studio Editoriale Doppiavoce, Napoli, pp 43-51

Catani F, Casagli N, Ermini L, Righini G, Menduni G (2005) Landslide hazard and risk mapping at catchment scale in the Arno River basin. Landslides 2:329-342

Catani F, Segoni S, Falorni G (2007) Accurate basin scale soil depth modelling and its impact on shallow landslides prediction. European Geosciences Union General Assembly 2007, Vienna, Austria. Geophys Res Abstr 9(10828)

Cepeda J, Colonnelli S, Meyer NK, Kronholm K (2012) SafeLand Deliverable D1.5: statistical and empirical models for prediction of precipitation-induced landslides. Available at http://www. safeland-fp7.eu/

Chacón J, Irigaray C, Fernández T, El Hamdouni R (2006) Engineering geology maps: landslides and geographical information systems. Bull Eng Geol Environ 65:341-411

Chau KT, Wong RHC, Liu J, Lee CF (2003) Rockfall hazard analysis for Hong Kong based on rockfall inventory. Rock Mech Rock Eng 36:383-408

Chen K, McAneney J, Blong R, Leigh R, Hunter L, Magill C (2004) Defining area at risk and its effect in catastrophe loss estimation: a dasymetric mapping approach. Appl Geogr 24(2004):97-117

Chung CF, Fabbri AG (1993) Representation of geoscience data for information integration. J Non-Renew Resour 2(2):122-139

Chung CF, Fabbri AG (2003) Validation of spatial prediction models for landslide hazard mapping. Nat Hazards 30(3):451-472

Coe JA, Michael JA, Crovelli RA, Savage WA (2000) Preliminary map showing landslides densities, mean recurrence intervals, and exceedance probabilities as determined from historic records. Open-file report 00-303. USGS, Seattle

Colesanti C, Wasowski J (2006) Investigating landslides with spaceborne Synthetic Aperture Radar (SAR) interferometry. Eng Geol 88:173-199

Collison A, Wade J, Griths S, Dehn M (2000) Modelling the impact of predicted climate change on landslide frequency and magnitude in SE England. Eng Geol 55:205-218

Comegna L, Picarelli L, Bucchignani E, Mercogliano, P (2012) Potential effects of incoming climate changes on the behaviour 
of slow active landslides in clay. Landslides (in press). doi:101007/s10346-012-0339-3

Copons R, Vilaplana JM (2008) Rockfall susceptibility zoning at a large scale: from geomorphological inventory to preliminary land use planning. Eng Geol 102:142-151

Copons R, Vilaplana JM, Linares R (2009) Rockfall travel distance analysis by using empirical models (Solà d'Andorra la Vella, Central Pyrenees). Nat Hazards Earth Syst Sci 9:2107-2118

Cornell CA, Jalayer F, Hamburger RO, Foutch DA (2002) Probabilistic basis for 2000 SAC federal emergency management agency steel moment frame guidelines. J Struct Eng 128:526533

Corominas J, Mavrouli O (2011a) Quantitative risk assessment for buildings due to rockfalls: some achievements and challenges. In: Journée de Rencontre sur les Dangers Naturels 2011, Lausanne, Switzerland, 17-18 Feb 2011 (in press)

Corominas J, Mavrouli O (2011b) Rockfall quantitative risk assessment. In: Lambert S, Nicot F (eds) Rockfall engineering: from prediction to mitigation. Wiley, New York, pp 255-296

Corominas J et al (eds) (2010) SafeLand Deliverable D2.1: overview of landslide hazard and risk assessment practices. Available at http://www.safeland-fp7.eu/

Corominas J, Moya J (2008) A review of assessing landslide frequency for hazard zoning purposes. Eng Geol 102:193-213

Corominas J, Moya J (2010) Contribution of dendrochronology to the determination of magnitude-frequency relationships for landslides. Geomorphology 124:137-149. doi:101016/jgeomorph 201009001

Corominas J, Copons R, Vilaplana JM, Altimir J, Amigó J (2003) Integrated landslide susceptibility analysis and hazard assessment in the principality of Andorra. Nat Hazards 30:421-435

Corominas J, Copons R, Moya J, Vilaplana JM, Altimir J, Amigó J (2005) Quantitative assessment of the residual risk in a rockfall protected area. Landslides 2:343-357

Cozzani V, Zanelli S (2001) An approach to the assessment of domino accidents hazard in quantitative area risk analysis. In: Pasman HJ, Fredholm O, Jacobsson A (eds) Loss prevention and safety promotion in the process industries. Elsevier, Amsterdam, pp 1263-1274

Crosta GB, Agliardi F (2003) A methodology for physically-based rockfall hazard assessment. Nat Hazards Earth Syst Sci 3:407-422

Crosta GB, Frattini P (2003) Distributed modelling of shallow landslides triggered by intense rainfall. Nat Hazards Earth Syst Sci 3(1-2):81-93

Crosta GB, Cucchiaro S, Frattini P (2003) Validation of semiempirical relationships for the definition of debris-flow behaviour in granular materials. In: Rickenmann D, Chen C (eds) Proceedings of the Third International Conference on DebrisFlow Hazards Mitigation: Mechanics, Prediction and Assessment, Davos, Switzerland. Millpress, Rotterdam, pp 821-831

Crosta GB, Agliardi F, Frattini P, Imposimato S (2004) A threedimensional hybrid numerical model for rockfall simulation. Geophys Res Abstr 6:04502

Crosta GB, Imposimato S, Roddeman DG (2008) Numerical modelling of entrainment/deposition in rock and debris-avalanches. Eng Geol 109(1-2):135-145

Crosta GB, Agliardi F, Frattini P, Sosoi R (eds) (2012) SafeLand Deliverable 1.1: landslide triggering mechanisms in Europeoverview and state of the art. Identification of mechanisms and triggers. Available at http://www.safeland-fp7.eu/

Crovelli RA (2000) Probabilistic models for estimation of number and cost of landslides. Open file report 00-249. US Geological Survey, Reston, p 23. http://pubs.usgs.gov/of/2002/ofr-02-424/

Crozier MJ (2005) Multiple occurrence regional landslide events in New Zealand: hazard management issues. Landslides 2:247-256
Crozier MJ, Preston NJ (1999) Modelling changes in terrain resistance as a component of landform evolution in unstable hill country. In: Hergarten S, Neugebauer HJ (eds) Process modelling and landform evolution, lecture notes in earth sciences 78, Springer, Berlin, pp 267-284

Cruden DM, Varnes DJ (1996) Landslide types and processes. In: Turner AT, Schuster RL (eds) Landslides-investigation and mitigation. Transportation Research Board Special Report no. 247. National Academy Press, Washington, DC, pp 36-75

Culshaw MG (2005) From concept towards reality: developing the attributed 3D geological model of the shallow subsurface. Q J Eng Geol Hydrogeol 38:231-284

Dai FC, Lee CF, Ngai YY (2002) Landslide risk assessment and management: an overview. Eng Geol 64:65-87

Davis PA, Goodrich MT (1990) A proposed strategy for the validation of ground-water flow and solute transport models. Technical report. Sandia National Labs, Albuquerque

Del Gaudio V, Pierri P, Wasowski J (2003) An approach to timeprobabilistic evaluation of seismically induced landslide hazard. Bull Seismol Soc Am 93(2):557-569

Den Eeckhaut Van, Vanwalleghem T, Poesen J, Govers G, Verstraeten G, Vandekerckhove L (2006) Prediction of landslide susceptibility using rare events logistic regression: a case-study in the Flemish Ardennes (Belgium). Geomorphology 76(3-4): 392-410

Den Eeckhaut Van, Reichenbach P, Guzzetti F, Rossi M, Poesen J (2009) Combined landslide inventory and susceptibility assessment based on different mapping units: an example from the Flemish Ardennes, Belgium. Nat Hazards Earth Syst Sci 9:507-521

Dietrich WE, Reiss R, Hsu ML, Montgomery DR (1995) A processbased model for colluvial soil depth and shallow landsliding using digital elevation data. Hydrol Process 9:383-400

Dobbs MR, Culshaw MG, Northmore KJ, Reeves HJ, Entwisle DC (2012) Methodology for creating national engineering geological maps of the UK. Q J Eng Geol Hydrogeol 45(3):335-347

D'Odorico P (2000) A possible bistable evolution of soil thickness. J Geophys Res 105(B11):25927-25935

Domaas U (1994) Geometrical methods of calculating rockfall range. Report 585910-1. Norwegian Geotechnical Institute, Oslo

Dorren LKA, Seijmonsbergen AC (2003) Comparison of three GISbased models for predicting rockfall runout zones at a regional scale. Geomorphology 56:49-64

Drummond C, Holte RC (2006) Cost curves: an improved method for visualizing classifier performance. Mach Learn 65(1):95-130

Dussauge-Peisser C, Helmstetter A, Grasso J-R, Hantz D, Desvarreux P, Jeannin M, Giraud A (2002) Probabilistic approach to rock fall hazard assessment: potential of historical data analysis. Nat Hazards Earth Syst Sci 2:15-26

Ermini L, Catani F, Casagli N (2005) Artificial neural networks applied to landslide susceptibility assessment. Geomorphology 66:327-343

Evans SG, Hungr O (1993) The assessment of rockfall hazard at the base of talus slopes. Can Geotech J 30:620-636

Eveleigh TJ, Mazzucchi TA, Sarkani S (2006) Systems engineering design and spatial modelling for improved natural hazard risk assessment. Disaster Prev Manag 15(4):636-648

Eveleigh TJ, Mazzucchi TA, Sarkani S (2007) Spatially-aware systems engineering design modelling applied to natural hazard vulnerability assessment. Syst Eng 10(3):187-202

Fannin RJ, Wise MP (2001) An empirical-statistical model for debris flow travel distance. Can Geotech J 38:982-994

Farina P, Colombo D, Fumagalli A, Marks F, Moretti S (2006) Permanent scatters for landslide investigations: outcomes from the ESA-SLAM project. Eng Geol 88:200-217

Farr TG, Rosen PA, Caro E, Crippen R, Duren R, Hensley S, Kobrick M, Paller M, Rodriguez E, Roth L, Seal D, Shaffer S, Shimada J, 
Umland J, Werner M, Oskin M, Burbank D, Alsdorf D (2007) The Shuttle Radar Topography Mission. Rev Geophys 45:RG2004. doi:101029/2005RG000183

Fell R, Corominas J, Bonnard Ch, Cascini L, Leroi E, Savage WZ (on behalf of the JTC-1 Joint Technical Committee on Landslides and Engineered Slopes) (2008a) Guidelines for landslide susceptibility, hazard and risk zoning for land use planning. Eng Geol 102:85-98

Fell R, Corominas J, Bonnard Ch, Cascini L, Leroi E, Savage WZ (on behalf of the JTC-1 Joint Technical Committee on Landslides and Engineered Slopes) (2008b) Guidelines for landslide susceptibility, hazard and risk zoning for land-use planning. Comment Eng Geol 102:99-111

Fell R, Ho KKS, Lacasse S, Leroi E (2005) A framework for landslide risk assessment and management. In: Hungr O, Fell R, Couture $\mathrm{R}$, Eberhardt $\mathrm{E}$ (eds) Landslide risk management. Taylor and Francis, London, pp 3-26

Ferlisi S, Cascini L, Corominas J, Matano F (2012) Rockfall risk assessment to persons travelling in vehicles along a road: the case study of the Amalfi coastal road (southern Italy). Nat Hazards 62(2):691-721

Ferretti A, Prati C, Rocca F (2001) Permanent scatterers in SAR interferometry. IEEE Trans Geosci Remote Sens 39(1):8-20

Finlay PJ, Fell RA (1996) Study of landslide risk assessment for Hong Kong. School of Engineering Report. The University of New South Wales, Sydney

Finlay PJ, Mostyn GR, Fell R (1999) Landslide risk assessment: prediction of travel distance. Can Geotech J 36:556-562

Fisher PF, Tate NJ (2006) Causes and consequences of error in digital elevation models. Prog Phys Geogr 30:467

Fotopoulou S, Pitilakis K (2013a) Vulnerability assessment of reinforced concrete buildings subjected to seismically triggered slow-moving earth slides. Landslides 10:563-582. doi:101007/ s10346-012-0345-5

Fotopoulou S, Pitilakis K (2013b) Fragility curves for reinforced concrete buildings to seismically triggered slow-moving slides. Soil Dyn Earthq Eng 48:143-161

Frattini P, Crosta GB, Sosio R (2009) Approaches for defining thresholds and return periods for rainfall-triggered shallow landslides. Hydrol Process 23(10):1444-1460

Frattini P, Crosta GB, Carrara A (2010) Techniques for evaluating the performance of landslide susceptibility models. Eng Geol 111:62-72

Frattini P, Crosta GB, Lari S, Agliardi F (2012) Probabilistic rockfall hazard analysis (PRHA). In: Eberhardt E, Froese C, Turner AK, Leroueil S (eds) Landslides and engineered slopes: protecting society through improved understanding. Taylor \& Francis, London, pp 1145-1151

Friele P, Jakob M, Clague J (2008) Hazard and risk from large landslides from Mount Meager Volcano, British Columbia, Canada. Georisk 2(1):48-64

Fuchs S (2008) Vulnerability to torrent events-empirical evidence from Austria. Geophys Res Abstr 10:04632. ISSN 1029-7006

Fuchs S, Heiss K, Hübl J (2007) Towards an empirical vulnerability function for use in debris flow risk assessment. Nat Hazards Earth Syst Sci 7:495-506

Gentile F, Bisantino T, Trisorio Liuzzi G (2008) Debris-flow risk analysis in south Gargano watersheds (Southern Italy). Nat Hazards 44:1-17

GEO (2006) Assessment of landslide risk in natural hillsides in Hong Kong. Report no. 191. Hong Kong Geotechnical Engineering Office, Hong Kong, p 117

GEO-SLOPE (2011) SLOPE/W. GEO-SLOPE International, Calgary. http://www.geo-slope.com

Ghosh S, Günther A, Carranza EJM, van Westen CJ, Jetten VG (2010) Rock slope instability assessment using spatially distributed structural orientation data in Darjeeling Himalaya (India). Earth Surf Proc Land 35(15):1773-1792

Ghosh S, van Westen CJ, Carranza EJ, Jetten VG (2011) Integrating spatial, temporal, and magnitude probabilities for medium-scale landslide risk analysis in Darjeeling Himalayas, India. Landslides 9:371-384

Gilbert GF (1884) Finley's tornado predictions. Am Meteorol J $1: 166-172$

Gitirana Jr G, Santos M, Fredlund M (2008) Three-dimensional slope stability model using finite element stress analysis. In: GeoCongress 2008, New Orleans, LA, USA, 9-12 March 2008, pp 191-198

Glade T (2003) Landslide occurrence as a response to land use change: a review of evidence from New Zealand. Catena 51(3-4, 1):297-314

Glade T, Crozier MJ (2005) A review of scale dependency in landslide hazard and risk analysis. In: Glade T, Anderson M, Crozier MJ (eds) Landslide hazard and risk. Wiley, London, pp $75-138$

Glade T, Anderson M, Crozier MJ (2005) Landslide hazard and risk. Wiley, Chichester, p 802

Godt JW, Baum RL, Savage WZ, Salciarini D, Schulz WH, Harp EL (2008) Transient deterministic shallow landside modelling: requirements for susceptibility and hazard assessment in a GIS framework. Eng Geol 102:214-226

Gorsevski PV, Gessler P, Foltz RB (2000) Spatial prediction of landslide hazard using discriminant analysis and GIS. In: GIS in the Rockies 2000 Conference and Workshop: Applications for the 21st Century, Denver, CO, USA, 25-27 Sept 2000

Gorsevski PV, Gessler PE, Foltz RB, Elliot WJ (2006a) Spatial prediction of landslide hazard using logistic regression and ROC analysis. Trans GIS 10(3):395-415

Gorsevski PV, Gessler PE, Boll J, Elliot WJ, Foltz RB (2006b) Spatially and temporally distributed modelling of landslide susceptibility. Geomorphology 80(3-4):178-198

Gorum T, Fan X, van Westen CJ, Huang RQ, Xu Q, Tang C, Wang G (2011) Distribution pattern of earthquake-induced landslides triggered by the 12 May 2008 Wenchuan earthquake. Geomorphology 133(3-4):152-167

Govi M, Sorzana PF (1980) Landslide susceptibility as function of critical rainfall amount in Piedmont basins (NorthWestern Italy). Studia Geomorphologica Carpatho-Balcanica 14:43-61

Granger K, Jones T, Leiba M, Scott G (1999) Community risks in Cairns: a multi-hazard risk assessment. Australian Geological Survey Organisation, Canberra

Gray DH, Megahan WF (1981) Forest vegetation removal and slope stability in the Idaho Batholith. Research paper INT-97. USDA, Washington, DC, p 34

Guimaraes RF, Montgomery DR, Greenberg HM, Fernandes NF, Trancoso Gomes RA, de Carvalho J, Osmar A (2003) Parameterization of soil properties for a model of topographic controls on shallow landsliding: application to Rio de Janeiro. Eng Geol 69(1-2):99-108

Günther A (2003) SLOPEMAP: programs for automated mapping of geometrical and kinematical properties of hard rock hill slopes. Comput Geosci 29:865-875

Gustavsson M, Kolstrup E, Seijmonsbergen AC (2006) A new symbol-and-GIS based detailed geomorphological mapping system: renewal of a scientific discipline for understanding landscape development. Geomorphology 77(1-2):90-111

Guthrie RH, Evans SG (2004) Analysis of landslide frequencies and characteristics in a natural system. Coast British Columbia Earth Surf Process Landf 29:1321-1339

Guthrie RH, Deadman PJ, Raymond Cabrera A, Evans SG (2008) Exploring the magnitude-frequency distribution: a cellular automata model for landslides. Landslides 5:151-159 
Guzzetti F, Carrara A, Cardinali M, Reichenbach P (1999) Landslide hazard evaluation: a review of current techniques and their application in a multi-scale study. Central Italy Geomorphol 31(1-4):181-216

Guzzetti F, Cardinali M, Reichenbach P, Carrara A (2000) Comparing landslide maps: a case study in the upper Tiber River Basin, central Italy. Environ Manage 25(3):247-363

Guzzetti F, Crosta G, Detti R, Agliardi F (2002a) STONE: a computer program for the three-dimensional simulation of rock-falls. Comput Geosci 28:1081-1095

Guzzetti F, Malamud BD, Turcotte DL, Reichenbach P (2002b) Power-law correlations of landslide areas in central Italy. Earth Planet Sci Lett 195:169-183

Guzzetti F, Reichenbach P, Wieczorek GF (2003) Rockfall hazard and risk assessment in the Yosemite Valley, California, USA. Nat Hazards Earth Syst Sci 3:491-503

Guzzetti F, Galli M, Reichenbach P, Ardizzone F, Cardinali M (2005) Landslide hazard assessment in the Collazzone area, Umbria, Central Italy. Nat Hazards Earth Syst Sci 6:115-131

Guzzetti F, Reichenbach P, Ardizzone F, Cardinali M, Galli M (2006) Estimating the quality of landslide susceptibility models. Geomorphology 81(1-2):166-184

Guzzetti F, Peruccaci S, Rossi M, Stark C (2007) Rainfall thresholds for the initiation of landslides in central and southern Europe. Meteorol Atmos Phys 98(3):239-267

Guzzetti F, Peruccaci S, Rossi M, Stark C (2008) The rainfall intensity-duration control of shallow landslides and debris flows: an update. Landslides 5:3-17

Guzzetti F, Mondini AS, Cardinali M, Fiorucci F, Santangelo M, Chan KT (2012) Landslide inventory maps: new tools for an old problem. Earth Sci Rev 112:42-66

Haneberg WC (2004) A rational probabilistic method for spatially distributed landslide hazard assessment. Environ Eng Geosci $\mathrm{X}: 27-43$

Hanley JA, McNeil BJ (1982) The meaning and use of the area under a receiver operating characteristic (ROC) curve. Radiology 143(1):29-36

Hardingham AD, Ho KKS, Smallwood ARH, Ditchfield CS (1998) Quantitative risk assessment of landslides-a case history from Hong Kong. In: Proceedings of the seminar on geotechnical risk management. Geotechnical Division, Hong Kong Institution of Engineers, Hong Kong, pp 145-152

Hart RD (1993) An introduction to distinct element modelling for rock engineering. In: Hudson JA (ed) Comprehensive rock engineering. Pergamon, Oxford

Haugen ED, Kaynia AM (2008) Vulnerability of structures impacted by debris flow. In: Chen Z-Y, Zhang J-M, Ho K, Wu F-Q, Li Z-K (eds) Landslides and engineered slopes. Taylor \& Francis, London, pp 381-387

Haugerud RA, Harding DJ, Johnson SY, Harless JL, Weaver CS, Sherrod BL (2003) High-resolution LiDAR topography of the Puget Lowland. Washington-a bonanza for earth science. GSA Today 13:4-10

Heidke P (1926) Berechnung des Erfolges und der Güte der Windstärkevorhersagen im Sturmwarnungdienst (Calculation of the success and goodness of strong wind forecasts in the storm warning service). Geografika Annaler 8:301-349

Hengl T, Heuvelink GBM, Stein A (2004) A generic framework for spatial prediction of soil variables based on regression-kriging. Geoderma 120(1-2):75-93

Hervás J, Barredo JI, Rosin PL, Pasuto A, Mantovani F, Silvano S (2003) Monitoring landslides from optical remotely sensed imagery: the case history of Tessina landslide, Italy. Geomorphology 54:63-75

Heuvelink GBM (1998) Error propagation in environmental modelling with GIS. Taylor \& Francis, London, p 127
Ho KKS, Ko FWY (2009) Application of quantified risk analysis in landslide risk management practice: Hong Kong experience. Georisk 3:134-146

Ho KKS, Leroi E, Roberds B (2000) Quantitative risk assessmentapplication, myths and future direction. In: Proceedings of the International Conference on Geotechnical and Geological Engineering (GeoEng2000), Melbourne, Australia, 9-24 Nov 2000, $1: 269-312$

Hoblitt RP, Walder JS, Driedger CL, Scott KM, PringlePT, Vallance JW (1998) Volcano hazards from Mount Rainier, Washington. Revised open-file report 98-428. USGS, Reston

Hoek E, Grabinsky MW, Diederichs MS (1993) Numerical modelling for underground excavations. Trans Inst Min Metall Sect A 100:A22-A30

Homma T, Saltelli A (1996) Importance measures in global sensitivity analysis for nonlinear models. Reliab Eng Syst Saf 52:1-17

Hong Y, Adler R, Huffman G (2007) Use of satellite remote sensing data in the mapping of global landslide susceptibility. Nat Hazards 43:245-256

Horton P, Jaboyedoff M, Bardou E (2008) Debris flow susceptibility mapping at a regional scale. In: Locat J, Perret D, Turmel D, Demers D, Leroueil S (eds) Proceedings of the 4th Canadian Conference on Geohazards: From Causes to Management. Presse de l'Université Laval, Québec, pp 399-406

Hovius N, Stark CP, Allen PA (1997) Sediment flux from a mountain belt derived by landslide mapping. Geology 25:231-234

Hsü KJ (1975) Catastrophic debris stream (sturzstroms) generated by rockfalls. Geol Soc Am Bull 86:129-140

Humbert M (1972) Les mouvements de terrains. Principes de réalisation d'une carte prévisionnelle dans les Alpes. Bull du BRGM Sect III 1:13-28

Hungr O (1995) A model for the run out analysis of rapid flow slides, debris flows and avalanches. Can Geotech J 32:610-623

Hungr O (1997) Some methods of landslide hazard intensity mapping. In: Cruden D, Fell R (eds) Landslide risk assessment. A.A. Balkema, Rotterdam, pp 215-226

Hungr O, Evans SG (1988) Engineering evaluation of fragmental rockfall hazards. In: Bonnard C (ed) 5th International Symposium on Landslides, vol 1. A.A. Balkema, Lausanne, pp 685-690

Hungr O, Evans SG, Hazzard J (1999) Magnitude and frequency of rock falls and rock slides along the main transportation corridors of south-western British Columbia. Can Geotech J 36:224238

Hungr O, Evans SG, Bovis MJ, Hutchinson JN (2001) A review of the classification of landslides of the flow type. Environ Eng Geosci VII(3):221-238

Hungr O, Corominas J, Eberhardt E (2005) Estimating landslide motion mechanism, travel distance and velocity - state of the art report. In: Hungr O, Fell R, Couture R, Eberhardt E (eds) Landslide risk management. A.A. Balkema, Amsterdam, pp $99-128$

Hungr O, McDougall S, Wise M, Cullen M (2008) Magnitudefrequency relationships of debris flows and debris avalanches in relation to slope relief. Geomorphology 96:355-365

Hungr O, Leroueil S, Picarelli L (2012) Varnes classification of landslide types, an update. In: Eberhardt E, Froesse C, Turner AK, Leroueil $\mathrm{S}$ (eds) Landslides and engineered slopes: protecting society through improved understanding, vol 1. CRC Press, Boca Raton, pp 47-58

Hürlimann M, Copons R, Altimir J (2006) Detailed debris flow hazard assessment in Andorra: a multidisciplinary approach. Geomorphology 78(3-4):359-372

Hürlimann M, Rickenmann D, Medina V, Bateman A (2008) Evaluation of approaches to calculate debris-flow parameters for hazard assessment. Eng Geol 102:152-163 
Hutchinson JN (1986) A sliding-consolidation model for flow slides. Can Geotech J 23:115-126

IAEG Commission on Landslides (1990) Suggested nomenclature for landslides. Bull Int Assoc Eng Geol 41:13-16

IUGS Working Group on Landslides, Committee on Risk Assessment (1997) Quantitative risk assessment for slopes and landslidesthe state of the art. In: Cruden D, Fell R (eds) Landslide risk assessment. A.A. Balkema, Amsterdam, pp 3-12

Iverson RM (2000) Landslide triggering by rain infiltration. Water Resour Res 36:1897-1910

Iverson RI, Denlinger RP (2001) Flow of variably fluidized granular masses across three dimensional terrain. Coulomb mixture theory. J Geophys Res 106(B1):537-552

Iverson RM, Schilling SP, Vallance JW (1998) Objective delineation of lahar-inundation hazard zones. Geol Soc Am Bull 110(8):972-984

Jaboyedoff M (2003) Conefall v.10: a program to estimate propagation zones of rockfall, based on cone method. Quanterra, Lausanne. http://www.quanterra.com

Jaboyedoff M, Labiouse V (2003) Preliminary assessment of rockfall hazard based on GIS data. In: ISRM 2003: Technology Roadmap for Rock Mechanics, Gauteng, South Africa, 8-12 Sept 2003, pp 575-578

Jaboyedoff M, Labiouse V (2011) Preliminary estimation of rockfall runout zones. Nat Hazards Earth Syst Sci 11:819-828

Jaboyedoff M, Dudt JP, Labiouse V (2005) An attempt to refine rockfall hazard zoning based on the kinetic energy, frequency and fragmentation degree. Nat Hazards Earth Syst Sci 5:621-632

Jaboyedoff M, Oppikofer T, Abellán A, Derron M-H, Loye A, Metzger R, Pedrazzini A (2012) Use of LIDAR in landslide investigations: a review. Nat Hazards 61(1):5-28

Jaiswal P, van Westen CJ (2009) Estimating temporal probability for landslide initiation along transportation routes based on rainfall thresholds. Geomorphology 112:96-105

Jaiswal P, van Westen CJ, Jetten V (2010) Quantitative assessment of direct and indirect landslide risk along transportation lines in southern India. Nat Hazards Earth Syst Sci 10(6):1253-1267

Jaiswal P, van Westen CJ, Jetten V (2011) Quantitative estimation of landslide risk from rapid debris slides on natural slopes in the Nilgiri hills, India. Nat Hazards Earth Syst Sci 11:17231743

Jakob M (1996) Morphometric and geotechnical controls of debrisflow frequency and magnitude in southwestern British Columbia. Ph.D. thesis. Geography Department, The University of British Columbia, Vancouver

Jakob M (2005) A size classification for debris flows. Eng Geol 79:151-161

Jakob M (2012) The fallacy of frequency. Statistical techniques for debris flow frequency magnitude analysis. In: Proceedings of the International Landslide Conference, Banff, Canada, 2-8 June 2012, 1:741-750

Jakob M, Friele P (2010) Frequency and magnitude of debris flows on Cheekye River British Columbia. Geomorphology 114:382-395

Jakob M, Weatherly H (2005) Debris flow hazard and risk assessment. Jones Creek, Washington. In: Hungr O, Fell R, Couture R, Eberhardt E (eds) Landslide risk management proceedings. Taylor \& Francis, London, pp 533-542

Jakob M, Stein D, Ulmi M (2012) Vulnerability of buildings to debris flow impact. Nat Hazards 60:241-261

Jibson RW, Harp EL, Michael JA (1998) A method for producing digital probabilistic seismic landslide hazard maps: an example from the Los Angeles, California, area. Open file report. US Geological Survey, Reston, pp 98-113

Jones CL, Higgins JD Andrew RD (2000) Colorado Rock Fall Simulation Program, version 40. Colorado Department of Transportation, Colorado Geological Survey, Denver
Jongmans D, Garambois S (2007) Geophysical investigation of landslides: a review. Bull Soc Geol France 178:101-112

Kääb A (2010) Photogrammetry for early recognition of high mountain hazards: new techniques and applications. Phys Chem Earth Part B 25(9):765-770

Kanungo DP, Arora MK, Sarkar S, Gupta RP (2006) A comparative study of conventional, ANN black box, fuzzy and combined neural and fuzzy weighting procedures for landslide susceptibility zonation in Darjeeling Himalayas. Eng Geol 85(3-4):347-366

Kappes M, Keiler M, Glade T (2010) From single- to multi-hazard risk analyses: a concept addressing emerging challenges. In: Malet JP, Glade T, Casagli N (ed) Proc Int Conf on Mountain Risks: Bringing Science to Society, Firenze, Italy, 24-26 Nov 2010, pp 351-356

Kaynia AM, Papathoma-Köhle M, Neuhäuser B, Ratzinger K, Wenzel H, Medina-Cetina Z (2008) Probabilistic assessment of vulnerability to landslide: application to the village of Lichtenstein, Baden-Württemberg, Germany. Eng Geol 101:33-48

Keefer DK (1984) Landslides caused by earthquakes. Geol Soc Am Bull 95(4):406-421

Keefer DK (2002) Investigating landslides caused by earthquakes-a historical review. Surv Geophys 23:473-510

Kienholz H (1978) Map of geomorphology and natural hazards of Grindelwald, Switzerland, scale 1:10,000. Artic Alp Res 10:169-184

King D, MacGregor C (2000) Using social indicators to measure community vulnerability to natural hazards. Aust $\mathrm{J}$ Emerg Manag 15(3):52-57

Koutsourelakis PS (2010) Assessing structural vulnerability against earthquakes using multi-dimensional fragility surfaces: a Bayesian framework. Probab Eng Mech 25:49-60

Kramer SL (1996) Geotechnical earthquake engineering. PrenticeHall, Englewood Cliffs

Kuriakose SL (2010) Physically-based dynamic modelling of the effect of land use changes on shallow landslide initiation in the Western Ghats of Kerala, India. Ph.D. thesis. University of Utrecht, Utrecht, ISBN 978-90-6164-298-5

Kuriakose SL, Devkota S, Rossiter DG, Jetten VJ (2009) Prediction of soil depth using environmental variables in an anthropogenic landscape, a case study in the Western Ghats of Kerala, India. Catena 79(1):27-38

Lacasse S, Eidsvik U, Nadim F, Hoeg K, Blikra LH (2008) Event tree analysis of Aknes rock slide hazard. In: 4th Canadian Conf on Geohazards, Quebec City, Canada, 20-24 May 2008, pp 551-557

Laigle D, Coussot P (1997) Numerical modelling of mudflows. J Hydraul Eng ASCE 123(7):617-623

Lee S (2005) Application of logistic regression model and its validation for landslide susceptibility mapping using GIS and remote sensing data. Int J Remote Sens 26(7):1477-1491

Lee EM, Jones DKC (2004) Landslide risk assessment. Thomas Telford, London, p 454

Lee EM, Brunsden D, Sellwood M (2000) Quantitative risk assessment of coastal landslide problems. In: Bromhead E, Dixon N, Ibsen M-L (eds) Landslides in Research Theory and Practice: Eighth International Symposium on Landslides. Thomas Telford, London, 2:899-904

Lee EM, Meadowcroft IC, Hall JW, Walkden M (2002) Coastal landslide activity: a probabilistic simulation model. Bull Eng Geol Environ 61:347-355

Lee S, Ryu J-H, Won J-S, Park H-J (2004) Determination and application of the weights for landslide susceptibility mapping using an artificial neural network. Eng Geol 71(3-4):289-302

Leroi E, Bonnard Ch, Fell R, McInnes R (2005) Risk assessment and management-state of the art report. In: Hungr O, Fell R, 
Couture R, Eberhardt E (eds) Landslide risk management. A.A. Balkema, Amsterdam, pp 159-198

Leroueil S (2001) Natural slopes and cuts: movement and failure mechanisms. Géotechnique 51(3):197-243

Leroueil S, Locat J, Vaunat J, Picarelli L, Faure R (1996) Geotechnical characterisation of slope movements. In: Proc VII Int Symp on Landslides, Trondheim, Norway, 17-21 June 1996, 1:53-74

Lewis J (1984) Multi-hazard history of Antigua. Disasters 8(3):190-197

Li T (1983) A mathematical model for predicting the extent of a major rockfall. Z Geomorphol 24:473-482

Li Z, Nadim F, Huang H, Uzielli M, Lacasse S (2010) Quantitative vulnerability estimation for scenario-based landslide hazards. Landslides 7(2):125-134

Lopez Saez J, Corona C, Stoffel M, Schoeneich P, Berger F (2012) Probability maps of landslide reactivation derived from tree-ring records: Pra Bellon landslide, southern French Alps. Geomorphology 138:189-202

Lu P, Stumpf A, Kerle N, Casagli N (2011) Object-oriented change detection for landslide rapid mapping. IEEE Geosci Remote Sens Lett 99:701-705

Luzi L (1995) Application of favourability modelling to zoning of landslide hazard in the Fabriano Area, Central Italy. In: Proc First Joint Eur Conf \& Exhibition on Geographical Information, The Hague, Netherlands, 26-31 March 1995, pp 398-402

Malamud BD, Turcotte DL, Guzzetti F, Reichenbach P (2004) Landslide inventories and their statistical properties. Earth Surf Proc Land 29:687-711

Malet J-P, Maquaire O, Locat J, Remaître A (2004) Assessing debris flow hazard associated with slow moving landslides: methodology and numerical analyses. Landslides J Int Consortium Landslides 1:83-90

Malet J-P, van Asch ThWJ, van Beek R, Maquaire O (2005) Forecasting the behaviour of complex landslides with a spatially distributed hydrological model. Nat Hazards Earth Syst Sci 5(1):71-85

Mansour MF, Morgenstern NI, Martin CD (2011) Expected damage from displacement of slow-moving slides. Landslides 8(1):117-131

Martha TR, Kerle N, Jetten V, van Westen CJ, Kumar KV (2010a) Characterising spectral, spatial and morphometric properties of landslides for semi-automatic detection using object-oriented methods. Geomorphology 116(1-2):24-36

Martha TR, Kerle N, Jetten V, van Westen CJ, Vinod Kumar K (2010b) Landslide volumetric analysis using Cartosat-1-derived DEMs. Geosci Remote Sens Lett EEE 7(3):582-586

Marzocchi W, Garcia-Aristizabal A, Gasparini P, Mastellone ML, Di Ruocco A (2012) Basic principles of multi-risk assessment: a case study in Italy. Nat Hazards 62:551-573

Matthews JA, Brunsden D, Frenzel B, Gläser B, Weiß MM (1997) Rapid mass movement as a source of climatic evidence for the Holocene. Paleoclimate Res 19:444

Mavrouli O, Corominas J (2010a) Rockfall vulnerability assessment for reinforced concrete buildings. Nat Hazards Earth Syst Sci 10:2055-2066

Mavrouli O, Corominas J (2010b) Vulnerability of simple reinforced concrete buildings in front of the rockfall impact. Landslides 7(2):169-180

McDougall S, Hungr O (2004) A model for the analysis of rapid landslide run out motion across three dimensional terrain. Can Geotech J 41:1084-1097

Melchiorre C, Frattini P (2012) Modelling probability of rainfallinduced shallow landslides in a changing climate, Otta, Central Norway. Clim Chang 113(2):413-436
Melchiorre C, Castellanos Abella EA, van Westen CJ, Matteucci M (2011) Evaluation of prediction capability, robustness, and sensitivity in non-linear landslide susceptibility models, Guantánamo, Cuba. Comput Geosci 37(4):410-425

METI/NASA (2009) ASTER Global Digital Elevation Model. Ministry of Economy, Trade and Industry of Japan (METI)/ National Aeronautics and Space Administration (NASA), Tokyo/Washington, DC. http://asterweb.jpl.nasa.gov/gdem.asp and http://www.gdem.ersdac.jspacesystems.or.jp

Metternicht G, Hurni L, Gogu R (2005) Remote sensing of landslides: an analysis of the potential contribution to geo-spatial systems for hazard assessment in mountainous environments. Remote Sens Environ 98(23):284-303

Meunier P, Hovius N, Haines AJ (2007) Regional patterns of earthquake-triggered landslides and their relation to ground motion. Geophys Res Lett 34(20):L20408

Michoud C, Abellán A, Derron MH, Jaboyedoff M (eds) (2010) SafeLand Deliverable D4.1: review of techniques for landslide detection, fast characterization, rapid mapping and long-term monitoring. Available at http://www.safeland-fp7.eu/

Michoud C, Derron MH, Hortin P, Jaboyedoff M, Baillifard FJ, Loye A, Nicolet P, Pedrazzini A, Queyrel A (2012) Rockfall hazard and risk assessments along roads at a regional scale: example in Swiss Alps. Nat Hazards Earth Syst Sci 12:615-629

Miles SB, Keefer DK (2009) Evaluation of CAMEL—comprehensive areal model of earthquake-induced landslides. Eng Geol 104:1-15

Miller DJ, Sias J (1998) Deciphering large landslides: linking hydrological groundwater and stability models through GIS. Hydrol Process 12:923-941

Mondini AC, Guzzetti F, Reichenbach P, Rossi M, Cardinali M, Ardizzone M (2011) Semiautomatic recognition and mapping of rainfall induced shallow landslides using optical satellite images. Remote Sens Environ 115(7):1743-1757

Montgomery DR, Dietrich WE (1994) A physically based model for the topographic control on shallow landsliding. Water Resour Res 30(4):1153-1171

Nadim F, Kjeksta O (2009) Assessment of global high-risk landslide disaster hotspots. In: Sassa K, Canuti P (eds) Landslides-diaster risk reduction. Springer, Berlin, pp 213-221

Nadim F, Kjekstad O, Peduzzi P, Herold C, Jaedicke C (2006) Global landslide and avalanche hotspots. Landslides 3(2):159-174

Negulescu C, Foerster E (2010) Parametric studies and quantitative assessment of the vulnerability of a RC frame building exposed to differential settlements. Nat Hazards Earth Syst Sci 10: 1781-1792

Nelson A, Reute HI, Gessler P (2009) Chapter 3: DEM production methods and sources. In: Hengl T, Reute HI (eds) Developments in soil science, vol 33. Elsevier, Amsterdam, pp 65-85

NIBS (2004) Earthquake loss estimation methodology HAZUS. National Institute of Building Sciences, FEMA, Washington, DC

Nielson BG, DesRoches R (2007) Analytical seismic fragility curves for typical bridges in the Central and Southeastern United States. Earthq Spectra 23(3):615

Niethammer U, James MR, Rothmund S, Travelletti J, Joswig M (2011) Very high spatial resolution monitoring of the SuperSauze landslide with an UAV-based remote sensing technique. Eng Geol. doi:101016/jenggeo201103012

OFAT, OFEE, OFEFP (1997) Recommandations 1997: prise en compte des dangers dus aux mouvements de terrain dans le cadre des activités de l'aménagement du territoire. OCFIM, Berne, p 42

Ohlmacher GC, Davis JC (2003) Using multiple logistic regression and GIS technology to predict landslide hazard in northeast Kansas. USA Eng Geol 69(33):331-343 
Pack RT, Tarboton DG, Goodwin CN (1998) The SINMAP approach to terrain stability mapping. In: 8th Congr Int Assoc Eng Geol, Vancouver, Canada, 21-25 Sept 1998

Papathoma-Köhle M, Keiler M, Totschnig R, Glade T (2012) Improvement of vulnerability curves using data from extreme events: a debris-flow event in South Tyrol. Nat Hazards 64:2083-2105

Pastor M, Quecedo M, Fernández Merodo JA, Herreros MI, González E, Mira P (2002) Modelling tailing dams and mine waste dumps failures. Geotechnique LII(8):579-592

Pastor M, Haddad B, Sorbino G, Cuomo S, Drempetic V (2009) A depth-integrated, coupled SPH model for flow-like landslides and related phenomena. Int $\mathrm{J}$ Numer Anal Meth Geomech 33:143-172

Peirce CS (1884) The numerical measure of the success of predictions. Science 4:453-454

Pelletier JD, Malamud BD, Blodgett T, Turcotte DL (1997) Scaleinvariance of soil moisture variability and its implications for the frequency-size distribution of landslides. Eng Geol 48:255-268

Penížek V, Borůvka L (2006) Soil depth prediction supported by primary terrain attributes: a comparison of methods. Plant Soil Environ 52(9):424-430

Petley DN (2012) Landslides and engineered slopes: protecting society through improved understanding. In: Eberhardt E, Froese C, Turner AK, Leroueil S (eds) Landslides and engineered slopes, vol 1. CRC, London, pp 3-13

Pfeiffer TJ, Bowen TD (1989) Computer simulations of rockfalls. Bull Assoc Eng Geol 26:135-146

Pike RJ (2000) Geomorphometry-diversity in quantitative surface analysis. Prog Phys Geogr 24(1):1-20

Pinyol NM, Alonso EE (2010) Criteria for rapid sliding II: thermohydro-mechanical and scale effects in Vaiont case. Eng Geol 114:211-227

Piteau DR, Clayton R (1976) Computer rockfall model. In: Proc Meeting on Rockfall Dynamics and Protective Work Effectiveness, ISMES, Bergamo, Italy, 20-21 May 1976, pp 123-125

Pitilakis K, Fotopoulou S et al (eds) (2011) SafeLand Deliverable D2.5: physical vulnerability of elements at risk to landslides: methodology for evaluation, fragility curves and damage states for buildings and lifelines. Available at http://www.safeland-fp7. $\mathrm{eu} /$

Porter K, Eeri M, Kennedy R, Bachman R (2007) Creating fragility functions for performance-based earthquake engineering. Background Object Eng 23(2):471-489

Prochaska AB, Santi PM, Higgins JD, Cannon SH (2008) Debris-flow runout predictions based on the average channel slope (ACS). Eng Geol 98:29-40

Provost F, Fawcett T (1997) Analysis and visualization of classifier performance: comparison under imprecise class and cost distributions. In: Proceedings of the Third International Conference on Knowledge Discovery and Data Mining. AAAI, Menlo Park, pp 43-48

Provost F, Fawcett T (2001) Robust classification for imprecise environments. Mach Learn 42(3):203-231

Quan Luna B, Blahut J, Van Westen CJ, Sterlacchini S, van Asch TWJ, Akbas SO (2011) The application of numerical debris flow modelling for the generation of physical vulnerability curves. Nat Hazards Earth Syst Sci 11:2047-2060. doi:10.5194/nhess11-2047-2011

Quecedo M, Pastor M, Herreros MI, Fernandez Merodo JA (2004) Numerical modelling of the propagation of fast landslides using the finite element method. Int J Numer Meth Eng 59(6):755-794

Quinn PE, Hutchinson DJ, Diederichs MS, Rowe RK (2011) Characteristics of large landslides in sensitive clay in relation to susceptibility, hazard, and risk. Can Geotech J 48:12121232
Razak KA, Straatsma MW, van Westen CJ, Malet J-P, de Jong SM (2011) Airborne laser scanning of forested landslides characterization: terrain model quality and visualization. Geomorphology 126:186-200

Reid LM, Page MJ (2003) Magnitude and frequency of landsliding in a large New Zealand catchment. Geomorphology 49:71-88

Remondo J, Bonachea J, Cendrero A (2005) A statistical approach to landslide risk modelling at basin scale: from landslide susceptibility to quantitative risk assessment. Landslides 2:321-328

Remondo J, Bonachea J, Cendrero A (2008) Quantitative landslide risk assessment and mapping on the basis of recent occurrences. Geomorphology 94:496-507

Rickenmann D (1999) Empirical relationships for debris flows. Nat Hazards 19:47-77

Rickenmann D (2005) Runout prediction methods. In: Jakob M, Hungr O (eds) Debris-flow hazards and related phenomena. Praxis, Chichester, pp 305-324

Roberds W (2005) Estimating temporal and spatial variability and vulnerability. In: Hungr O, Fell R, Couture R, Eberhardt E (eds) Landslide risk management. Taylor \& Francis, London, pp 129-158

Roberds WJ, Ho KKS (1997) A quantitative risk assessment and risk management methodology for natural terrain in Hong Kong. In: First ASCE Int Conf on Debris-Flow Hazards Mitigation: Mechanics, Prediction and Assessment, San Francisco, CA, USA, 7-9 Aug 1997

Romeo R, Floris M, Veneri F (2006) Area-scale landslide hazard and risk assessment. Environ Geol 51:1-13

Rossi M, Guzzetti F, Reichenbach P, Mondini AC, Peruccacci S (2010) Optimal landslide susceptibility zonation based on multiple forecasts. Geomorphology 114(3):129-142

Salciarini D, Godt JW, Savage WZ, Baum RL, Conversini P (2008) Modelling landslide recurrence in Seattle, Washington, USA. Eng Geol 102(3-4):227-237

Saltelli A, Tarantola A, Campolongo F, Ratto M (2004) Sensitivity analysis in practice - a guide to assessing scientific models. Wiley, Chichester

Santacana N, Baeza B, Corominas J, De Paz A, Marturiá J (2003) A GIS-based multivariate statistical analysis for shallow landslide susceptibility mapping in La Pobla de Lillet area (Eastern Pyrenees, Spain). Nat Hazards 30:281-295

Savage SB, Hutter K (1991) The dynamics of avalanches of granular materials from initiation to runout. Part I Anal Acta Mech 86:201-223

Savage WZ, God JW, Baum RL (2004) Modelling time-dependent areal slope instability. In: Lacerda W, Ehrlich M, Fountoura SAB, Sayao ASF (eds) Landslide Evaluation and Stabilization: IX International Symposium on Landslides, Rio de Janeiro, vol 1. A.A. Balkema, Amsterdam, pp 23-38

Saygili G, Rathje EM (2009) Probabilistically based seismic landslide hazard maps: an application in Southern California. Eng Geol 109:183-194

Scheidegger A (1973) On the prediction of the reach and velocity of catastrophic landslides. Rock Mech 5:231-236

Scheidl C, Rickenmann D (2010) Empirical prediction of debris-flow mobility and deposition on fans. Earth Surf Process Landf 35:157-173

Schmidt J, Matcham I, Reese S, King A, Bell R, Henderson R, Smart G, Cousins J, Smith W, Heron D (2011) Quantitative multi-risk analysis for natural hazards: a framework for multi-risk modelling. Nat Hazard 58:1169-1192. doi:101007/s11069-011-9721-z

Schuster RL, Logan RL, Pringle PT (1992) Prehistoric rock avalanches in the Olympic Mountains. Wash Sci 258:1620-1621

Shinozuka M, Feng MQ, Lee J, Naganuma T (2000) Statistical analysis of fragility curves. J Eng Mech ASCE 126(12): 1224-1231 
Shrestha HK, Yatabe R, Bhandary NP (2008) Groundwater flow modelling for effective implementation of landslide stability enhancement measures. Landslides 5:281-290

Simoni S, Zanotti F, Bertoldi G, Rigon R (2008) Modelling the probability of occurrence of shallow landslides and channelized debris flows using GEOtop-FS. Hydrol Process 22:532-545

Singhroy V (2005) Remote sensing of landslides. In: Glade T, Anderson M, Crozier MJ (eds) Landslide hazard and risk. Wiley, Chichester, pp 469-492

Smith MJ, Pain CF (2009) Applications of remote sensing in geomorphology: applications of remote sensing in geomorphology. Prog Phys Geogr 33:568

Smith K, Petley DN (2008) Environmental hazards: assessing risk and reducing disaster. Taylor \& Francis, London

Soeters R, van Westen CJ (1996) Slope instability recognition, analysis and zonation. In: Turner AK, Schuster RL (eds) Landslides investigation and mitigation. TRB Special Report 247. National Academy Press, Washington, DC, pp 129-177

Sosio R, Crosta GB, Hungr O (2008) Complete dynamic modelling calibration for the Thurwieser rock avalanche (Italian Central Alps). Eng Geol 100:11-26

Springman S, Seward L, Casini F, Askerinejad A, Malet J-P, Spickerman A, Travelletti J (eds) (2011) SafeLand Deliverable D1.3: analysis of the results of laboratory experiments and of monitoring in test sites for assessment of the slope response to precipitation and validation of prediction models. Available at http://www.safeland-fp7.eu/

Squarzoni C, Delacourt C, Allemand P (2003) Nine years of spatial and temporal evolution of the La Vallette landslide observed by SAR interferometry. Eng Geol 68:53-66

Stark CP, Hovius N (2001) The characterization of the landslide size distributions. Geophys Res Lett 28:1091-1094

Stead D, Eberhardt E, Coggan J, Benko B (2001) Advanced numerical techniques in rock slope stability analysis: applications and limitations. In: LANDSLIDES - Causes, Impacts and Countermeasures, Davos, Switzerland, 17-21 June 2001, pp 615-624

Stephenson DB (2000) Use of the "odds ratio" for diagnosing forecast skill. Weather Forecast 15:221-232

Sterlacchini S, Ballabio C, Blahut J, Masetti M, Sorichetta A (2011) A spatial agreement of predicted patterns in landslide susceptibility maps. Geomorphology 125(1):51-61

Stevens W (1998) RocFall: a tool for probabilistic analysis, design of remedial measures and prediction of rockfalls. MaSc thesis, University of Toronto, Toronto

Stoffel M (2010) Magnitude-frequency relationships of debrisflows - a case study based on field surveys and tree-ring records. Geomorphology 116:67-76

Stumpf A, Malet J-P Kerle N (2011) SafeLand Deliverable D4.3: creation and updating of landslide inventory maps, landslide deformation maps and hazard mapsas inputs for QRA using remote-sensing technology. Available at http://www.safelandfp7.eu/

Suzen ML, Doyuran V (2004) Data driven bivariate landslide susceptibility assessment using geographical information systems: a method and application to Asarsuyu catchment. Turk Eng Geol 71:303-321

Swets JA (1988) Measuring the accuracy of diagnostic systems. Science 240(4857):1285-1293

Tacher L, Bonnard C, Laloui L, Parriaux A (2005) Modelling the behaviour of a large landslide with respect to hydrogeological and geomechanical parameter heterogeneity. Landslides 2:3-14

Talebi A, Troch PA, Uijlenhoet R (2008) A steady-state analytical slope stability model for complex hillslopes. Hydrol Process 22(4):546-553
Tapsell S, McCarthy S, Faulkner H, Alexander M (2010) Social vulnerability to natural hazards. CapHaz-Net WP4 Report. Flood Hazard Research Centre-FHRC, Middlesex University, London. Available at: http://caphaz-net.org/outcomes-results/ CapHaz-Net_WP4_Social-Vulnerability2.pdf

TC32-Technical Committee 32 (Engineering Practice of Risk Assessment and Management) of the International Society of Soil Mechanics and Geotechnical Engineering (ISSMGE) (2004) Risk assessment-glossary of terms. http://www.engmath.dal.ca/ tc32/2004Glossary_Draft1.pdf

Thiery Y, Malet J-P, Sterlacchini S, Puissant A, Maquaire O (2007) Landslide susceptibility assessment by bivariate methods at large scales: application to a complex mountainous environment. Geomorphology 92(1-2):38-59. doi:101016/jgeomorph2007 02020

Travelletti J, Malet J-P, Schmittbuhl J, Toussaint R, Delacourt C, Stumpf A (2010) A multi-temporal image correlation method to characterize landslide displacements. Ber Geol B-A 82:50-57

Tsai CC, Chen ZS, Duh CT, Horng FW (2001) Prediction of soil depth using a soil-landscape regression model: a case study on forest soils in southern Taiwan. Natl Sci Counc Repub China Part B Life Sci 25(1):34-39

Tsao TC, Hsu WK, Cheng CT, Lo WC, Chen CY, Chang YL, Ju JP (2010) A preliminary study of debris flow risk estimation and management in Taiwan. In: Chen S-C (ed) International Symposium Interpraevent in the Pacific Rim in Taipei, Taiwan, 26-30 April 2010, pp 930-939

Turner AK, Schuster LR (eds) (1996) Landslides, investigation and mitigation. Transportation Research Board Special Report 247. National Research Council, National Academy Press, Washington, DC, p 673

UN-ISDR (2004) Terminology of disaster risk reduction. United Nations International Strategy for Disaster Reduction, Geneva. http://www.unisdr.org/eng/library/lib-terminology-eng\%20home. htm

Uzielli M, Lacasse S (2007) Probabilistic estimation of vulnerability to landslides. In: Proc 13th Panamerican Conf on Soil Mechanics and Geotechnical Engineering, Margarita, Venezuela, 16-20 July 2007

Uzielli M, Nadim F, Lacasse S, Kaynia AM (2008) A conceptual framework for quantitative estimation of physical vulnerability to landslides. Eng Geol 102:251-256

Valadao P, Gaspar JL, Queiroz G, Ferreira T (2002) Landslides density map of S Miguel Island, Azores archipelago. Nat Hazard Earth Syst Sci 2:51-56

Van Asch ThWJ, Malet J-P, van Beek LPH, Amitrano D (2007) Techniques, advances, problems and issues in the modelling of landslide hazard. Bull Soc Géol France 178(2):6-35

Van Beek LH (2002) Assessment of the influence of changes in landuse and climate on landslide activity in a Mediterranean environment. Ph.D. thesis, University of Utrecht, Utrecht, p 363

Van Beek LPH, Van Asch TWJ (2004) Regional assessment of the effects of land-use change and landslide hazard by means of physically based modelling. Nat Hazards 30(3):289-304

Van Den Eeckhaut M, Hervás J (2012) State of the art of national landslide databases in Europe and their potential for assessing landslide susceptibility, hazard and risk. Geomorphology 139-140:545-558

Van Den Eeckhaut M, Poesen J, Govers G, Verstraeten G, Demoulin A (2007) Characteristics of the size distribution of recent and historical landslides in a populated hilly region. Earth Planet Sci Lett 256:588-603

Van Dine DF, Rodman RF, Jordan P, Dupas J (2005) Kuskonook Creek, an example of a debris flow analysis. Landslides 2(4):257-265. doi:101007/s10346-005-0017 
Van Steijn H (1996) Debris-flow magnitude frequency relationships for mountainous regions of Central and Northern Europe. Geomorphology 15:259-273

Van Westen CJ (1993) Application of geographic information systems to landslide hazard zonation. Ph.D. dissertation. ITC publ. no. 15. ITC, Enschede, p 245

Van Westen CJ, Montoya L, Boerhoom L, Coto EB (2002) Multihazard risk assessment using GIS in urban areas: a case study for the city of Turrialba, Costa Rica. In: Proc Regional Workshop on Best Practices in Disaster Mitigation: Lessons Learned from the Asian Urban Disaster Mitigation Program and Other Initiatives, Bali, Indonesia, 24-26 Sept 2002, pp 53-72

Van Westen CJ, Seijmonsbergen AC, Mantovani F (1999) Comparing landslide hazard maps. Nat Hazards 20(2-3):137-158

Van Westen CJ, Van Asch TWJ, Soeters R (2005) Landslide hazard and risk zonation; why is it still so difficult? Bull Eng Geol Environ 65(2):167-184

Van Westen CJ, Castellanos Abella EA, Sekha LK (2008) Spatial data for landslide susceptibility, hazards and vulnerability assessment: an overview. Eng Geol 102(3-4):112-131

Varnes DJ (1984) Landslide hazard zonation: a review of principles and practice. Natural Hazard Series, vol 3. UNESCO, Paris

Wang KL, Lin MI (2010) Development of shallow seismic landslide potential map based on Newmark's displacement: the case study of Chi-Chi earthquake, Taiwan. Environ Earth Sci 60:775-785

Wechsler SP (2007) Uncertainties associated with digital elevation models for hydrologic applications: a review. Hydrol Earth Syst Sci 11:1481-1500

Wieczorek GF (1984) Preparing a detailed landslide-inventory map for hazard evaluation and reduction. Bull Assoc Eng Geol 21(3):337-342

Wilson RA (2004) The rise and fall of a debris flow warning system for the San Francisco Bay Region, California. In: Glade T, Anderson M, Crozier MJ (eds) Landslide hazard and risk. Wiley, New York, pp 493-516

Wilson RA, Moon AT, Hendricks M, Stewart IE (2005) Application of quantitative risk assessment to the Lawrence Hargrave Drive Project, New South Wales, Australia. In: Hungr O, Fell R, Couture R, Eberhardt E (ed) Landslide risk management. Taylor \& Francis, London, ISBN 04-1538-043X

Winter MG, Smith J, Fotopoulou S, Pitilakis K, Mavrouli O, Corominas J, Argyroudis S (submitted) Physical vulnerability of elements at risk to landslides: methodology for evaluation, fragility curves and damage states for buildings and lifelines. Bull Eng Geol Env
Wong HN (2005) Landslide risk assessment for individual facilitiesstate of the art report. In: Hungr O, Fell R, Couture R, Eberhardt E (eds) Proceedings of the International Conference on Landslide Risk Management. Taylor \& Francis, London, pp 237-296

Wong HN, Ho KKS (1998) Overview of risk of old man-made slopes and retaining walls in Hong Kong. In: Proceedings of the Seminar on Slope Engineering in Hong Kong. A.A. Balkema, Hong Kong, pp 193-200

Wong HN, Chen YM, Lam KC (1997a) Factual report on the November 1993 natural terrain landslides in three study areas on Lantau Island. GEO Report No 61. Geotechnical Engineering Office, Hong Kong, p 42

Wong HN, Ho KKS, Chan YC (1997b) Assessment of consequence of landslides. In: Cruden D, Fell R (eds) Landslide risk assessment. A.A. Balkema, Rotterdam, pp 111-149

WP/WLI (1993) A suggested method for describing the activity of a landslide. Bull Int Assoc Eng Geol 47:53-57

Wu TH, Abdel-Latif MA (2000) Prediction and mapping of landslide hazard. Can Geotech J 37:781-795

Wu TH, Tang WH, Einstein HH (1996) Landslide hazard and risk assessment. In: Turner AT, Schuster RL (eds) Landslidesinvestigation and mitigation. Transportation Research Board Special Report no. 247. National Academy Press, Washington, DC, pp 106-118

Xie M, Tetsuro E, Zhou G, Mitani Y (2003) Geographic Information Systems based three-dimensional critical slope stability analysis and landslide hazard assessment. J Geotech Geoenviron Eng 129(12):1109-1118

Yin KJ, Yan TZ (1988) Statistical prediction model for slope instability of metamorphosed rocks. In: Proc 5th Int Symp on Landslides, vol 2, Lausanne, Switzerland, 10-15 July 1988, 2:1269-1272

Zêzere JL, Garcia RAC, Oliveira SC, Reis E (2008) Probabilistic landslide risk analysis considering direct costs in the area north of Lisbon (Portugal). Geomorphology 94:467-495

Zinck JA, López J, Metternicht GI, Shrestha DP, Vázquez-Selem L (2001) Mapping and modelling mass movements and gullies in mountainous areas using remote sensing and GIS techniques. Int J Appl Earth Obs Geoinf 3(1):43-53

Zuccaro G, Santo F, De Gregorio D, Di Crescenzo G (2011) Methodology for buildings at site specific to local scales. In: Safeland Deliverable D2.5: physical vulnerability of elements at risk to landslides: methodology for evaluation, fragility curves and damage states for buildings and lifelines. Available at http:// www.safeland-fp7.eu/ 